


\section{Diretor Editorial}

Rui Resende (ISMAI)

\section{Diretor Editorial Adjunto}

Hugo Sarmento (FCDEF-UC/CIDAF)

Adilson Marques (FMH-UL)

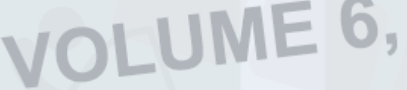

\section{Conselho Editorial}

Ágata Aranha (UTAD), Alcides Scaglia (UNICAMP), Antonino Pereira (ESEV-IPV), Carlos Zuluaga (Universidad de Caldas), Cecília Borges (Universidad Montreal), Tiago Sousa (FCDEF-UC), Galcemar Martins (UDESC), Hélder Lopes (UMA), José Rodrigues (ESDRM-IPSantarém), Juarez Nascimento (UFSC), Larissa Benites (UDESC), Larrisa Galati (UNICAMP), Miguel Saavedra (UDC), Nuno Pimenta (IPMAIA), Paula Batista (FADEUP), Ricardo Lima (IPVC), Roberto Hernández (Universidad Autonoma), Rui Gomes (Universidade do Minho), Samuel Neto (UNESP), Sergio Ibanez (UNEX), Susana Franco (ESDRMIPSantarém), Vitor Ferreira (FMH-UL).

\section{Edição}

Sociedade Científica de Pedagogia do Desporto

\section{Capa}

Mariana Moreira

ISSN 1647-9696 


\section{Original Articles}

Profissionais de Fitness: Enquadramentos

Susana Franco

Análise das relações interpessoais dos alunos em Educação Física

10

Elisa Ângelo, Francisco Campos, Elsa Silva, Luís Rama

Relação entre frequência de prática e importância atribuída pelos praticantes

Ricardo Gomes, Diana Franco, Maria Dias, Fernando Martins, António Damásio, Francisco Campos

Análise sociológica sobre o karaté em Portugal

Vitor Rosa

Perceções discentes sobre a escola e a educação física: influências na prática de atividade física

Francisca Góis, Élvio Gouveia, João Martins, Valter Barbosa Filho, Adilson Marques

Physical Education Cooperating Teachers' perspectives on professional ethics

Elsa Ribeiro-Silva, Catarina Amorim

Coach-Athletes Communication: Data from the Communication Behaviors Evaluation

A. Rui Gomes, Albino Almeida, Rui Resende, Catarina Morais

Viabilidade do planeamento por etapas: visão dos estudantes-estagiários 


\title{
EDITORIAL
}

A edição de junho de 2020 é marcada pelo surgimento de uma pandemia que afetou o normal funcionamento de todo o planeta. Neste novo contexto que todos teremos que superar o JSPR continua a percorrer o seu caminho na divulgação científica de trabalhos relacionados com a Pedagogia do Desporto. Damos nota de um incremento de submissões ao JSPR que denota o percurso sério e regular que o JSPR está a trilhar. Estamos em condições de informar que as negociações para incluirmos o DOI (Digital Object Identifier) nas nossas publicações está muito adiantado e que essa possibilidade levará a uma identificação e consequente maior visibilidade dos artigos publicados pelo JSPR.

Informamos com satisfação que os números especiais da revista sobre Supervisão de estágios em Educação Física e o de Desporto de Natureza tiveram adesão positiva por parte da comunidade e irão ser publicados ainda durante o corrente ano. Apelamos a que continuem a submeter trabalhos ao JSPR.

The June 2020 issue is marked by the emergence of a pandemic that has affected the normal functioning of the entire planet. In this new context we will all have to overcome the JSPR continues to go its way in the scientific dissemination of works related to the Sport Pedagogy. We note an increase in submissions to JSPR that denotes the serious and regular route that JSPR is taking. We are in a position to inform you that negotiations to include DOI (Digital Object Identifier) in our publications are very prompt and that this possibility will lead to an identification and consequent greater visibility of articles published by JSPR.

We inform with satisfaction that the special issues of the journal on Supervision of internships in Physical Education and Nature Sport have had positive support by the community and will be published later this year. We call on you to continue submitting papers to JSPR.

La edición de junio de 2020 está marcada por la aparición de una pandemia que ha afectado el funcionamiento normal de todo el planeta. En este nuevo contexto que todos tendremos que superar el JSPR sigue su camino en la difusión científica de obras relacionadas con la Pedagogía del Deporte. Observamos un aumento en las sumisiones a JSPR que denota la ruta seria y regular que JSPR está tomando. Estamos en condiciones de informarle que las negociaciones para incluir el DOI (Digital Object Identifier) en nuestras publicaciones son muy tempranas y que esta posibilidad dará lugar a una identificación y consecuente mayor visibilidad de los artículos publicados por JSPR. Informamos con satisfacción que los números especiales de la revista sobre Supervisión de las Prácticas Supervisadas en Educación Física y Deporte de la Naturaleza han contado con un apoyo positivo de la comunidad y se publicarán a finales de este año. Le pedimos que continúe enviando artículos a JSPR.

\author{
Rui Resende \\ Hugo Sarmento \\ Adilson Marques
}




\title{
Profissionais de Fitness: Enquadramentos
}

\author{
Susana Franco $^{1,2}$ \\ 1 Escola Superior de Desporto de Rio Maior - Instituto Politécnico de Santarém \\ 2 Centro de Investigação em Qualidade de Vida (CIEQV)
}

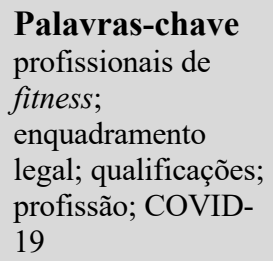

\section{RESUMO}

No presente artigo, após efetuado um enquadramento sobre da área do Fitness, é realizada uma reflexão acerca do enquadramento legal e das qualificações dos profissionais de fitness, assim como da sua atividade profissional, identificando-se alguns aspetos a melhorar, e, consequentemente, potenciando a qualidade e a confiança no setor do Fitness, promovendo o aumento da prática de exercício físico das populações.

Keywords
fitness
professionals; legal
framework;
qualifications;
profession; COVID-
19

Introdução

A área do Fitness continua em expansão a nível mundial (IHRSA, 2019). Esta área é uma das privilegiadas na contribuição da promoção de um estilo de vida saudável na sociedade, que é uma das preocupações mundiais (World Health Organization, 2013), tendo os profissionais do fitness um papel primordial neste sentido (Armour \& Chambers, 2014).

A qualidade do serviço prestado aos cidadãos, na área do exercício físico (Lei n. ${ }^{\circ}$ 3/2020 de 31 de março), é também uma preocupação, sendo os profissionais de fitness um dos principais atributos na prestação da qualidade do serviço, assim como na satisfação e retenção dos praticantes (Gonçalves, Buchman, \& Carvalho, 2013; Murray \& Howat, 2002; Papadimitriou \& Karteroliotis, 2000; Theodorakis, Alexandris, Rodriguez, \& Sarmento, 2004; Theodorakis, Howat, Ko, \& Avourdiadou, 2014; Varghese, 2014).

Para que tal aconteça é necessário ter profissionais qualificados, com boas condições de trabalho, o que se repercutirá numa melhor prestação de serviço. É ainda importante regular o setor do Fitness, dignificando a profissão e promovendo a confiança no setor.

Deste modo, o presente artigo, pretende levar a uma reflexão acerca do enquadramento legal e das qualificações dos profissionais de fitness, assim como da sua atividade profissional, após efetuado um enquadramento acerca da área do Fitness.

\section{Enquadramento da área do Fitness}

$\mathrm{Na}$ atualidade, são amplamente reconhecidos os inúmeros benefícios, na saúde e na qualidade de vida, da prática regular de exercício físico (Blair, 2009; Physical Activity Guidelines Advisory Committe, 2008; Trost, Blair, \& Khan, 2014; World Health Organization, 2010).

Em 2016, o Governo Português, nas suas Grandes Opções do Plano para 2016-2019, propôs na agenda para $o$ Desporto nacional aumentar significativamente a prática desportiva (Lei n. ${ }^{\circ}$ 7B/2016 de 31 de março).

Em 2017, segundo o Eurobarómetro do Desporto e Atividade Física (TNS Opinion \& Social, 2018), a prática de exercício físico, desporto e atividade física dos cidadãos portugueses era ainda reduzida, sendo Portugal um dos três países da União Europeia com maior percentagem de cidadãos que 
nunca tinham praticado exercício ou desporto $(68 \%)$, e o país com a segunda maior percentagem (64\%) de cidadãos que nunca tinham realizado atividade física (e.g. deslocar-se de bicicleta, fazer jardinagem, dançar, etc...). Em termos de prática de atividade física vigorosa, apenas $7 \%$ dos portugueses realizavam entre quatro a sete vezes por semana, $13 \%$ entre uma a três vezes por semana e $79 \%$ nunca praticavam, sendo que dos cidadãos que realizavam atividade física vigorosa, menos de metade $(45 \%)$ se aproximava ou cumpria o mínimo sugerido pela Organização Mundial de Saúde (mínimo 75 minutos de atividade física vigorosa por semana) (World Health Organization, 2010). Ao nível da atividade física de intensidade moderada, $10 \%$ dos portugueses praticavam entre quatro a sete vezes por semana, $17 \%$ entre uma a três vezes por semana e $72 \%$ nunca realizavam. Dos cidadãos que efetuavam atividade física moderada, apenas $11 \%$ se aproximavam do sugerido pela Organização Mundial de Saúde (mínimo 150 minutos de atividade física moderada por semana) (World Health Organization, 2010).

Não obstante, segundo o referido Eurobarómetro (TNS Opinion \& Social, 2018), Portugal foi o país da União Europeia que mais cresceu em termos de percentagem de praticantes em ginásios, deste 2013 ( $10 \%$ de aumento), contando com $27 \%$ de pessoas que praticam desporto ou atividade física nestes locais.

Também, na última década, o número de ginásios tem vindo aumentar em Portugal, (INE, 2019).

A nível Europeu, o número de praticantes de fitness também tem vindo a aumentar (64.8 milhões em 2019), assim como o número de ginásios (63.644) (EuropeActive, 2020b).

É reconhecido que os profissionais do fitness, assim como do treino desportivo e da educação física, têm um papel primordial na educação das populações para um estilo de vida mais ativo (Armour \& Chambers, 2014). Realça-se que o papel destes profissionais, em termos educativos das populações, deverá ir ainda mais além da educação para um estilo de vida ativo e saudável, evocando outros valores do Desporto como por exemplo valores sociais e pessoais (e.g. lealdade, cooperação, coragem, resolução de problemas, força de vontade, autocontrolo, resistência, perseverança, determinação, autonomia) (Franco, Silva, \& Simões, 2019; Sanmartín, 2004).

$\mathrm{Na}$ Estratégia Nacional para a Promoção da Atividade Física, da Saúde e do Bem-Estar (ENPAF) para 2016-2025, ambiciona-se reduzir em $10 \%$ a prevalência de atividade física insuficiente (Silva, Graça, Mata, Arriaga, \& Silva, 2016). Em termos estratégicos, no referido programa, é mencionado o trabalho em parceria com vários profissionais, nomeadamente os que trabalham em municípios, associações, clubes ou empresas, como sejam os profissionais de fitness. A existência de profissionais de fitness com as devidas qualificações poderá favorecer as referidas parcerias, reforçando a confiança no setor no Fitness.

\section{Enquadramento legal e qualificações dos profissionais de fitness}

No Plano 2020-2023, o Governo Português volta a reconhecer a importância da atividade física para a saúde e qualidade de vida dos cidadãos, referindo que investirá na melhoria da qualidade do serviço prestado aos cidadãos, na área do exercício físico, valorizando a formação e a regulação do setor (Lei n. ${ }^{\circ}$ 3/2020 de 31 de março).

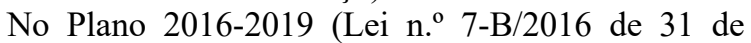
março), para concretizar o objetivo de dar um novo impulso ao desenvolvimento do Desporto e aumentar significativamente a sua prática, o Governo Português, apresentava como uma das suas preocupações estratégicas a qualificação dos técnicos e agentes que intervêm no Desporto.

Não obstantes estas preocupações, na área do Fitness a legislação acerca dos profissionais que intervêm neste setor, mantem-se inalterada desde 2014. Em 2012 foi aprovado o regime de responsabilidade técnica pela direção e orientação das atividades desportivas desenvolvidas nos ginásios, que enquadra as duas figuras de profissionais legalmente reconhecidos na área, em Portugal, o diretor técnico (DT) e o técnico de exercício físico (TEF) (Lei n. ${ }^{\circ}$ 39/2012 de 28 de agosto). E em 2014 a portaria que definiu os procedimentos necessários para a manutenção do título profissional de DT e de TEF (Portaria n. ${ }^{\circ}$ $36 / 2014$ de 14 de fevereiro).

A legislação acerca do regime de acesso e exercício da atividade de treinador de desporto, que também foi atualizada em 2012 (Lei n. ${ }^{\circ}$ 40/2012 de 28 de agosto) no mesmo dia da dos TEFs e DTs (Lei n. ${ }^{\circ}$ 39/2012 de 28 de Agosto), foi recentemente alterada (Lei n. ${ }^{\circ} 106 / 2019$ de 6 de setembro).

Realça-se que a legislação que enquadra a profissão de treinador de desporto estabelece níveis de exercício na mesma (grau I a grau IV), os quais estão associados a determinadas competências.

Quer o título profissional de treinador de desporto, quer o título de DT ou de TEF, poderá ser acedido através da obtenção de licenciatura na área da Educação Física ou Desporto (nível 6 do quadro nacional de qualificações - QNQ). No entanto, enquanto para treinador de desporto deverá o IPDJ, I.P. reconhecer a formação, considerando as competências previstas para determinado grau e determinada modalidade desportiva, para DT ou TEF "basta" ser licenciado na referida área, independentemente da especificidade da área desportiva.

Não obstante, para aceder ao título de TEF também poderá ser através da obtenção de um curso de especialização tecnológica (CET; nível 5 do QNQ), através da realização de um curso de Técnico 
Especialista em Exercício Físico (TEEF; ANQEP, 2015), o qual se encontra direcionado para formar para as competências específicas destes profissionais.

Em 2015 foi iniciado o funcionamento dos cursos CET de TEEF e, desde então, os referidos referenciais não voltaram a ser atualizados. Passados cinco anos de experiência de formação, baseada nestes referenciais, deveria existir uma reflexão acerca dos mesmos identificando as necessidades de adequação. Realça-se o facto de os referenciais de formação para os treinadores de desporto terem sido atualizados no presente ano (IPDJ, 2020), esperando-se assim que o mesmo aconteça na área do Fitness.

A legislação atual (Lei n. ${ }^{\circ}$ 39/2012 de 28 de agosto) estabelece as funções que os DTs e os TEFs devem assumir, não obstante existirem outras inúmeras, por alguns, igualmente realizadas.

Também, várias são as ocupações que os profissionais de fitness exercem, que vão desde a intervenção em diferentes atividades (e.g. Step, Localizada, Indoor Cycling, Stretching, Corpo e Mente, Cross Training, Musculação, Cardiofitness, etc...), à intervenção com diferentes populações (e.g. crianças; jovens; adultos; idosos; gravidez e pós-parto; atletas de outras modalidades desportivas; populações clínicas, com doenças como a diabetes, cancro, obesidade, problemas respiratórios, cardíacos, músculo-esqueléticos, entre outros...), trabalhando com diversos materiais e tecnologias. Com base nas ocupações destes profissionais, a EuropeActive desenvolveu os designados EuropeActive Standards, para algumas das ocupações na área do Fitness, que estabelecem os conhecimentos e as competências mínimas requeridas para cada ocupação (EuropeActive, 2020a)

Para além duma formação superior no âmbito das Ciências do Desporto que permitirá uma atuação mais consistente e fundamentada por parte dos profissionais de fitness (Malek, Nalbone, Berger, \& Coburn, 2002; Stacey, Hopkins, Adamo, Shorr, \& Prud'homme, 2010) devem os programas de formação, direcionados para estes profissionais, proporcionar as devidas competências e conhecimentos para estes saberem como agir no âmbito da sua atuação (Franco \& Simões, 2015). Dado o elevado nível de autonomia dos profissionais de fitness e o alargado escopo da sua atuação em termos de funções, organizações, atividades, populações, materiais, tecnologias... (De Lyon, Neville, \& Armour, 2017), deve também haver um direcionamento pessoal da formação mediante o desenrolar da sua atuação profissional, em termos de formação contínua, tal como preconizado pela legislação portuguesa (Portaria n. ${ }^{\circ}$ 36/2014 de 14 de fevereiro). Mediante a complexidade, profundidade e abrangência do conhecimento e competências requeridos na atuação dos profissionais de fitness, deveria assim ser requerido um título também com diferenciação de níveis, tal como existe para os treinadores de desporto.

A, já referida, Lei n. ${ }^{\circ}$ 39/2012 de 28 de agosto define o regime jurídico da responsabilidade técnica pela direção e orientação das atividades desportivas desenvolvidas nos ginásios e em health clubs, sendo obrigatório ter título de DT ou de TEF para atuar legalmente nesses locais. No entanto, os TEFs exercem a sua profissão, não só nos ginásios, como no exterior (outdoor), por exemplo em parque, jardins, ciclovias, etc... no domicílio dos praticantes, e online, não sendo, atualmente, legalmente necessário ter título para atuar nesses outros locais. $\mathrm{O}$ contexto online cresceu exponencialmente desde a COVID-19, pandemia que levou as pessoas a isolarem-se umas das outras, ficando em casa, sem irem ao ginásio, potenciando assim os serviços online. Se se pretende melhorar a qualidade do serviço prestado aos cidadãos, na área do exercício físico, (Lei n. ${ }^{\circ}$ 3/2020 de 31 de março), independentemente do local onde este venha a ser prestado, devem os profissionais ter o devido título, que certifica que estes têm as apropriadas competências e conhecimentos para atuar com a devida qualidade.

Realça-se que, empregar profissionais certificados, com formação específica creditada, assim como com o devido título profissional, são duas das tendências mundiais na área do Fitness para 2020 (Thompson, 2019).

\section{Enquadramento da atividade dos profissionais de fitness}

Segundo o IPDJ, I.P., no final de 2017 existiam, em Portugal, cerca de 14.000 TEFs/DTs com título, $62 \%$ do género masculino e $38 \%$ do género feminino, com uma média de idades de 35 anos, sendo que mais de $70 \%$ destes tinham entre 24 e 40 anos de idade. Este corpo profissional é ainda relativamente jovem, tal como a área do Fitness.

O Barómetro do Fitness em Portugal 2019, promovido pela Associação de Ginásios e Academias de Portugal (AGAP), refere-se a cerca de 12.000 instrutores de fitness a atuar em ginásios, sendo que destes apenas $27 \%$ trabalhavam a tempo integral (Pedragosa \& Cardadeiro, 2020). Não obstante as vantagens que um freelancer possa ter a trabalhar como profissional de fitness, nomeadamente em determinada especialidade, permitindo-lhe obter uma remuneração por hora superior e trabalhando menos horas, trabalhar com contrato, particularmente a tempo integral, traz uma maior estabilidade e segurança profissional (Fitness Australia, 2016). A título de exemplo, na fase de pandemia, derivada da COVID-19, que forçou o fecho do funcionamento presencial dos ginásios, vários foram os profissionais que, em condições contratuais mais precárias, ficaram sem emprego. Pela elevada capacidade de empreendedorismo e 
adaptação que muitos destes profissionais têm, vários foram os que se adaptaram a um novo modus operandi online e/ou outdoor.

Refira-se que num estudo acerca dos profissionais de fitness, em Espanha, os freelancers apresentavam menor nível de burnout e maior satisfação no trabalho (Gil, 2013). Por outro lado, num outro estudo, também com profissionais de fitness, na Grécia, a segurança no trabalho revelou apresentar uma correlação significativa positiva com a satisfação no trabalho (Koustelios, Kouli, \& Theodorakis, 2003).

$\mathrm{O}$ facto de os profissionais trabalharem a tempo parcial num ginásio, não significa que não tenham um horário completo. Veja-se por exemplo um estudo realizado na Austrália que revelou que os profissionais de fitness trabalhavam em média 43 horas/semana, com apenas $32 \%$ contratados a tempo integral. Num estudo realizado em Espanha, a média de horas no local de trabalho era 27 horas/semana, sendo que cerca de $10 \%$ se encontrava no local de trabalho mais de 40 horas/semana (Gil, 2013), e num estudo efetuado nos EUA os treinadores personalizados (PTs) referiram trabalhar em média 32 horas/semana. Realça-se o facto de muitas vezes os profissionais de fitness planearem e "treinarem" as aulas que vão lecionar fora do horário oficial de trabalho no ginásio, sobrecarregando as horas de trabalho destes profissionais.

Também as amplitudes de horário laboral são por vezes estendidas, podendo começar com o horário de abertura (e.g. sete horas) e terminar no horário de fecho do ginásio (e.g. 22 horas). O tipo de jornada de trabalho destes profissionais parece estar associado ao burnout e à satisfação no trabalho (Gil, 2013). O facto de os profissionais de fitness estarem mais satisfeitos com o seu trabalho, tal como em outras profissões, poderá contribuir para um alto comprometimento organizacional e uma menor taxa de rotatividade de emprego (Llorente \& Macías, 2005; Yousef, 2017).

Por outro lado, o elevado número de horas de trabalho (Bratland-Sanda, Sundgot-Borgen, \& Myklebust, 2015), nomeadamente com muitas delas a realizar exercício físico conjuntamente com os praticantes, particularmente se em alto impacto, ou em ajudas aos praticantes que também requerem esforço físico, poderá levar a lesões músculosesquelética. Num estudo com 4975 PTs, nos EUA, $50 \%$ tinham lesões nos membros inferiores, $23 \%$ nos membros superiores, $15 \%$ na zona lombar e $13 \%$ tinham lesões na cabeça/pescoço (Waryasz, Daniels, Gil, Suric, \& Eberson, 2016), e num estudo com instrutores de aulas de grupo de fitness, na Noruega, $47 \%$ reportaram ter tido pelo menos uma lesão derivada da profissão e $76 \%$ referiram ter dores músculo-esqueléticas durante o seu último mês de trabalho (Bratland-Sanda et al., 2015). A título de exemplo do elevado número de horas em exercício físico por parte dos profissionais de fitness, refira-se o estudo, realizado em Portugal, em que se observou, nas aulas de grupo de Localizada, que em média os profissionais passavam $69 \%$ da aula em exercício, simultaneamente com os praticantes (Franco, Rodrigues, \& Castañer, 2012).

Não obstante as referidas circunstâncias, num estudo piloto, verificou-se que os profissionais de fitness parecem apresentar uma perceção positiva acerca da sua qualidade de vida (Vieira, Ramos, Simões, Franco, \& Esteves, 2019).

Atualmente está a decorrer um estudo, designado de VidaProFit, que permitirá caracterizar os profissionais de fitness em Portugal, assim como as suas condições de trabalho, satisfação no trabalho e qualidade de vida. Conhecer estas variáveis poderá contribuir para se tomarem melhores decisões no sentido da melhoria das condições de trabalho e de vida destes profissionais, com possíveis consequências positivas em termos de prestação de melhor qualidade de serviço para os praticantes com quem trabalham (Ramos, Esteves, Franco, Vieira, \& Simões, 2019).

Em 2018 foram criadas três associações de profissionais de fitness, estabelecendo a sua representatividade institucional, nomeadamente: Associação Portuguesa de Fisiologistas do Exercício (APFE, 2020), que pretende o reconhecimento e regulamentação da profissão, permitindo uma representação organizada e a dignificação e estabelecimento de uma identidade profissional forte e diferenciada; Associação Portuguesa de Técnicos de Exercício Físico (APTEF, 2020), que tem como missão promover os profissionais e profissões na área do Exercício Físico; União Portuguesa dos Diretores e Técnicos de Exercício Físico (UPDTEF, 2020), que visa a dignificação profissional, social e humana dos profissionais, defendendo os seus direitos, a ética, a deontologia e a qualificação dos profissionais. Considera-se extremamente positiva a sua existência, devendo agora, não descurando as suas especificidades e missões, com a devida flexibilidade, encontrar um entendimento que beneficie os profissionais de fitness, promovendo a confiança no setor do Fitness.

\section{Conclusão}

A área do Fitness continua em franca expansão mundial, podendo as suas atividades contribuir para ajudar a cumprir os objetivos mundiais de tornar as populações mais ativas fisicamente. Os profissionais de fitness têm um papel primordial nesse sentido. Para tal é imperativo ter profissionais qualificados de qualidade.

Apesar de Portugal ter legislação que enquadra os profissionais de fitness, o que é um franco avanço relativamente a grande parte dos países, é necessário dar um salto qualitativo. Espera-se que a legislação que enquadra os profissionais de fitness venha a ser adaptada, nomeadamente em termos de níveis e de alargamento de contextos, de modo a que os 
profissionais possam ser diferenciados mediante a especificidade, complexidade e profundidade das suas competências e conhecimentos, na abrangência da sua atuação, valorizando a formação e a regulação do setor, tal como estabelecido no programa do governo para 2020-2023 (Lei n. ${ }^{\circ}$ 3/2020 de 31 de março).

Importa também conhecer melhor as características desta profissão e destes profissionais, de modo a identificar as necessidades de melhoria das condições de trabalho. Acredita-se que com melhores condições de trabalho e melhor qualidade de vida, os profissionais de fitness poderão prestar um serviço com ainda melhor qualidade, que é uma das preocupações do setor do Fitness e do Governo Português.

\section{Referências}

ANQEP. (2015). Referencial de formação - Técnico Especialista em Exercício Físico. Retrieved from http:/www.catalogo.anqep.gov.pt/PDF/Qualificacao ReferencialPDF/1520/EFA/duplacertificacao/81332 5_RefEFA

APFE. (2020). Associação Portuguesa dos Fisiologistas do Exercício. Retrieved from https://www.apfe.pt/

APTEF. (2020). Associação Portuguesa de Técnicos de Exercício Físico. Retrieved from http://aptef.pt/aptef/

Armour, K. M., \& Chambers, F. C. (2014). "Sport \& exercise pedagogy": The case for a new integrative sub-discipline in the field of sport \& exercise sciences/kinesiology/human movement sciences. Sport, Education \& Society, 19(7), 855-868.

Blair, S. N. (2009). Physical inactivity: The biggest public health problem of the 21st Century. British Journal of Sports Medicine, 43(1), 1-2.

Bratland-Sanda, S., Sundgot-Borgen, J., \& Myklebust, G. (2015). Injuries and musculoskeletal pain among Norwegian group fitness instructors. European Journal of Sport Science, 15(8), 784-792.

De Lyon, A. T. C., Neville, R. D., \& Armour, K. M. (2017). The role of fitness professionals in public health: A review of the literature. Quest, 69(3), 313330 .

EuropeActive. (2020a). EuropeActive standards. Retrieved from https://www.ehfa-standards.eu/esstandards

EuropeActive. (2020b). European Health \& Fitness Market - Report 2020: Deloitte \& EuropeActive.

Fitness Australia. (2016). Profile of the fitness industry in Australia - Fitness industry workforce. Alexandria: Fitness Australia - The Health \& Fitness Industry Association.
Franco, S., Rodrigues, J., \& Castañer, M. (2012). Case Study 6.3: The behaviour of fitness instructors and the preferences and satisfaction levels of users. In O. Camerino, M. Castañer \& M. T. Anguera (Eds.), Mixed methods research in the movement sciences (pp. 202-214). Oxon: Routledge.

Franco, S., Silva, M., \& Simões, V. (2019). Papel educativo dos profissionais de fitness - Estudo exploratório. Journal of Sport Pedagogy and Research, 5(2), 7.

Franco, S., \& Simões, V. (2015). Lazer e qualidade de vida: Formação de técnicos de fitness. In $\mathrm{R}$. Resende, A. Albuquerque, \& A. R. Gomes (Eds.), Formação e saberes em desporto e educação física (pp. 477-508). Lisboa: Visão e Contextos.

Gil, D. B. (2013). Buenas prácticas de gestión, satisfacción laboral, burnout e intención de abandono en profesionales del sector del fitness. $(\mathrm{PhD})$, Universidad Europea, Madrid.

Gonçalves, C., Buchman, C., \& Carvalho, M. J. (2013). Perceção da qualidade do serviço e satisfação dos sócios de fitness: Contribuições para o papel do gestor. Revista Intercontinental de Gestão Desportiva, 3(S2), 47-58.

IHRSA. (2019). The 2019 IHRSA Global Report The State of the Health Club Industry: IHRSA.

INE. (2019). Enterprises (N. ${ }^{\circ}$ by geographic localization (NUTS - 2013) and economic activity (Subclass - CAE Rev. 3). Annual - Statistics Portugal, integrated business accounts system. Retrieved from https://www.ine.pt/xportal/xmain?xpid=INE\&xpgid $=$ ine indicadores\&indOcorrCod $=0008466 \& \&$ contex to $=\bar{b} \bar{d} \&$ selTab $=$ tab2\&xlang $=$ en

IPDJ. (2020). Referenciais de formação geral Cursos de treinadores de desporto. Lisboa: Instituto Português do Desporto e Juventude.

Koustelios, A., Kouli, O., \& Theodorakis, N. (2003). Job security and job satisfaction among greek fitness instructors. Perceptual and Motor Skills, 97(1), 192194.

Lei n. ${ }^{\circ}$ 3/2020 de 31 de março. Diário da República N. ${ }^{\circ} 64-1$. $^{\text {a Série. }}$

Lei n. ${ }^{\circ}$ 7-B/2016 de 31 de março. Diário da República N. 63 - 1. ${ }^{a}$ Série.

Lei n. ${ }^{\circ}$ 39/2012 de 28 de agosto. Diário da República n. ${ }^{\circ} 166$ - 1. ${ }^{\text {a }}$ Série.

Lei n. ${ }^{\circ}$ 40/2012 de 28 de agosto. Diário $d a$ República N. ${ }^{\circ} 166$ - 1. ${ }^{\text {a }}$ Série.

Lei n. ${ }^{\circ} 106 / 2019$ de 6 de setembro. Diário da República N. ${ }^{\circ} 171$ - 1. ${ }^{\text {a }}$ Série. 
Llorente, R. M., \& Macías, E. F. (2005). Job satisfaction as an indicator of the quality of work. The Journal of Socio-Economics, 34(5), 656-673.

Malek, M. H., Nalbone, D. P., Berger, D. E., \& Coburn, J. W. (2002). Importance of health sciences education for personal fitness trainers. Journal of Strength and Conditioning Research, 16(1), 19-24.

Murray, D., \& Howat, G. (2002). The relationships among service quality, value, satisfaction, and future intentions of customer at an australian sports and leisure centre. Sport Management Review, 5(1), 2543.

Papadimitriou, D. A., \& Karteroliotis, K. (2000). The service quality expectations in private sport and fitness centers: A reexamination of the factor structure. Sport Marketing Quarterly, 9(3), 157-164.

Pedragosa, V., \& Cardadeiro, E. (2020). Caracterização do fitness em Portugal 2019: Principais resultados do setor. Portugal Activo, 5, 89.

Physical Activity Guidelines Advisory Committe. (2008). Physical Activity Guidelines Advisory Committee Report 2008. Washington, DC: U.S. Department of Health and Human Services.

Portaria n. ${ }^{\circ}$ 36/2014 de 14 de fevereiro. Diário da República n. ${ }^{\circ} 32$ - 1 . $^{\text {a }}$ Série.

Ramos, L., Esteves, D., Franco, S., Vieira, I., \& Simões, V. (2019). Fitness professional: Narrative review. Journal of Human Sport and Exercise, 14(Proc4), S1311-S1314.

Sanmartín, M. G. (2004). El valor del deporte en la educación integral del ser humano. Revista de Educación, 335, 105-126.

Silva, P. R., Graça, P., Mata, F., Arriaga, M. T., \& Silva, A. J. (2016). Estratégia nacional para a promoção da atividade física, da saúde e do bemestar 2016-2025. Lisboa: Direção-Geral da Saúde (DGS).

Stacey, D., Hopkins, M., Adamo, K. B., Shorr, R., \& Prud'homme, D. (2010). Knowledge translation to fitness trainers: A systematic review. Implementation Science, 5(1), 28.

Theodorakis, N., Alexandris, K., Rodriguez, P., \& Sarmento, P. J. (2004). Measuring customer satisfaction in the context of health clubs in Portugal. International Sports Journal, 8(1), 44-53.

Theodorakis, N., Howat, G., Ko, Y. J., \& Avourdiadou, S. (2014). A comparison of service evaluation models in the context of sport and fitness centres in Greece. Managing Leisure, 19(1), 18-35.

Thompson, W. R. (2019). Worldwide survey of fitness trends for 2020. ACSM's Health \& Fitness Journal, 23(6), 10-18.
TNS Opinion \& Social. (2018). Special Eurobarometer 472 / Wave EB88.4 "Sport and physical activity". Brussels: TNS Opinion \& Social.

Trost, S. G., Blair, S. N., \& Khan, K. M. (2014). Physical inactivity remains the greatest public health problem of the 21st century: Evidence, improved methods and solutions using the ' 7 investments that work' as a framework. British Journal of Sports Medicine, 48, 169-170.

UPDTEF. (2020). União Portuguesa dos Diretores e Técnicos de Exercício Físico. Retrieved from http://www.updtef.pt/

Varghese, T. (2014). customer expectations and perceptions in physical fitness service. a sudy in the context of Kerala, India. Research Journal of Social Science \& Management, 3(11), 200-205.

Vieira, I., Ramos, L., Simões, V., Franco, S., \& Esteves, D. (2019). Qualidade de vida dos profissionais de fitness - Estudo piloto. Journal of Sport Pedagogy and Research, 5(2), 5.

Waryasz, G. R., Daniels, A. H., Gil, J. A., Suric, V., \& Eberson, C. P. (2016). Personal trainer demographics, current practice trends and common trainee injuries. Orthopedic Reviews, 8(6600), 98105.

World Health Organization. (2010). Global recommendation on physical activity for health. Geneve: World Health Organization.

World Health Organization. (2013). Global action plan for the prevention and control of noncommunicable diseases 2013-2020. Geneve: World Health Organization.

Yousef, D. A. (2017). Organizational commitment, job satisfaction and attitudes toward organizational change: A study in the local government. International Journal of Public Administration, 40(1), 77-88. 


\title{
Análise das relações interpessoais dos
}

\section{alunos em Educação Física}

\author{
Elisa Ângelo ${ }^{1}$, Francisco Campos ${ }^{2,3}$, Elsa Silva ${ }^{1,4}$, Luís Rama $^{1,4}$ \\ ${ }^{1}$ Faculdade de Ciências do Desporto e Educação Física, Universidade de Coimbra; \\ ${ }^{2}$ Unidade de Investigação Aplicada em Ciências do Desporto; \\ ${ }^{3}$ Escola Superior de Educação de Coimbra - Instituto Politécnico de Coimbra; \\ ${ }^{4}$ Centro de Investigação do Desporto e da Atividade Física;
}

\section{Palavras-chave: Relacionamento interpessoal; Aceitação; Rejeição; Bem-estar; Estilo de vida.}

\section{RESUMO}

A Educação Física, quando lecionada de forma integradora e facilitadora de novas aprendizagens, permite ao aluno a aquisição de algumas competências específicas (eg. relacionamento interpessoal). Assim, temos como objetivos: a) caracterizar o sentimento de bem-estar e estilo de vida dos adolescentes de uma turma do 9..$^{\circ}$ ano de escolaridade; b) caracterizar o relacionamento interpessoal, tanto em termos de aceitação como de rejeição; c) associar o relacionamento interpessoal (aceitação e rejeição) dos alunos com o sentimento de bem-estar e estilo de vida. Participaram neste estudo 28 adolescentes, dos 14 aos 16 anos de idade. Foi operacionalizado um programa de intervenção nas aulas de Educação Física, durante 14 semanas, construído fundamentalmente por exercícios em grupo (a pares). Antes e depois do programa, foi aplicado um questionário, construído e validado de acordo com a literatura de referência. Após o programa de intervenção ocorreram melhorias no relacionamento interpessoal entre os alunos da turma, e houve maior aceitação e menor rejeição. Este conhecimento permitir-nos-á intervir de forma mais profícua e proveitosa atendendo às relações enraizadas no seio de um grupo.

\section{Keywords: Personal relationship; Acceptance; Rejection; Well-being; Lifestyle.}

\begin{abstract}
Physical Education, when taught in an integrating and facilitating way of learning, allows students to acquire specific skills (eg., interpersonal relationship). Thus, we aim to: a) characterize the well-being and lifestyle of young teenagers in $9^{\text {th }}$ grade class; b) characterize the interpersonal relationship, both in terms of acceptance and rejection; c) associate the interpersonal relationship (acceptance and rejection) of the students with them well-being and lifestyle feeling. Twenty-eight students, from 14 to 16 years old, participated in the study. An intervention program was applied in Physical Education classes, for 14 weeks, based on group exercises (in pairs). Before and after the intervention, was applied a questionnaire, constructed and validated according to the reference literature. After the intervention program, student's interpersonal relationship improved and there were greater acceptance and less rejection. This in-depth knowledge will enable us to pedagogically act in a more fruitful way given the relationship rooted within a group.
\end{abstract}




\section{Introdução}

A Educação Física (EF) é um meio extraordinário de formação pessoal e social (Rosado, 1998). Boas práticas resultam em experiências enriquecedoras, tanto a nível individual como enquanto membro de um grupo, possibilitando - através de exercícios, atividades e modalidades desportivas - desenvolver aspetos, qualidades e competências imprescindíveis para um sentimento de bem-estar no aluno (Silva, 2010). Se lecionada de forma integradora, e facilitadora de novas aprendizagens, profícuas, permite ao aluno a aquisição de uma sensação de bem-estar e um estilo de vida positivo (Chicon, 2008), tal como melhorar o relacionamento interpessoal (Santos, Silva, Santos, \& Silva, 2017).

O desenvolvimento de competências sociais, pelo relacionamento interpessoal, desde a infância até à idade adulta, é parte integrante do processo de maturação de qualquer indivíduo. Esse processo, em idades precoces (infância e adolescência), dá-se principalmente através da interação com os pais, amigos e colegas de escola (Caballo \& Marinho, 2002). Na infância e na adolescência, são desenvolvidas as skills sociais (comportamento emitido por um indivíduo em contexto interpessoal, expressando-se em opiniões, sentimentos, atitudes e desejos) (Caballo \& Marinho, 2002; Silva 2010).

A adolescência é entendida como um micromundo em transformação (Bouzas, 2011). Atualmente, o estilo de vida adotado por muitos adolescentes é marcado por características que fazem com que o relacionamento interpessoal seja pouco potenciado. $\mathrm{O}$ uso excessivo de novas tecnologias (eg., tablet e smartphone) ou a falta de tempo dos pais - cada vez mais obrigados a cumprir com funções profissionais exigindo mais tempo e menos disponibilidade para os filhos - são alguns exemplos considerados (Campos et al., 2018) que podem influenciar de forma negativa a capacidade dos jovens se relacionar socialmente com os colegas, amigos, familiares e mesmo com outras pessoas menos próximas.

Como referido por Borsari (1980), para que haja desenvolvimento com sucesso na infância e na adolescência (desde o Ensino Pré-escolar até ao Ensino Superior), em termos educativos e sociais, ou mesmo em termos de saúde no seu sentido lato mais do que a ausência de doença, um completo sentimento de bem-estar físico, mental e social (World Health Organization, 2016) -, a EF tem necessidade de se organizar numa base de responsabilização e atribuição de funções e papéis sociais, o só por si justifica a importância de estudar o relacionamento interpessoal nestas idades precoces.

Assim, os objetivos da presente investigação são:

a) caracterizar o sentimento de bem-estar e estilo de vida dos adolescentes de uma turma do 9. ${ }^{\circ}$ ano de escolaridade; b) caracterizar o relacionamento interpessoal na mesma turma, quanto à aceitação e à rejeição (matriz sociométrica);

c) associar o relacionamento interpessoal (aceitação e rejeição) dos adolescentes da turma com o seu estilo de vida e sentimento de bem-estar.

Após definir e implementar um programa de intervenção, com base nos dados obtidos, pretendese:

d) caracterizar o estilo de vida e o sentimento de bem-estar dos jovens da turma, e comparar os resultados com o obtido antes do programa de intervenção;

e) caracterizar o relacionamento interpessoal, em termos de aceitação e rejeição, e comparar os resultados com o obtido antes do programa de intervenção.

O desporto e a sua prática regular, entre outros aspetos, permite ao adolescente: sentir que se pertence e integra uma equipa; trabalhar em grupo para obtenção de um qualquer objetivo; enfrentar - e cumprir - as regras impostas por um mediador (professor), que, por si e transposto para o quotidiano em qualquer outra situação social que implique a necessidade de se relacionar com os pares (crianças, jovens e adultos), o ajuda neste processo por vezes demasiado complexo (relacionamento interpessoal) (Rosado, 1998).

Ao conhecer melhor os alunos com que lidamos, e como funcionam em grupo (turma), é possível definir um conjunto de estratégias - educativas - no sentido de estimular o relacionamento interpessoal e, como consequência, promover mais e melhores aprendizagens, num ambiente mais positivo e motivador. Entendemos que estas estratégias podem interferir positivamente com a qualidade de vida geral dos agora jovens adolescentes, mas muito em breve jovens adultos, socialmente a passarem a desempenhar papéis mais ativos, interventivos e dinâmicos.

\section{Metodologia}

\section{Participantes}

Participaram neste estudo 28 jovens adolescentes do 9. ${ }^{\circ}$ ano de escolaridade, de uma turma de uma escola urbana da Figueira da Foz, distrito de Coimbra. Destes, 13 são do género feminino (46.40\%) e 15 do género masculino (53.60\%), dos 14 e os 16 anos de idade $(14.18 \pm 0.54)$. Esta turma estava identificada pelo Conselho de Turma pelo facto de os seus alunos manifestarem problemas de relacionamento interpessoal.

\section{Instrumentos}

No início do estudo foi aplicado um questionário a todos os alunos da turma, construído e validado conforme o recomendado em Hill e Hill (2002), 
tendo sido adotados, sequencialmente, os seguintes procedimentos:

a) foi feita a primeira versão do instrumento, atendendo aos objetivos do estudo e com base noutros questionários utilizados no mesmo âmbito;

b) consultaram-se dois especialistas, doutorados em Ciências do Desporto, e com experiência em investigação de cariz qualitativo (eg., questionários e entrevistas), para análise e emissão de parecer acerca da validade do instrumento;

c) após reformulação da primeira versão, com base nas recomendações feitas pelo primeiro painel, esta foi aplicada a uma turma com as mesmas características (eg., ano de escolaridade, classe social e idade), para identificar a possível existência de dúvidas e dificuldades no preenchimento, por exemplo quanto à terminologia que era utilizada ao longo das questões apresentadas (aplicação piloto);

d) após uma nova reformulação, a terceira versão foi enviada a um novo painel de experts, que não os primeiros e em igual número, com as mesmas características em termos de formação académica e experiência de investigação;

e) não foi feita qualquer sugestão para melhoria, sendo o questionário, segundo os especialistas consultados, considerado válido para os objetivos do presente estudo.

$\mathrm{O}$ instrumento foi aplicado após a respetiva autorização dos pais ou tutores de todos os alunos, solicitada e recebida pela Diretora de Turma.

A primeira parte é constituída por 16 questões que permitem caracterizar social e demograficamente os alunos. A segunda é constituída por 10 itens, respondidos através de uma escala de concordância de likert de 10 pontos, em que o 0 (zero) corresponde a "nada" e o 10 corresponde a "muito", para recolha de informação acerca do bemestar e estilo de vida dos jovens de acordo com a sua autoperceção. Por fim, a terceira parte é constituída por 6 questões, 3 associadas ao processo de aceitação interpessoal e outras 3 ao processo de rejeição, onde o inquirido ordena hierarquicamente os colegas de turma em função de algumas situações hipotéticas, resultando duas matrizes sociométricas, uma de aceitação e outra de rejeição.

\section{Procedimentos}

Foi contactada a Diretora de Turma para solicitar autorização aos pais e tutores de todos os alunos. Após a receção e confirmação das autorizações, o questionário foi aplicado em ambiente calmo, propício a um preenchimento adequado (Hill \& Hill, 2002). Em termos globais e numa fase prévia, foram explicados os objetivos, o que efetivamente se pretendia com a aplicação, e reforçada a importância de as respostas serem fornecidas com sinceridade. Após a implementação do programa de intervenção, o questionário foi novamente aplicado a todos os alunos, no final do ano letivo (3. ${ }^{\circ}$ período), servindo os dados recolhidos desta segunda aplicação para avaliar o seu efeito nos diferentes alunos e na turma, pela comparação com os resultados obtidos antes da sua operacionalização.

\section{Programa de intervenção}

Com base nos resultados prévios, conducentes com os objetivos iniciais, e que nos permitiram perceber os índices de aceitação e rejeição na turma, foi pensado, planeado e operacionalizado um programa para minimizar a rejeição e potenciar a aceitação entre os elementos da turma.

Este consistiu num conjunto de exercícios (treino funcional) ministrado durante a fase inicial da aula de EF (aquecimento). Teve uma duração de 14 semanas e 23 sessões (11 aulas de 90 minutos e 12 de 45 minutos). Nas sessões de 90 minutos, o programa de exercício tinha uma duração de 10 minutos; nas de 45 minutos essa duração era de apenas 5 minutos. Por motivos vários (eg., feriados), das 28 aulas possíveis de serem lecionadas durante as 14 semanas, não foi possível a aplicação em cinco aulas.

Tal como referido, pretendeu-se potenciar a aceitação e minimizar a rejeição, através dos exercícios propostos e organização da atividade (eg., trabalho a pares, em cooperação, para obtenção de um objetivo comum para os dois alunos).

Por exemplo, uma das sessões-tipo, sendo as outras muito similares em termos de estrutura, conteúdos e organização dos alunos, foi constituída por 8 exercícios (polichinelo, skipping, agachamento, afundo, abdominal, prancha, extensão de braços e “carrinho de mão"). Utilizámos estratégias no sentido de permitir que os exercícios fossem realizados a pares (eg., polichinelo frente a frente, agachamento frente a frente com mãos dados para melhor equilíbrio), dinâmicas e materiais que permitiram preparar os conteúdos ministrados na fase fundamental, relacionados com a Unidade Didática em causa (eg., uso da bola de Rugby no afundo - após a realização do exercício a bola era passada para o colega que estava colocado à sua frente -, introduzindo logo no aquecimento alguns conteúdos, neste caso o passe e a receção, desenvolvidos na fase principal da sessão).

Os grupos (pares) eram formados com base nos resultados da primeira recolha. Tivemos atenção, por exemplo, às relações de rejeição recíprocas que existiam na turma e juntávamos esses mesmos alunos de forma a permitir que pela cooperação tida durante o exercício proposto, ocorressem melhorias quanto ao relacionamento interpessoal e, como consequência, passasse a haver uma maior aceitação entre os pares envolvidos.

Tivemos igualmente especial atenção à forma como o feedback pedagógico era emitido. Todas as palavras-chave eram cuidadosamente selecionadas 
por forma a estimular um sentimento de entreajuda, fortalecendo e desenvolvendo a coesão da turma.

\section{Análise estatística}

Em relação ao objetivo a) foi realizada a análise descritiva através dos valores centrais - média (M), e de dispersão - desvio padrão (DP). Os dados permitiram perceber como estes jovens se sentem, e qual a sua perceção em relação aos itens em avaliação (estilo de vida e sentimento de bem-estar). No que concerne ao objetivo b) são apresentados os dados provenientes de uma matriz sociométrica baseada nos trabalhos de Northway e Weld (1999). Com esta, foi possível perceber quais as relações de interação estabelecidas dentro da turma, os colegas que preferencialmente são escolhidos para a realização ou participação em determinadas situações hipotéticas (aceitação) e os que, por quaisquer outros motivos, são excluídos (rejeição). Esta matriz ajuda a avaliar a integração de um indivíduo num grupo e, com base nestes dados, suporta a intervenção pedagógica (Northway \& Weld, 1999). Foram realizadas duas matrizes, uma de aceitação e outra de rejeição. A posição sociométrica - grau em que cada aluno é aceite pelos restantes elementos da turma - foi aferida a partir do número de vezes em que foi escolhido. O Índice de Posição Sociométrica (IPS) aplica-se a ambas as matrizes e é classificado por Northway e Weld (1999) da seguinte forma (Tabela 1).

Em relação ao objetivo c), aplicou-se o teste de correlação de Spearman (rho), após a não verificação dos pressupostos de normalidade (Shapiro-wilk) (Pallant, 2011; Pestana \& Gageiro, 2008).

Tabela 1. Índice de Posição Sociométrica (IPS)

\begin{tabular}{lcc}
\cline { 2 - 3 } $\begin{array}{l}\text { 1. IPS muito acima (MAc) } \\
\text { probabilidade }\end{array}$ & da & $>14$ \\
\hline 2. IPS acima $(\mathrm{Ac})$ da probabilidade & 10 a 14 \\
\hline 3. IPS médio $(\mathrm{Me})$ & 9 \\
\hline $\begin{array}{l}\text { 4. IPS abaixo }(\mathrm{Ab}) \text { da probabilidade } \\
\text { 5. IPS muito abaixo (MAb) }\end{array}$ & 4 a 8 \\
probabilidade & $<4$ \\
\hline
\end{tabular}

Foi seguida a mesma lógica na análise dos dados para os objetivos d) e e), no que concerne respetivamente aos objetivos a) e b), referindo-se estes em concreto ao obtido após o programa de intervenção. Os dados foram analisados através do software Statistical Package for the Social Sciences (SPSS) (v24.0), para um nível de significância de $10 \%(p<0.10)$.

\section{Resultados}

\section{Pré-programa de intervenção}

A caracterização do estilo de vida e sentimento de bem-estar dos adolescentes da turma - objetivo a) são analisados com base no valor mínimo ( $\mathrm{min}$ ), máximo (máx), de $\mathrm{M}$ e DP (Tabela 2).

Tabela 2. Estilo de vida e sentimento de bem-estar

\begin{tabular}{|c|c|c|c|c|}
\hline & $\min$ & máx & $\mathbf{M}$ & $\mathbf{D P}$ \\
\hline 1. Sinto-me satisfeito com a minha escola. & 4 & 10 & 8.11 & 1.54 \\
\hline 2. Sinto-me bem comigo mesmo. & 1 & 10 & 7.18 & 2.85 \\
\hline 3. Sinto-me à vontade para conversar com os meus amigos. & 3 & 10 & 8.33 & 1.86 \\
\hline $\begin{array}{l}\text { 4. Sinto que sou ativo fisicamente, praticando atividade desportiva } \\
\text { com regularidade }\end{array}$ & 3 & 10 & 7.57 & 2.58 \\
\hline $\begin{array}{l}\text { 5. Sinto que sou conflituoso, tendo dificuldade em ter/fazer novos } \\
\text { amigos. }\end{array}$ & 0 & 9 & 2.25 & 3.05 \\
\hline 6. Sinto que tenho uma alimentação equilibrada e diversificada. & 5 & 10 & 8.21 & 1.31 \\
\hline 7. Sinto que durmo e descanso bem durante a noite. & 4 & 10 & 8.14 & 1.58 \\
\hline $\begin{array}{l}\text { 8. Sinto que consigo conversar com os meus pais acerca de } \\
\text { quaisquer problemas do dia-a-dia. }\end{array}$ & 3 & 10 & 8.14 & 2.18 \\
\hline 9. Sinto que, em termos gerais, penso de uma forma positiva. & 0 & 10 & 7.18 & 2.88 \\
\hline $\begin{array}{l}\text { 10. Sinto que grande parte do meu tempo é ocupado com videojogos } \\
\text { (playstation, tablet, smartphone...). }\end{array}$ & 0 & 9 & 4.96 & 2.47 \\
\hline
\end{tabular}

Pelos valores mais elevados, destaque para o item 3. "sinto-me à vontade para conversar com os meus amigos" e o item 6. "sinto que tenho uma alimentação equilibrada e diversificada". Por outro lado, os itens onde ocorreram valores mais baixos foram o 5. "sinto que sou conflituoso, tendo dificuldade em ter/fazer novos amigos" e o 10. "sinto que grande parte do meu tempo é ocupado com videojogos (playstation, tablet, smartphone...)".

Assim é possível depreender que, em termos de relacionamento interpessoal, os jovens adolescentes da turma sentem-se à vontade para falar com os colegas e não se consideram conflituosos. Quanto aos hábitos de alimentação e ao estilo de vida (recurso às novas tecnologias), os resultados não se alinham com o apresentando por Campos et al. 
(2019), o que possivelmente se justifica pela idade ou contexto educativo desse trabalho (Pré-escolar e 1. ${ }^{\circ}$ Ciclo do Ensino Básico). Foi possível verificar que a alimentação não é "equilibrada e diversificada" e que em relação às práticas de lazer e uso do tempo livre, o mesmo item - "sinto que grande parte do meu tempo é ocupado com videojogos (playstation, tablet ou smartphone...)" é, naquele contexto, o que apresenta valores de resposta mais elevados logo, aquele que as crianças até aos 10 anos de idade (sensivelmente) dedicam e passam mais tempo por dia (Campos et. al., 2019). Sequencialmente, são apresentados e discutidos os dados referentes ao objetivo b). Em termos de aceitação, destaque para o aluno n. ${ }^{\circ} 25$, escolhido 19 vezes por 11 colegas da turma, com um IPS muito acima da probabilidade (19x/11; MAc). Igualmente pelo alto número de aceitações, destaque para os alunos n. ${ }^{\circ} 9$ (18x/10; MAc), n. ${ }^{\circ} 20$ (16x/9; MAc), n. ${ }^{\circ}$ 22 (15x/19; MAc), n. ${ }^{\circ} 26$ (15x/9; MAc) e n. ${ }^{\circ} 15$ $(15 \mathrm{x} / 8$; MAc). Por outro lado, os jovens que apresentam índices de aceitação mais baixos são o n. ${ }^{\circ} 7(2 \mathrm{x} / 2 ; \mathrm{MAb})$, e os n. ${ }^{\circ} 2,16$ e 19 , que não apresentam qualquer índice de aceitação por parte dos colegas de turma $(0 \mathrm{x} / 0 ; \mathrm{MAb})$.

A matriz sociométrica permite-nos perceber as relações estabelecidas dentro do grupo, assim como as relações de reciprocidade (de escolhas recíprocas), relatadas em Northway e Weld (1999). Para melhor entendermos a dinâmica da turma, em termos de aceitação, é apresentada a figura 1 .

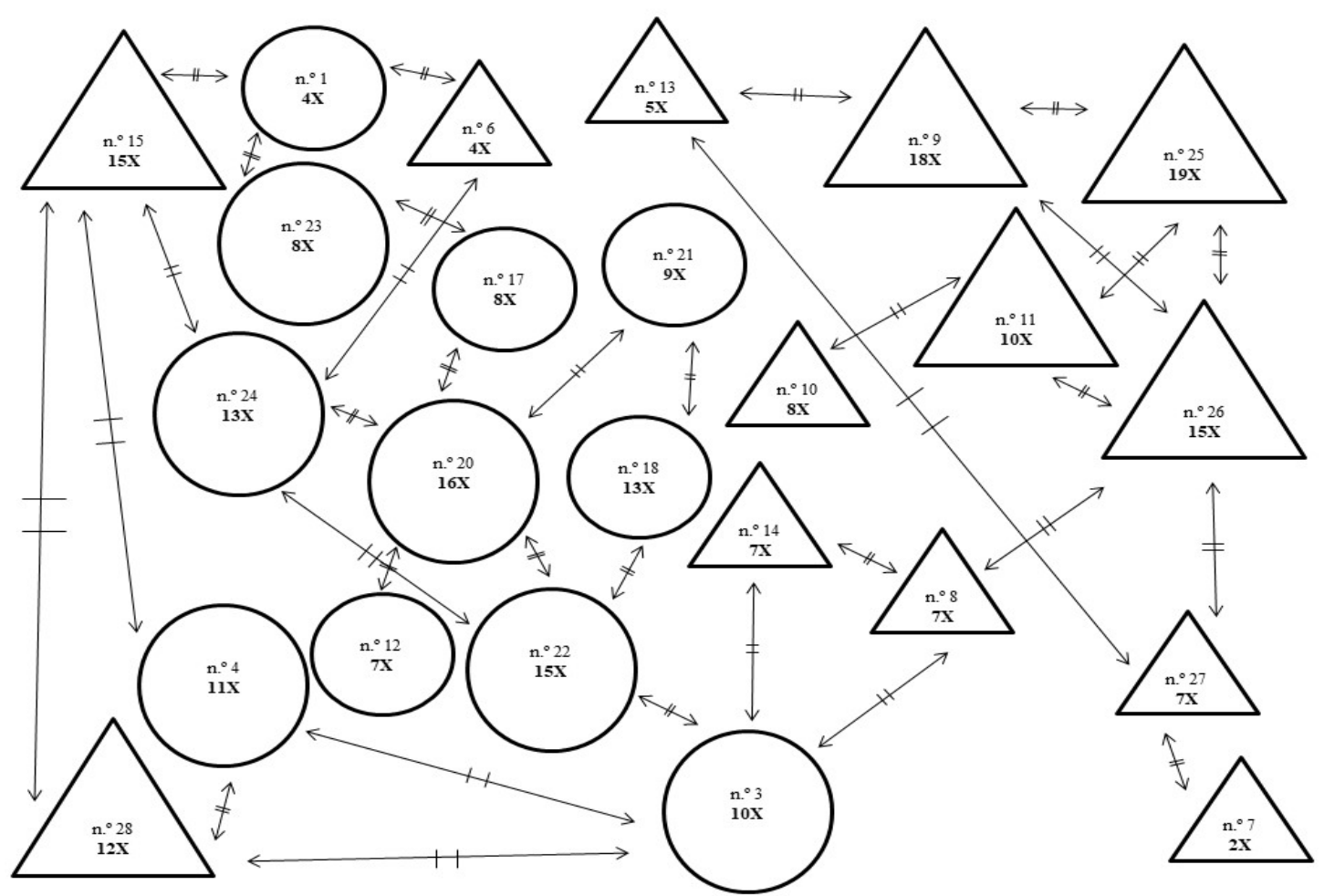

Figura 1. Sociograma de aceitação relacional (escolhas recíprocas)

Os rapazes são representados por triângulos e as raparigas por circunferências. Em cada figura geométrica (triângulos e circunferências) é colocado o número do aluno e o número de vezes em que foi referenciado pelos colegas (eg., "n. ${ }^{\circ} 310 \mathrm{X}$ " indica que o aluno $\mathrm{n}^{\circ} 3$ foi referenciado 10 vezes pelos elementos da turma).

É possível verificarmos que há relações recíprocas de aceitação entre 24 dos 28 alunos, com destaque para os alunos n. ${ }^{\circ} 3$ e n. ${ }^{\circ} 20$ (5 relações recíprocas), ambos do género feminino, e o n. ${ }^{\circ} 15$ (4 relações recíprocas), masculino. Pela análise da figura 1 , atendendo ao género, constata-se que há uma tendência para os jovens se relacionarem reciprocamente com outros jovens do mesmo género, isto é, rapazes com rapazes e raparigas com raparigas, com algumas exceções (eg., aluno n. ${ }^{\circ} 15$, do género masculino, o qual apresenta 3 relações recíprocas com raparigas e uma com um rapaz) o que confirma o exposto em Papalia e Olds (2000) e Silva (2010): "as crianças de mesmo sexo têm interesses comuns (...) as meninas e os meninos brincam e conversam uns com os outros de modo distinto (...) crianças do mesmo sexo ajudam-nas a aprender comportamentos e a incorporar papéis sociais" (Silva, 2010, p. 10).

Ainda em relação ao objetivo b), mas no que concerne à rejeição, destaque para o aluno n. ${ }^{\circ} 19$, escolhido 49 vezes por 21 alunos da turma, com IPS muito acima da probabilidade $(49 \mathrm{x} / 21$; MAc). Numa mesma lógica destacamos o n. ${ }^{\circ} 2\left(33 \mathrm{x} / 15\right.$; MAc), $n .^{\circ}$ 7 (26x/11; MAc), n. ${ }^{\circ} 28$ (18x/8; MAc), n. ${ }^{\circ} 10$ (16x/7; MAc), n..$^{\circ} 13$ (16x/6; MAc) e n. ${ }^{\circ} 23$ (15x/10; MAc). Pela ausência de qualquer referenciação da 
parte dos colegas destacamos os . $^{\circ} 1,12,17,18,21, \quad 22 \quad$ e $\quad 24 \quad(0 \mathrm{x} / 0 ; \quad$ MAb) (Figura 2).

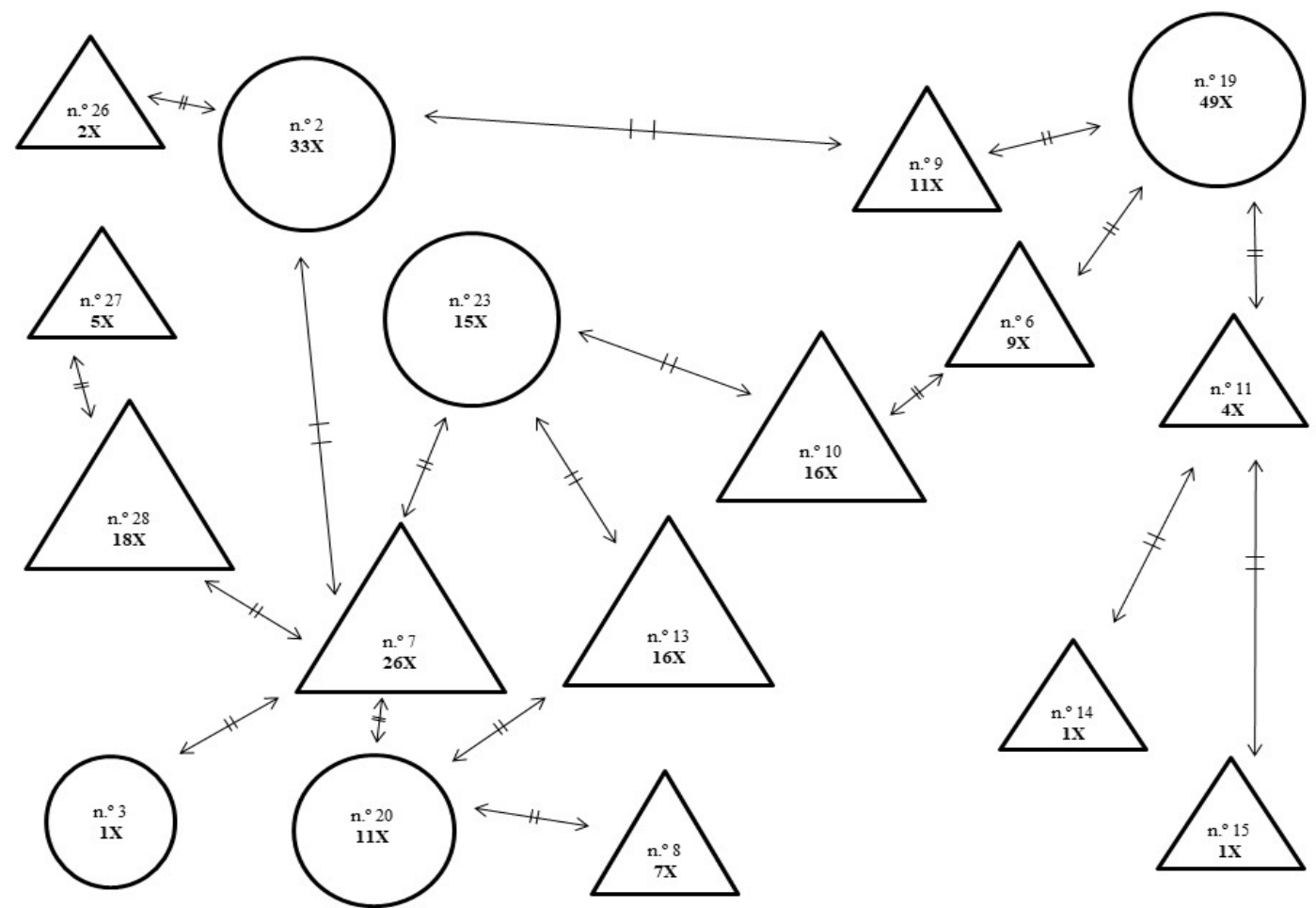

Figura 2. Sociograma de rejeição relacional (escolhas recíprocas)

Entre os 28 alunos, há 18 relações recíprocas de rejeição. Destaque para o n. ${ }^{\circ} 7$, um rapaz, com 5. Destas, 4 são estabelecidas com raparigas $\left(n .^{\circ} 2\right.$, n. $^{\circ}$ 3, n. $^{\circ} 20$, n. $^{\circ}$ 23) o que, e tal como na aceitação, confirma o exposto em Papalia e Olds (2000) e Silva (2010). Os alunos mais referenciados são do género feminino - n. ${ }^{\circ} 19$ (49X) e n. ${ }^{\circ} 2$ (33X) - e a maior parte das rejeições recíprocas ocorre entre as raparigas e os rapazes (13 de um total de 18).

Quanto ao objetivo c), na tabela 3 apresentamos os valores de associação entre relacionamento interpessoal (aceitação) e sentimento de bem-estar e estilo de vida. Por outro lado, na tabela 4 é apresentado e discutido o processo de rejeição.

Tabela 3 - Associação entre o relacionamento interpessoal (aceitação) e o bem-estar e estilo de vida

N. ${ }^{\circ}$ de vezes em N. ${ }^{\circ}$ de colegas que foi escolhido que o escolheram

\begin{tabular}{|c|c|c|c|c|}
\hline & rho & $p$ & rho & $p$ \\
\hline 1. Sinto-me satisfeito com a minha escola. & 0.083 & 0.673 & 0.081 & 0.681 \\
\hline 2. Sinto-me bem comigo mesmo. & -0.107 & 0.589 & -0.150 & 0.445 \\
\hline 3. Sinto-me à vontade para conversar com os meus amigos. & -0.060 & 0.765 & -0.044 & 0.826 \\
\hline $\begin{array}{l}\text { 4. Sinto que sou ativo fisicamente, praticando atividade } \\
\text { desportiva com regularidade }\end{array}$ & 0.359 & $0.061 *$ & 0.365 & $0.056^{*}$ \\
\hline $\begin{array}{l}\text { 5. Sinto que sou conflituoso, tendo dificuldade em ter/fazer } \\
\text { novos amigos. }\end{array}$ & -0.294 & 0.129 & -0.272 & 0.162 \\
\hline $\begin{array}{l}\text { 6. Sinto que tenho uma alimentação equilibrada e } \\
\text { diversificada. }\end{array}$ & 0.014 & 0.943 & -0.004 & 0.982 \\
\hline 7. Sinto que durmo e descanso bem durante a noite. & -0.057 & 0.773 & -0.076 & 0.699 \\
\hline $\begin{array}{l}\text { 8. Sinto que consigo conversar com os meus pais acerca de } \\
\text { quaisquer problemas do dia-a-dia. }\end{array}$ & -0.151 & 0.442 & -0.174 & 0.375 \\
\hline $\begin{array}{l}\text { 9. Sinto que, em termos gerais, penso de uma forma } \\
\text { positiva. }\end{array}$ & -0.146 & 0.460 & -0.290 & 0.134 \\
\hline $\begin{array}{l}\text { 10. Sinto que grande parte do meu tempo é ocupado com } \\
\text { videojogos (playstation, tablet, smartphone...). }\end{array}$ & 0.037 & 0.853 & -0.025 & 0.901 \\
\hline
\end{tabular}


É possível verificar que existe uma correlação significativa entre o item $\mathrm{n}^{\circ}$ 4. "sinto-me ativo fisicamente, praticando atividade desportiva com regularidade" e o índice de aceitação para com os colegas, pelo número de vezes que foi escolhido ( $r h o=0.359 ; p=0.061)$ e colegas que o escolheram ( $r h o=0.365 ; p=0.056)$. Quanto fisicamente mais ativos estes jovens se sentem, mais aceitação têm junto do grupo (turma). Nos praticantes regulares de atividade desportiva a competência motora é regrageral mais elevada (Campos et al., 2018; Gísladóttir, Haga, \& Sigmundsson, 2019), pelo que a probabilidade de ser opção (aceitação) junto do grupo aumenta, principalmente quando as situações hipotéticas de escolha estão relacionadas com esse aspeto (eg., a participação num torneio desportivo questões 1 e 2).

Tabela 4 - Associação entre o relacionamento interpessoal (rejeição) e o bem-estar e estilo de vida

\begin{tabular}{|c|c|c|c|c|}
\hline & \multicolumn{2}{|c|}{$\begin{array}{l}\text { N. }{ }^{\circ} \text { de vezes em } \\
\text { que foi escolhido }\end{array}$} & \multicolumn{2}{|c|}{$\begin{array}{l}\mathrm{N}{ }^{\circ} \text { de colegas } \\
\text { que o escolheram }\end{array}$} \\
\hline & rho & $p$ & rho & $p$ \\
\hline 1. Sinto-me satisfeito com a minha escola. & -0.089 & 0.654 & -0.144 & 0.465 \\
\hline 2. Sinto-me bem comigo mesmo. & 0.299 & 0.122 & 0.318 & 0.199 \\
\hline 3. Sinto-me à vontade para conversar com os meus amigos. & -0.092 & 0.650 & 0.102 & 0.611 \\
\hline $\begin{array}{l}\text { 4. Sinto que sou ativo fisicamente, praticando atividade } \\
\text { desportiva com regularidade }\end{array}$ & 0.005 & 0.979 & -0.043 & 0.827 \\
\hline $\begin{array}{l}\text { 5. Sinto que sou conflituoso, tendo dificuldade em ter/fazer } \\
\text { novos amigos. }\end{array}$ & 0.267 & 0.169 & 0.222 & 0.256 \\
\hline $\begin{array}{l}\text { 6. Sinto que tenho uma alimentação equilibrada e } \\
\text { diversificada. }\end{array}$ & -0.133 & 0.500 & -0.169 & 0.363 \\
\hline 7. Sinto que durmo e descanso bem durante a noite. & 0.183 & 0.352 & 0.129 & 0.512 \\
\hline $\begin{array}{l}\text { 8. Sinto que consigo conversar com os meus pais acerca de } \\
\text { quaisquer problemas do dia-a-dia. }\end{array}$ & 0.201 & 0.306 & 0.141 & 0.475 \\
\hline $\begin{array}{l}\text { 9. Sinto que, em termos gerais, penso de uma forma } \\
\text { positiva. }\end{array}$ & 0.407 & $0.031 *$ & 0.433 & $0.021 *$ \\
\hline $\begin{array}{l}\text { 10. Sinto que grande parte do meu tempo é ocupado com } \\
\text { videojogos (playstation, tablet, smartphone...). }\end{array}$ & -0.035 & 0.860 & -0.121 & 0.538 \\
\hline
\end{tabular}

* Significativo para $p<0.10$.

Existe uma correlação significativa, linear e positiva, entre o item n. 9 . "sinto que, em termos gerais, penso de uma forma positiva" e o índice de rejeição, tanto pelo número de vezes que foi escolhido ( $r h o=0.407 ; p=0.031$ ) como pelo número de colegas que o escolhem $(r h o=0.433 ; p=0.021)$. É possível verificar que, quanto mais positivamente pensam, mais elevada é a rejeição. Pensar excessivamente de forma positiva pode transmitir autoconfiança descomedida, o que muitas vezes é entendido como um comportamento essencialmente presunçoso (Peale, 2019).

Conforme referido em Chicon (2008), “já vivenciámos muitas vezes a exclusão disfarçada dos menos hábeis, dos mais gordinhos, dos mais lentos, (...) daqueles que não se enquadram em um padrão preestabelecido" (p. 32) e, socialmente, esta ideia de autoconfiança excessiva é muitas vezes associada à presunção, o que não se encaixa no padrão social e cultural pré-estabelecido. "Maniento", "convencido" ou outras expressões similares, pouco agradáveis, eram ouvidas semanalmente nas aulas de EF, quando alguns alunos tentavam classificar comportamentos dos seus colegas. Entendemos que a linha que separa a autoconfiança da presunção é ténue, e que esta pode muitas vezes ser interpretada de forma errónea, levando à rejeição ou à não aceitação de alguns elementos no seio de um grupo.

\section{Pós-programa de intervenção}

Após operacionalização do programa de intervenção, descrito na Metodologia, importa apresentar e discutir os principais resultados plasmados nos objetivos d) e e). Começamos com o objetivo d), apresentado os seus resultados na tabela 5. Focando a análise no relacionamento interpessoal, no item 3 há um aumento do valor médio de resposta, de 8.33 para 8.52 , que nos permite depreender que, após o programa, os alunos se sentem melhor e mais à-vontade para conversar com os colegas. Por outro lado, em relação ao item n. ${ }^{\circ} 5$, existe uma diminuição do valor de resposta. Como a expressão utilizada é conotada negativamente (conflituoso), é possível concluir que quanto mais baixo o valor de resposta, menos conflituosos e menos dificuldades sentem para fazer e manter amigos. Assim, como ocorreu uma diminuição do valor médio, de 2.25 para 1.30 , é possível afirmar que, após a sua participação no programa, ocorreram melhorias também nesta componente. 
Tabela 5. Estilo de vida e sentimento de bem-estar (pré e pós-programa de intervenção)

\begin{tabular}{|c|c|c|c|c|}
\hline & \multicolumn{2}{|c|}{$\begin{array}{l}\text { Pré-programa } \\
\text { de intervenção }\end{array}$} & \multicolumn{2}{|c|}{$\begin{array}{l}\text { Pós-programa } \\
\text { de intervenção }\end{array}$} \\
\hline & $\mathbf{M}$ & DP & $\mathbf{M}$ & DP \\
\hline 1. Sinto-me satisfeito com a minha escola. & 8.11 & 1.54 & 7.63 & 1.80 \\
\hline 2. Sinto-me bem comigo mesmo. & 7.18 & 2.85 & 6.89 & 2.29 \\
\hline 3. Sinto-me à vontade para conversar com os meus amigos. & 8.33 & 1.86 & 8.52 & 2.17 \\
\hline $\begin{array}{l}\text { 4. Sinto que sou ativo fisicamente, praticando atividade } \\
\text { desportiva com regularidade }\end{array}$ & 7.57 & 2.58 & 7.56 & 2.48 \\
\hline $\begin{array}{l}\text { 5. Sinto que sou conflituoso, tendo dificuldade em ter/fazer } \\
\text { novos amigos. }\end{array}$ & 2.25 & 3.05 & 1.30 & 1.99 \\
\hline $\begin{array}{l}\text { 6. Sinto que tenho uma alimentação equilibrada e } \\
\text { diversificada. }\end{array}$ & 8.21 & 1.31 & 7.26 & 2.01 \\
\hline 7. Sinto que durmo e descanso bem durante a noite. & 8.14 & 1.58 & 7.44 & 2.10 \\
\hline $\begin{array}{l}\text { 8. Sinto que consigo conversar com os meus pais acerca de } \\
\text { quaisquer problemas do dia-a-dia. }\end{array}$ & 8.14 & 2.18 & 7.44 & 2.72 \\
\hline $\begin{array}{l}\text { 9. Sinto que, em termos gerais, penso de uma forma } \\
\text { positiva. }\end{array}$ & 7.18 & 2.88 & 6.56 & 2.00 \\
\hline $\begin{array}{l}\text { 10. Sinto que grande parte do meu tempo é ocupado com } \\
\text { videojogos (playstation, tablet, smartphone...). }\end{array}$ & 4.96 & 2.47 & 5.59 & 1.92 \\
\hline
\end{tabular}

Por fim, no que concerne ao objetivo e), pela análise do sociograma (aceitação) do pós-programa de intervenção (Figura 3), é possível verificarmos que o número de relações recíprocas aumentou de 36 para
40, que nos remete para um aumento de aceitação interpessoal dentro da turma.

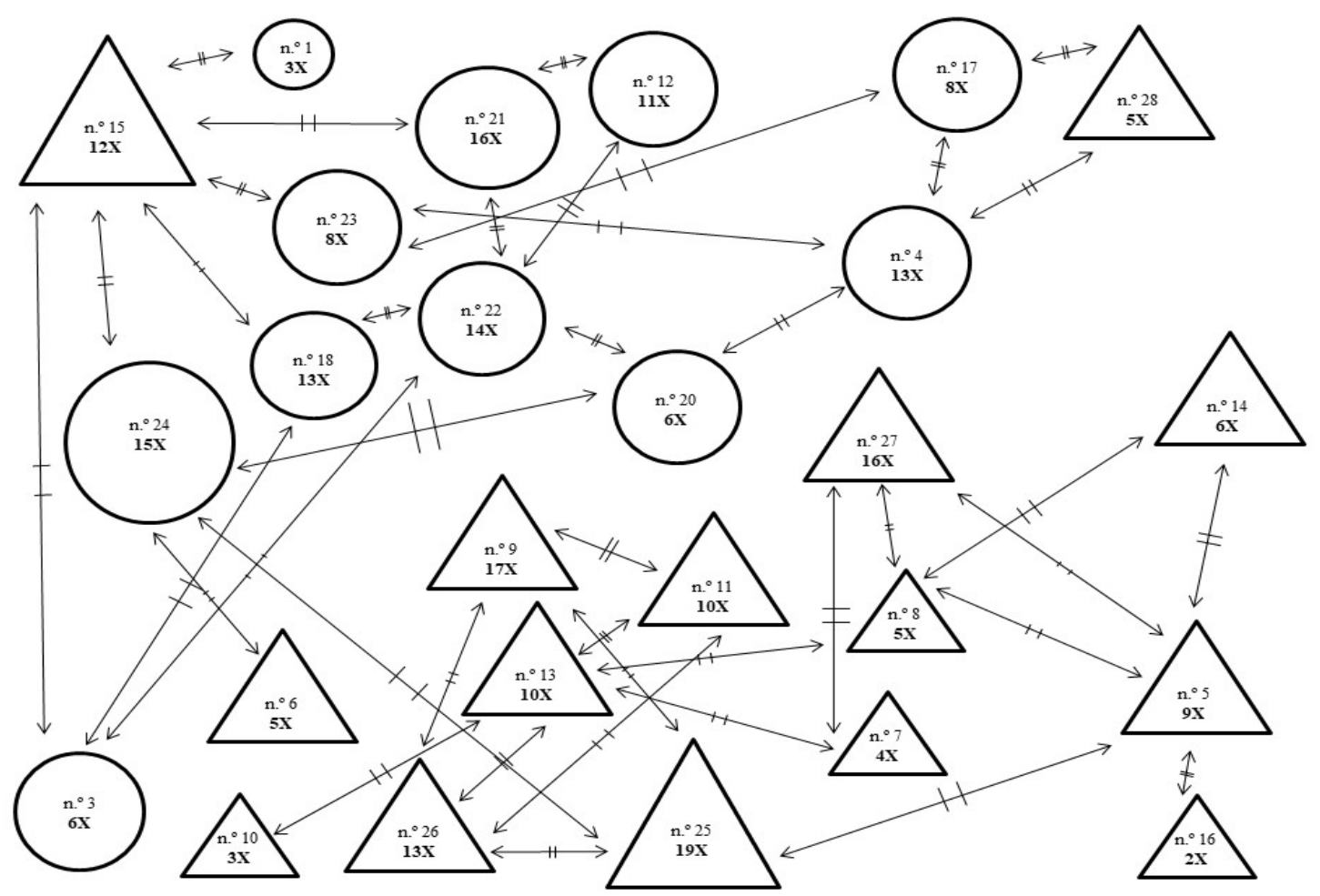

Figura 3. Sociograma de aceitação relacional (escolhas recíprocas): pós-programa de intervenção

Por sua vez, em relação ao processo de rejeição, comparando os dados com os obtidos antes da implementação do programa de intervenção (Figura 2), é possível verificar que ocorreu a diminuição do número de relações recíprocas, de 18 para 11 (Figura 4). Com o programa, diminuíram as relações de rejeição, havendo uma maior pré-disponibilidade dos alunos para interagirem em determinadas situações que envolvam o relacionamento com os seus colegas de turma. 


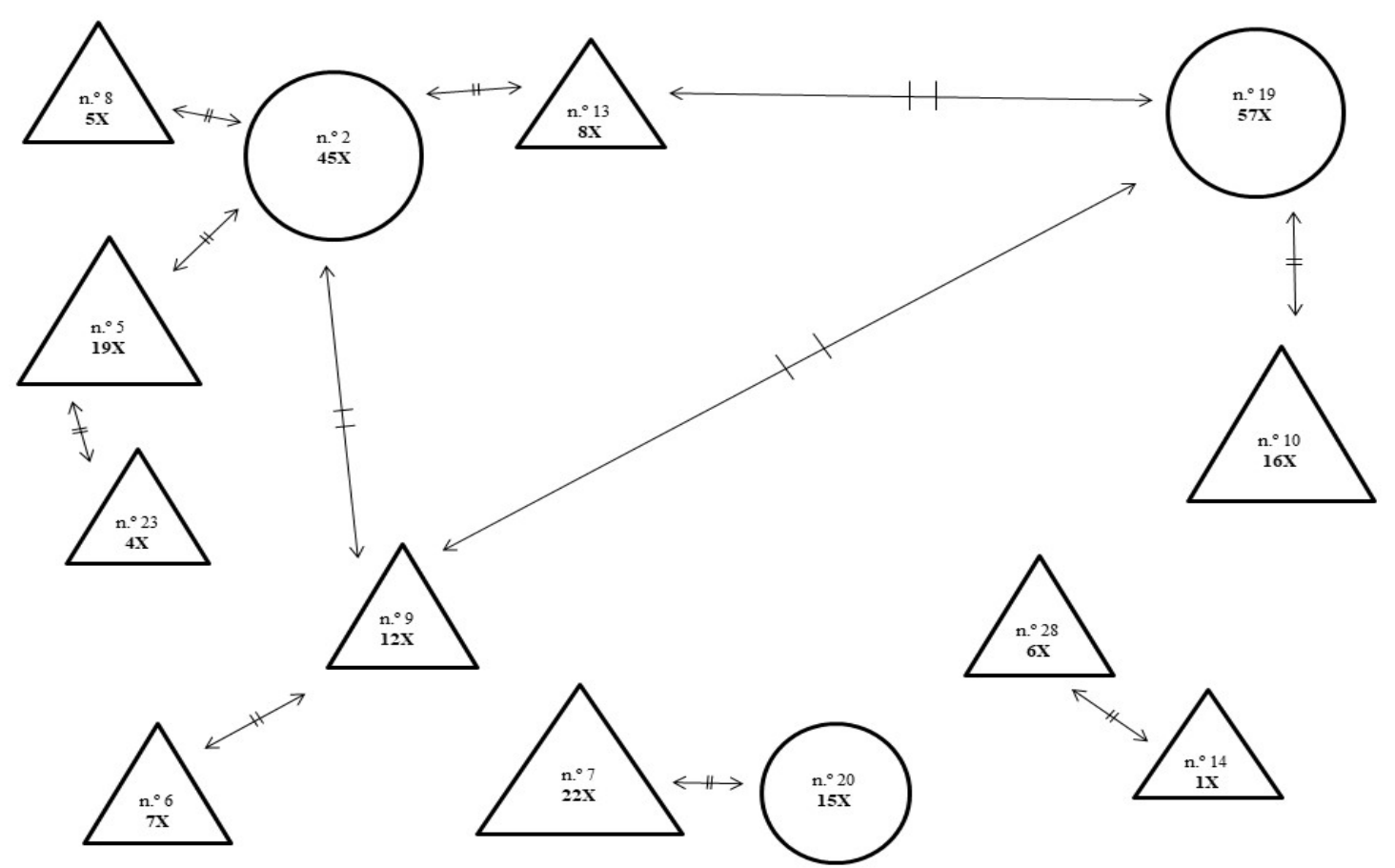

Figura 4. Sociograma de rejeição relacional (escolhas recíprocas): pós-programa de intervenção

Os resultados obtidos após o programa de intervenção suportam a ideia de que a EF quando lecionada de forma integradora, permite ao aluno a aquisição de uma sensação de bem-estar e estilo de vida positivo (Chicon, 2008), tal como o ajuda a melhorar o relacionamento interpessoal (Santos et al., 2017), de uma importância fundamental no processo de maturação social (Caballo \& Marinho, 2002).

\section{Conclusão}

É possível concluir que o relacionamento interpessoal dos jovens adolescentes melhorou após a participação no programa de intervenção. Perceber que tiveram melhores resultados nos itens 3. "sintome à vontade para conversar com os meus amigos" e 5. "sinto que sou conflituoso, tendo dificuldade em ter e fazer amigos", valoriza o programa delineado e comprova que a estruturação de uma aula de EF, organizada por forma a potenciar o relacionamento interpessoal, induz um efeito positivo neste âmbito. Para além disso, o facto de terem aumentado as relações de aceitação e diminuído as de rejeição, comprovou, uma vez mais, a efetividade do programa definido para a obtenção do principal objetivo proposto: a melhoria do relacionamento interpessoal dentro da turma, através das aulas de EF.

O conhecimento aprofundado da turma e dos seus elementos, dos mecanismos de relacionamento, uma das principais problemáticas atuais, permite ao professor intervir de forma mais assertiva e profícua dando o verdadeiro sentido ao contexto educativo, considerando as relações enraizadas no seio de um grupo.

O estímulo, pela realização de algumas tarefas em contexto de aula, colocando em cooperação os alunos com indicadores de rejeição recíproca, é uma estratégia a adotar nas aulas de EF, pelo menos em parte destas, com o objetivo de fortalecer a coesão grupal, melhorando assim a motivação e vontade de participar nas tarefas e, em consequência, a aprendizagem dos conteúdos e competências trabalhadas. Na nossa opinião, o melhor clima de aula, bem como o facto dos alunos sentirem mais motivação e predisposição para a aprendizagem, faz com que o seu empenho seja maior. Consequentemente, maior empenho da sua parte implicará uma maior proatividade, intervenção, dedicação, esforço, vontade e aprendizagem.

$\mathrm{O}$ estudo do bem-estar e do estilo de vida permite conhecer um pouco mais dos alunos com que lidamos. E se a adolescência é um micromundo em transformação (Bouzas, 2011), é importante conhecê-lo, pelo menos algumas das suas principais características, para que a intervenção didáticopedagógica possa ser efetivamente adequada, promovendo, além do desenvolvimento desportivo, o desenvolvimento de algumas competências pessoais e sociais para a vida (Camiré \& Santos (2019).

Sugerimos a realização de mais estudos neste contexto, com um maior número de alunos, bem como com outras faixas etárias e contextos (Préescolar, 1. ${ }^{\circ}$ Ciclo do Ensino Básico, 2. ${ }^{\circ}$ Ciclo do Ensino Básico ou Ensino Secundário), suprimindo uma das principais limitações deste trabalho 
(número de participantes). Além do referido, e como recomendação para futuros trabalhos, seria importante considerar mais tempo por aula destinado aos programas de intervenção (eg., 30 minutos nas sessões de 90 minutos e 15 nas de 45 minutos, um terço do tempo total das aulas).

\section{Referências}

Borsari, J. (1980). Educação física da pré-Escola à universidade. São Paulo: Editora Pedagógica e Universitária (EPU).

Bouzas, I. (2011). A especificidade dos adolescentes. Adolescência \& Saúde, 8(2), 5.

Caballo, V., \& Marinho, M. (2002). Comportamento antissocial infantil e o seu impacto para a competência social. Psicologia, Saúde e Doença, 3(2), 141-147.

Camiré, M., \& Santos, F. (2019). Promoting positive youth development and life skills in youth sport. Journal of Sport Pedagogy and Research, 5(1), $27-$ 34.

Campos, F., Melo, R., Martins F., Damásio, A., Mendes, R., \& Gomes, R. (2018). Alimentação, estilo de vida, prática desportiva, composição corporal e competência motora em crianças do ensino Pré-escolar e $1 .{ }^{\circ}$ CEB (FORMIGA). II Fórum da REDESPP, ESECS-IP Leiria. Leiria - Portugal.

Campos, F., Mendes, T., Melo, R., Martins, F., Damásio, A., Gomes, R., \& Mendes, R. (2019). Lifestyle, diet, sleep, sports practice and body composition in the $1^{\text {st }}$ Cycle of Basic Education. Health and Well-being Intervention International Congress, ESS-IP Viseu. Viseu - Portugal.

Chicon, J. (2008). Inclusão e exclusão no contexto da educação física escolar. Movimento, 14(1), 13-38.
Gísladóttir, T., Haga, M., \& Sigmundsson, H. (2019). Motor competence in adolescents: exploring association with physical fitness. Sports, 7(176), 111.

Hill, M., \& Hill, A. (2002). Investigação por questionário (2a ed.). Lisboa: Sílabo.

Maroco, J. (2010). Análise estatística com PASW statistics. Lisboa: Report Number.

Northway, M., \& Weld, L. (1999). Testes sociométricos: Um guia para professores. Lisboa: Livros Horizonte.

Pallant, J. (2011). SPSS survival manual: A step-bystep guide to data analysis using SPSS ( $4^{\text {th }}$ ed.). Crows Nest NSW: Allen \& Unwin.

Papalia, D., \& Olds, S. (2000). Desenvolvimento humano. Porto Alegre: Artes Médicas.

Peale, N. (2019). O poder do pensamento positive ( $3^{a}$ ed.). Amadora: Nascente.

Pestana, M., \& Gageiro, J. (2008). Análise de dados para ciencias sociais. A complementaridade do SPSS (5 ${ }^{a}$ ed.). Lisboa: Sílabo.

Rosado, A. (1998). Nas margens da educação física e desporto. Lisboa: Edições FMH.

Santos, C., Silva, K., Santos, R., \& Silva, F. (2017). A contribuição das aulas de educação física para a inclusão do aluno com TEA. ENAEDI, 1(1), 1-5.

Silva, J. (2010). Análise das relações interpessoais na aula de educação física escolar. Revista da Graduação, 3(1), 1-11.

World Health Organization (2016). Obesidade $e$ excesso de peso. Disponível em: http://www.who.int. 


\title{
Relação entre frequência de prática
}

\section{e importância atribuída pelos praticantes}

\author{
Ricardo Gomes ${ }^{1,2}$, Diana Franco', Maria Dias', Fernando Martins, ${ }^{1,2}$, \\ António Damásio ${ }^{1,2}$, Francisco Campos ${ }^{1,2}$ \\ ${ }^{1}$ Unidade de Investigação Aplicada em Ciências do Desporto; \\ ${ }^{2}$ Escola Superior de Educação de Coimbra - Instituto Politécnico de Coimbra;
}

\section{Palavras-chave: Fitness; Frequência de prática; Motivos de prática; Qualidade; Serviço.}

\section{RESUMO}

Para o sucesso dos ginásios é determinante conhecer as características dos consumidores, para atender às suas necessidades. Pretende-se caracterizar os praticantes de ginásio e relacionar a importância atribuída pelos mesmos aos motivos para a prática, qualidade dos serviços e qualidade dos instrutores, segundo a sua frequência de prática. Foi aplicado o questionário "Importância Atribuída no Fitness (IAF)" a 560 praticantes, dos 18 aos 71 anos de idade, 325 do género feminino e 235 do masculino. Para a caracterização foi utilizada estatística descritiva e para a correlação o teste de Spearman, para níveis de significância de $5 \%$. A maioria dos praticantes iniciou a prática com 20 anos ou menos (57.1\%), e já frequentou 1 a 3 ginásios (67.9\%). Treina sozinha (51.1\%) de 1 a 4 vezes por semana (74.2\%), de 31 a 90 minutos por sessão (87.6\%). Quanto maior a frequência de prática menor a importância que atribuem a preço acessível $(r=-0.106 ; p=0.012)$, proximidade para com o local de trabalho $(r=-0.096 ; p=0.025)$, planeamento $(r=-0.091$; $p=0.032)$ e instrução $(r=-0.088 ; p=0.039)$, entre outras. Os resultados permitirão aos responsáveis desenhar e melhorar a intervenção, tendo em consideração a especificidade do público-alvo, potenciando a satisfação e aumentando a fidelização.

\section{Keywords: \\ Fitness; Frequency of practice; Reasons for the practice; Quality; Service.}

\begin{abstract}
For the success of fitness organisations, it is determinant to know the characteristics of the consumers, to meet their demands. The aim of this investigation is to characterise the gym clients and relate the importance given to the reasons to practice, service quality and the quality of the instructor, according to their frequency of practice. The questionnaire "Importance Attributed in Fitness (IAF)" was applied to 560 clients, from 18 to 71 years old, 325 are female and 235 male. Descriptive statistics were used to characterization, and correlations were made with Spearman test, to a significance level of 5\%. The client's majority start their practice with 20 years of age or less $(57.1 \%)$ and have attended between 1 to 3 gyms (67.9\%). Practice alone (51.1\%), 1 to 4 times a week (74.2\%), for 31 to 90 minutes $(87.6 \%)$. Higher the frequency of practice was, the less importance is given to affordable price $(r=-0.106 ; p=0.012)$, proximity with workplace $(r=-0.096 ; p=0.025)$, planning $(r=-0.091 ; p=0.032)$ and instruction $(r=-0.088 ; p=0.039)$, among others. These results provide information that can be used to design or service improve, taking into consideration the specificity of the target, increasing their satisfaction and raise retention.
\end{abstract}




\section{Introdução}

De entre os temas que na atualidade têm suscitado um maior interesse na indústria do fitness, destacamse os motivos que levam um individuo à prática de atividade física em ginásio, a qualidade do serviço e a qualidade do instrutor (características/indicadores de qualidade) neste âmbito (Campos, Damásio, Martins, Simões, \& Franco, 2018; Campos et al., 2019).

O conceito de motivação relaciona-se com a direção, a intensidade e a persistência. A direção refere-se aos motivos que levam os praticantes à prática de uma atividade física específica (eg., Localizada) em detrimento de outra (eg., Hidroginástica); a intensidade expressa-se no esforço despendido aquando da prática dessa mesma atividade; por fim, a persistência, define-se como a capacidade de manutenção em prática, de não desistir, mesmo perante uma qualquer adversidade (Weinberg \& Gould, 2011).

A qualidade de um serviço é definida como uma avaliação global da sua importância (Parasuraman, Zeithaml, \& Berry, 1988). É de natureza subjetiva e, em muitos casos, de difícil quantificação. O desenvolvimento de um sistema integrado de gestão do serviço de fitness com base em parâmetros de qualidade é de imperativa relevância uma vez que contribui para uma melhor tomada de decisão do gestor intermédio - o Diretor Técnico, permitindolhe (re)desenhar operações do serviço para melhor satisfazer o consumidor, fidelizando-o e mantendo-o em prática, possivelmente, por mais tempo. A qualidade de uma qualquer experiência, no caso de induzir uma sensação de satisfação ao indivíduo que a vivenciou, irá promover, como consequência, uma intenção de fidelização, onde a perceção de qualidade está associada à continuidade de consumo (Campos, Damásio, et al., 2018; Campos et al., 2019; Parasuraman et al., 1988).

Nos serviços de fitness, um dos atributos mais valorizados, no domínio da satisfação e adesão a um ginásio, é a qualidade dos recursos humanos, em particular, a qualidade do instrutor (Gonçalves, Buchmann, \& Carvalho, 2013; Papadimitriou \& Karteroliotis, 2000). Assume-se também que o sucesso de uma organização pode depender do grau de satisfação dos consumidores (Sá \& Sá, 2002).

Pelo referido, com a presente investigação pretendese:

a) caracterizar a prática de atividade física em contexto de ginásio;

b) relacionar a importância atribuída pelos praticantes de fitness, em função dos motivos de prática (MP), qualidade do serviço (QS) e do instrutor (QI), segundo a frequência de prática (número de treinos realizados por semana).

O mercado do fitness está cada vez mais diversificado e complexo, pelo que se torna relevante aprofundar o conhecimento das características do praticante de atividade física em contexto de ginásio. O estudo desta variável frequência semanal - permite perceber de antemão as necessidades e preferências dos consumidores, uma vez que a prática em ginásios tem aumentado progressivamente nos últimos anos (Comissão Europeia, 2014; 2018). Para potenciar o aumento da prática de atividade física em ginásios, aproveitando esta conjuntura, importa que os serviços sejam desenhados em função das características do público-alvo, visando a sua satisfação e o aumento da fidelização.

\section{Métodos}

\section{Participantes}

Participaram no estudo 560 praticantes de atividades de fitness dos 18 aos 71 anos de idade $(31.33 \pm 11.51), \quad 325$ do género feminino $(32.16 \pm 11.37)$ e 235 do género masculino $(30.19 \pm 11.62)$, frequentadores de vários ginásios de Portugal Continental.

\section{Instrumentos}

Foi aplicado o questionário "Importância Atribuída no Fitness - Motivos de Prática (MP), Qualidade do Serviço (QS) e Qualidade do Instrutor (QI)", adaptado de Damásio e Campos (2016). Além dos itens relacionados com a caracterização sociodemográfica e da prática de atividade física, este contem 60 perguntas na totalidade das três dimensões em análise [MP (15 itens), QS (20 itens), QI (25 itens)]. Estes 60 itens são respondidos numa escala de importância atribuída de likert de 7 pontos, de 1 (nada importante) a 7 (totalmente importante).

\section{Procedimentos}

Após o contacto prévio com os responsáveis das entidades onde a recolha dos dados foi realizada, e a respetiva autorização, contactámos os instrutores e os responsáveis de sala [no caso das atividades individuais (eg., Musculação)] para contextualizar o estudo (âmbito, objetivos e o pretendido) e agendar as datas/horários de recolha.

A recolha foi efetuada no final da sessão de treino, no local de prática, por um grupo de avaliadores, devidamente treinados para tal efeito, respeitando o protocolo de recolha previamente facultado, segundo o recomendado na literatura de referência (Hill \& Hill, 2002). Todos os inquiridos foram informados do: âmbito, objetivo e pertinência da sua colaboração; importância da sinceridade na resposta; e confidencialidade/anonimato no tratamento e divulgação dos dados (consentimento informado).

\section{Análise estatística}


Para efeitos de caracterização da prática de atividade física em ginásio recorreu-se à estatística descritiva, pela análise das frequências absolutas e relativas.

Tendo em consideração o segundo objetivo importância atribuída pelos praticantes de fitness, em relação aos $\mathrm{MP}$, QS e QI, segundo a sua frequência de prática semanal -, efetuou-se a correlação de Spearman (r) (Laureano, 2013). Para classificar a intensidade da associação entre as variáveis, adotou-se a escala sugerida por Hopkins (2002): muito fraca $(r<0.1)$; fraca $(0.1<r \leq 0.3)$; moderada $(0.3<r \leq 0.5)$; forte $(0.5<r \leq 0.7)$; muito forte $(0.7<r \leq 0.9)$; quase perfeita $(r>0.9)$; perfeita $(r=1.0)$.

A análise estatística foi realizada através do software IBM SPSS (versão 25.0, IBM USA), para um nível de significância de $5 \%(p<0.05)$.

\section{Resultados}

Iniciamos a apresentação e discussão dos resultados com a caracterização da prática de atividade física em ginásio (Tabela 1), tentando responder ao primeiro objetivo.

Tabela 1 - Caracterização da prática de atividade física em ginásio $(n=560)$

\begin{tabular}{|c|c|c|}
\hline & $n$ & $\%$ \\
\hline \multicolumn{3}{|c|}{$\begin{array}{l}\text { Com que idade iniciou a prática de atividade física em ginásio? } \\
(n=520)\end{array}$} \\
\hline$\leq 20$ anos & 297 & $57.1 \%$ \\
\hline $21-30$ anos & 136 & $26.2 \%$ \\
\hline $31-40$ anos & 50 & $9.6 \%$ \\
\hline $41-50$ anos & 26 & $5.0 \%$ \\
\hline$>50$ anos & 11 & $2.1 \%$ \\
\hline \multicolumn{3}{|l|}{$\begin{array}{l}\text { Em quantos ginásios já esteve inscrito? } \\
(n=530)\end{array}$} \\
\hline 0 & 68 & $12.8 \%$ \\
\hline 1 & 136 & $25.6 \%$ \\
\hline 2 & 134 & $25.3 \%$ \\
\hline 3 & 90 & $17.0 \%$ \\
\hline 4 & 58 & $10.9 \%$ \\
\hline 5 & 22 & $4.2 \%$ \\
\hline 6 ou mais & 22 & $4.2 \%$ \\
\hline \multicolumn{3}{|c|}{$\begin{array}{l}\text { Como teve conhecimento do ginásio que frequenta atualmente? } \\
(n=529)\end{array}$} \\
\hline Ação de divulgação local do ginásio & 150 & $28.4 \%$ \\
\hline Canais de comunicação social (televisão, internet...) & 38 & $7.2 \%$ \\
\hline Amigos, colegas, vizinhos ou familiares & 318 & $60.1 \%$ \\
\hline Outra opção & 23 & $4.3 \%$ \\
\hline \multicolumn{3}{|l|}{$\begin{array}{l}\text { No ginásio, com quem costuma praticar atividade física? } \\
(n=518)\end{array}$} \\
\hline Sozinho & 265 & $51.1 \%$ \\
\hline Acompanhado (amigos, colegas ou outros familiares) & 221 & $42.7 \%$ \\
\hline Namorado(a), companheiro(a) ou cônjuge & 32 & $6.2 \%$ \\
\hline \multicolumn{3}{|c|}{$\begin{array}{l}\text { No ginásio, qual a frequência semanal de prática de atividade física? } \\
(n=554)\end{array}$} \\
\hline Menos de 1 vez por semana & 13 & $2.3 \%$ \\
\hline 1 a 2 vezes por semana & 135 & $24.4 \%$ \\
\hline 3 a 4 vezes por semana & 276 & $49.8 \%$ \\
\hline 5 a 6 vezes por semana & 116 & $21.0 \%$ \\
\hline Mais de 6 vezes por semana & 14 & $2.5 \%$ \\
\hline \multicolumn{3}{|c|}{$\begin{array}{l}\text { Qual a duração média (em minutos) de cada treino realizado? } \\
(n=554)\end{array}$} \\
\hline Menos de 30 minutos & 3 & $0.5 \%$ \\
\hline 31 a 60 minutos & 257 & $46.4 \%$ \\
\hline 61 a 90 minutos & 228 & $41.2 \%$ \\
\hline 91 a 120 minutos & 54 & $9.7 \%$ \\
\hline Mais de 120 minutos & 12 & $2.2 \%$ \\
\hline
\end{tabular}

Pelo apresentado, é possível verificar que a maioria dos praticantes inicia a prática de atividade física em ginásio até aos 20 anos de idade, frequentou 1 a 3 ginásios $(67.9 \%)[1(n=136 ; 25.6 \%) ; 2(n=134$; $25.3 \%) ; 3(n=90 ; 17.0 \%)]$, incluindo o que 
atualmente frequenta, e teve conhecimento deste através de amigos, colegas, vizinhos ou familiares.

Treinam maioritariamente sozinhos, apesar de um elevado número indicar que treina acompanhado $(48.9 \%)$ [amigos, colegas, outros familiares $(n=$ $221 ; 42.7 \%)$; namorado, companheiro, cônjuge ( $n=$ $32 ; 6.2 \%)$ ], 1 a 4 vezes por semana $(74.2 \%)$ [ 1 a $2(n$ $=135 ; 24.4 \%) ; 3$ a $4(n=276 ; 49.8 \%)], 31$ a 90 minutos por sessão $(87.6 \%)$ [31 a $60 \quad(n=257$; $46.4 \%) ; 61$ a $90(n=228 ; 41.2 \%)]$.

Relativamente ao objetivo b) - correlacionar a importância atribuída pelo praticante, em função dos
MP, QS e QI, de acordo com a frequência semanal de prática (o número de treinos) -, verificámos que não há associações estatisticamente significativas entre as variáveis em estudo, no que concerne aos MP, em nenhum dos 15 itens em avaliação.

Em relação à QS há 3 relações estatisticamente significativas que importa analisar e refletir: preço acessível; ginásio frequentado por poucos utilizadores; proximidade para com o local de trabalho (Tabela 2).

Tabela 2 - Correlações significativas entre a importância atribuída (itens da dimensão QS) e a frequência semanal de prática

\begin{tabular}{lccc} 
& $\boldsymbol{p}$ & $\boldsymbol{r}$ & Intensidade \\
\hline Preço acessível & 0.012 & -0.106 & fraca \\
Ginásio com poucos utilizadores & 0.013 & -0.106 & fraca \\
Proximidade para com o local de trabalho & 0.025 & -0.096 & muito fraca \\
\hline
\end{tabular}

Os 3 itens apresentam uma correlação negativa com a variável frequência semanal de prática, pelo que se pode concluir que quanto maior for a frequência de prática: menor é a importância atribuída ao baixo valor cobrado pelo serviço (preço acessível); menor é a importância atribuída ao facto de o ginásio ser frequentado por poucas pessoas (ginásio com poucos utilizadores); menor é a importância atribuída à sua localização próxima do local onde exerce funções profissionais (proximidade para com o local de trabalho). De forma objetiva podemos depreender que quanto mais assíduos são os praticantes, quanto mais eles praticam (maior frequência de prática semanal): menos se preocupam com os preços a pagar mensalmente: menos se preocupam com o elevado número de praticantes que frequenta regularmente o ginásio; e menos se preocupam com a distância entre local de trabalho e ginásio frequentado.

Por fim, e analisando a associação da frequência de prática de atividade física com a QI, há correlações significativas em 6 dos 25 itens (Tabela 3): formação; conhecimento; planeamento; inovação; humildade; instrução.

Tabela 3 - Correlações significativas entre a importância atribuída (itens da dimensão QI) e a frequência semanal de prática

\begin{tabular}{lccc} 
& $\boldsymbol{p}$ & $\boldsymbol{r}$ & Intensidade \\
\hline Formação & 0.011 & -0.108 & fraca \\
Conhecimento & 0.048 & -0.084 & muito fraca \\
Planeamento & 0.032 & -0.091 & muito fraca \\
Inovação & 0.020 & -0.099 & muito fraca \\
Humildade & 0.048 & -0.084 & muito fraca \\
Instrução & 0.039 & -0.088 & muito fraca \\
\hline
\end{tabular}

Tal como na dimensão QS, as correlações são negativas, o que permite verificar que quanto maior a frequência semanal de prática menor a importância atribuída a algumas características do instrutor de fitness, nomeadamente as indicadas na tabela 3 . Estas são as características que os utilizadores mais frequentes, de maior assiduidade, menos dão importância.

Analisando os dados de uma forma empírica, os resultados parecem ter a sua lógica. O praticante mais assíduo terá, regra geral, menor necessidade de um acompanhamento mais permanente, dando menor importância aos indicadores de qualidade previamente referidos. Relativizará a formação e o conhecimento do instrutor pois pode entender que necessita de um menor aporte deste em termos de prescrição do exercício. Relativizará o planeamento e a sua capacidade de inovação pois pode entender que realizará exercício em maior autonomia, com menor necessidade de supervisão técnica. Da mesma forma que relativizará a humildade e a instrução fornecida por considerar, porventura, que tem menor necessidade destas para melhorar a performance ou atingir os objetivos a que se propôs no início do programa de treino.

O estudo referente aos motivos de prática de atividade física em contexto específico de ginásio (Campos, Silva, et al., 2018), da qualidade do serviço (Campos, Costa, et al., 2018) e da qualidade dos instrutores de fitness (Franco et. al., 2018), permitiu perceber, segundo a perceção do praticante, e para cada uma destas dimensões, a que itens é 
dada mais importância (caracterização). $\quad \mathrm{Na}$ sequência destes, no estudo de Campos, Damásio et al. (2018), para além da caracterização, foi feita a comparação entre grupos segundo o género. É possível perceber que, nos itens onde há diferenças significativas, as mulheres apresentam valores médios de resposta mais altos do que os homens, pelo que é possível constatar que a importância por elas atribuida é maior. Realçamos o preço acessível e a proximidade para com o local de trabalho da dimensão QS, e a instrução da QI, as quais surgem igualmente com um papel de destaque no presente trabalho.

Objetivamente, no que concerne ao preço acessível (baixo) a pagar pela utilização do ginásio, à proximidade do ginásio para com o local onde exercem funções profissionais, e instrução facultada pelo instrutor aquando do treino, os resultados obtidos neste estudo complementam o apresentado por Campos, Damásio et al. (2018). Além de saber que as mulheres dão maior importância a estes itens, estes novos dados permitem-nos perceber que quanto maior a assiduidade do praticante (frequência de prática) menor importância lhes atribui.

Esta informação complementar permite a quem dirige um ginásio (Diretor Técnico) e ao próprio instrutor (a última peça organizacional, responsável pela prestação do serviço e pelo contacto final com o consumidor) que se possam adaptar quanto às características gerais do serviço (Diretor Técnico), ou quanto a estratégias didáticas e pedagógicas para conduzir o processo de treino (Técnico de Exercício Físico).

Se a motivação se relaciona com a direção, a intensidade e a persistência (Weinberg \& Gould, 2011) é muito importante conhecer os nossos consumidores, para que se saiba efetivamente o que se pode e deve fazer para melhorar a qualidade do serviço. O que se pode fazer para que comecem a fazer estas novas atividades, que quero lançar este mês no ginásio (direção)? O que se pode fazer para que se dediquem, aplicam e se esforcem ainda mais nas atividades que realizam (intensidade)? $\mathrm{E}$, principalmente, o que se pode fazer para que continuem em prática no meu ginásio, e não desistam ou procurem uma alternativa para a prática de atividade física (persistência)? São contribuições como a do presente estudo que nos permitem saber cada vez um pouco mais acerca deste mercado, e de como é possível melhorar a intervenção, em termos de coordenação ou supervisão (Diretor Técnico) e em termos de de intervenção técnica (Técnico de Exercício Físico).

\section{Conclusão}

Foi nosso objetivo caracterizar os praticantes em ginásio, e associar a regularidade da prática semanal com a motivação, qualidade do serviço e qualidade do instrutor, dando continuidade a um conjunto de trabalhos desenvolvidos recentemente (Campos, Costa, et al., 2018; Campos, Damásio, et al., 2018; Campos, Silva, et al., 2018; Campos et al., 2019; Damásio \& Campos, 2016; Franco et al., 2018).

De uma forma geral, podemos concluir que os praticantes mais regulares de atividade física em contexto de ginásio apresentam perceções distintas, cabendo à gestão de topo -Diretor Técnico - e aos instrutores de fitness - Técnicos de Exercício Físico - encontrar as soluções que permitam conceber um serviço que seja atrativo e garanta a manutenção do praticante. A esta ação, sustentada no layout do ginásio, acrescem as necessidades de inovação das diferentes componentes do serviço, visando responder às tendências, e às necessidades ou interesses deste segmento de praticantes, garantindo uma maior taxa de retenção. Para tal, requerem-se diferentes atitudes organizacionais e habilidades técnicas e didático-pedagógicas do instrutor, em permanente mutação (adaptação e adequação).

\section{Referências}

Campos, F., Costa, A., Berças, C., Fragoso, C., Gonçalves, C., Simões, M., ..., \& Damásio, A. (2018). A qualidade do serviço de fitness e atividades de ginásio. Journal of Sport Pedagogy and Research, 4(2), 6.

Campos, F., Craveiro, D., Alves, D., Bernardo, F., Cardoso, F., Martins, F., ..., \& Gomes, R. (2019). A perceção dos praticantes de hidroginástica em relação à qualidade do instrutor. Revista Iberoamericana de Psicología del Ejercicio y el Deporte, 14(1), 28-33.

Campos, F., Damásio, A., Martins, F., Simões, V., \& Franco, S. (2018). Importância atribuída no fitness: Perceção dos praticantes de acordo com o género. $2 .^{\circ}$ Fórum Desporto REDESPP - Escola Superior de Educação e Ciências Sociais do Instituto Politécnico de Leiria, Leiria.

Campos, F., Silva, D., Gonçalves, D., Bronze, J., Vicente, L., Santos, R., ..., \& Simões, V. (2018). Os motivos para a prática desportiva e importância atribuída no âmbito do fitness. Journal of Sport Pedagogy and Research, 4(2), 6.

Comissão Europeia (2014). Special Eurobarometer 412. Sport and physical activity. Bruxelas: Comissão Europeia.

Comissão Europeia (2018). Special Eurobarometer 472. Sport and physical activity. Bruxelas: Comissão Europeia.

Damásio, A., \& Campos, F. (2016). A importância atribuída aos motivos de prática desportiva e características de um serviço no âmbito do fitness. In T. Figueiredo, M. Espada, M. Boavida, \& D. Araújo (Eds.), XVII Jornadas da SPPD (p. 69). Setúbal: SPPD e ESE-IPS. 
Franco, S., Valagão, A., Silva, B., Sousa, J., Silva, J., Campos, F., ..., \& Simões, V. (2018). Importância atribuída aos indicadores de qualidade dos instrutores de fitness. Journal of Sport Pedagogy and Research, 4(2), 5.

Gonçalves, C., Buchmann, C., \& Carvalho, M. (2013). Perceção da qualidade do serviço e satisfação dos sócios de fitness: Contribuição para o papel do gestor. Revista Intercontinental de Gestão Desportiva, 3(S2), 47-58.

Hopkins, W. (2002). A scale of magnitudes for effect statistics: A new view of statistics. Retrieved from, www.sportsci.org/resource/stats/effectmag.html.

Laureano, R. (2013). Testes de hipóteses com o SPSS: O meu manual de consulta rápida (2 ${ }^{a}$ ed.). Lisboa: Sílabo.

Papadimitriou, D., \& Karteroliotis, K. (2000). The service quality expectations in private sport and fitness centers: A reexamination of the factor structure. Sport Marketing Quarterly, 9(3), 157-164.

Parasuraman, A., Zeithaml, V., \& Berry, L. (1988). SERVQUAL: Multiple-item scale for measuring consumer perceptions service quality. Journal of Retailing, 64(1), 12- 40.

Sá, C., \& Sá, D. (1999). Marketing para o desporto: Um jogo empresarial. Porto: IPAM.

Weinberg, R., \& Gould, D. (2001). Fundamentos da psicologia do esporte e do exercício ( $2^{a}$ ed.). Porto Alegre: Artmed. 


\title{
Análise sociológica sobre o karaté em
}

\section{Portugal}

\author{
Vítor Rosa ${ }^{1}$ \\ ${ }^{1}$ CeiED/ULHT;
}

\author{
Palavras-chave: \\ Sociologia; \\ Artes Marciais; \\ Desportos de \\ Combate.
}

\section{Keywords: \\ Sociology; \\ Martial arts; \\ Combat sport}

\section{RESUMO}

No âmbito das culturas dos karatecas graduados, pretendemos analisar, sociologicamente, em que medida a mítica tradição guerreira dos Samurais do Japão se encontra presente no processo de globalização do karaté, traduzida na conceção de treino, veiculado por uma filosofia oriental constitutiva de um estilo de vida identitário, que se afirmam como forma de resistência ao modelo de competição desportiva ocidental. Definimos três hipóteses e construímos um modelo de análise. Recorreu-se à metodologia extensiva e à aplicação de diversas técnicas de investigação social: observação direta e participante, entrevista semidiretiva e inquérito por questionário. O universo foi de 244 praticantes de karaté avançados (cintos castanho e negro), a nível nacional, tendo sido realizadas 31 entrevistas. Os resultados revelam que se encontra um estilo de vida identitário entre os praticantes experientes de karaté. A análise da informação aponta para a existência de um carácter multidimensional na orientação e valorização de diferentes aspetos do karaté. Os dados apontam ainda que as relações entre os praticantes experientes de karaté da vertente de não-competição e de competição desportiva têm vindo a caracterizar-se por tensões, dinâmicas de resistência e conflitos, geradores de cisões entre agentes de ensino, espaços de prática ou clubes e estrutura federativa.

\section{ABSTRACT}

In analysis of the cultures of graduated karatekas, we intend to analyze that the mythical warrior traditions of Japan Samurai is present in a dominant way in karate globalization process, constitutive by an eastern philosophy, an identity lifestyle, and private organizational involvements as a form of resistance to Western sports competition model. We set three hypotheses and construct an analysis model. We have used extensive methodology and the application of various techniques of social research: direct observation, participant observation, semi-directive interviews and survey. The universe was 244 practitioners of advanced karate (brown and black belts), at national level. 31 interviews have been made. The results show that there are an identity lifestyle among experienced practitioners of karate, although due to particular uses and social provisions. The analysis of the information mobilized points out the existence of a character multidimensional of orientation. The data also point out that the relationships between the experience apprentices of karate of the non-competition and sport competition have been becoming characterized for tensions, resistance and conflicts dynamics, generators of scissions among teaching agents, practice spaces or clubs and federal structure. 


\section{Introdução}

As artes marciais constituem um símbolo forte no Ocidente. As representações coletivas reenviam as artes marciais para as atividades tradicionais de combate saídas do Extremo-Oriente. Várias disciplinas japonesas (judo, jiu-jitsu, karaté, aikido, kendo, aido), coreanas (taekwondo), chinesas (taichi-chuan) ou vietnamitas (viet-vo-dao) desenvolveram-se em diversos estilos, formas, de práticas. Categorias de escolas e praticantes concorrentes coexistem no seu seio. Estruturadas inicialmente em torno de escolas e de mestres, perpetuadas principalmente em segredo, as artes marciais foram absorvidas por diversas instituições públicas, nomeadamente as federações desportivas e os estabelecimentos de ensino, designadamente as universidades.

O karaté, objeto de análise neste estudo, adquiriu progressivamente um lugar importante na cultura Ocidental. Ele marca simbolicamente os locais (dojos) no espaço social e nos momentos da vida coletiva. Ele suscita atividades, gestos, maneiras de estar, cuja significação se constrói na vida social. Desde a sua introdução na Europa, ele conheceu uma dinâmica que nos leva a interrogar a sua desportivização, a sua cultura, os aspetos religiosos e a relação com o corpo. A palavra "karaté" é composta por dois ideogramas: "kara", que, na sua versão original, significava "chinês(a)" e "te" que significa "mão". Kara também se refere à "ausência de qualquer intenção agressiva", evocando a experiência Zen do "vazio". As origens desta forma de luta são incertas, embora a bibliografia especializada refira que as suas raízes surgiram na Índia, seguiu para a China e chegou ao arquipélago de Okinawa, província mais a sul do Japão. Prática secreta de autodefesa no passado, acabaria por ser introduzida no Japão, no início do século XX, pela mão de Gichin Funakoshi (1868-1957), e aí institucionalizou-se como disciplina marcial moderna na charneira entre preparação física militar e desporto. As primeiras demonstrações de Funakoshi em Okinawa (em 1906) e em Tóquio (em 1922) entusiasmaram deveras os japoneses com esta arte espetacular. Na sequência da Segunda Guerra Mundial, a prática do karaté mundializou-se, tornando-se numa arte marcial relativamente massificada. Em Portugal, as artes marciais surgiram no início do século $\mathrm{XX}$, tendo-se assistido ao seu sucessivo crescimento (Rosa, 2008). O karaté, em particular, começou a ser praticado de forma mais sistemática a partir de 1963.

Neste artigo centramo-nos no estudo do karaté (e os seus diferentes estilos ${ }^{1}$ : shotokan, shotokai, goju-

\footnotetext{
1 Tomamos os termos "estilos" e "escolas" no sentido dado pelos praticantes de artes marciais. São a interpretação da técnica marcial de acordo com as características pessoais do praticante. Alguns praticantes
}

ryu, wado-ryu, shito-ryu), enquanto "objeto complexo", pois ele divide-se em múltiplas vertentes: como arte marcial a sua prática desdobrase em prática desportiva com finalidades competitivas e de desenvolvimento corporal e em disciplina marcial, exemplo de um conjunto de disciplinas derivadas de antigas práticas marciais que mantêm referências a tradições guerreiras, entre as quais a mítica tradição dos Samurais do Japão (Braustein, 1999; Figueiredo, 2006; Garcìa, Rosa, \& Gutièrrez, 2010; Rosa, 2007, 2008, 2016, 2017). Face a esta realidade, interrogámo-nos, como pergunta de partida da presente investigação, se a globalização do karaté teria preservado as suas características de arte marcial oriental? Pretendemos, então, demonstrar em que medida a mítica tradição guerreira dos Samurais do Japão se encontraria presente de forma dominante no processo de globalização do karaté, traduzida na conceção de treino enquanto expressão do Budô (via da guerra), veiculado por uma filosofia oriental constitutiva de um estilo de vida identitário, e envolvimentos organizacionais particulares, que se afirmariam como forma de resistência ao modelo de competição desportiva ocidental, apesar da existência de diferentes usos e disposições sociais por parte dos praticantes dos diferentes estilos de karaté, ainda que independentemente do sexo, da idade e da escolaridade. Considerámos três hipóteses de investigação: 1) que se encontraria um estilo de vida identitário entre os praticantes experientes do karaté, ainda que, decorrente de usos e disposições sociais particulares, se encontrasse alguma diferenciação segundo o estilo adotado na prática, independentemente do sexo, idade e escolaridade; 2) que a maioria dos praticantes experientes de karaté conceberia a sua prática como expressão do Budô, reproduzida de forma dominante pelos agentes de ensino da modalidade através de práticas de luta convencional, imagens, símbolos e veiculação de valores, independentemente do estilo de karaté, sexo, idade e escolaridade; 3 ) e que as relações entre os praticantes experientes de karaté da vertente de não-competição e de competição desportiva, têm vindo a caracterizar-se por tensões, dinâmicas de resistência e conflitos, geradores de cisões entre agentes de ensino, espaços de prática ou clubes e estrutura federativa, independentemente do estilo de karaté, sexo, idade e escolaridade.

Para a operacionalização das hipóteses, construiu-se um "Modelo de Análise", com base em quatro dimensões: na primeira dimensão, que designámos de "Representações sociais do karaté" (D.1), procura-se analisar as variáveis "Identidades e os usos sociais no karaté" (1.1), "Expressão Budô" (1.2) e "Disposições sociais para com a modalidade"

para obter um resultado imediato em termos de defesa pessoal praticam vários estilos de karaté em simultâneo. 
(1.3). Na segunda dimensão, o "Estilos de vida" (D.2), as variáveis "Valores" (2.1), "Envolvimentos no karaté" (2.2) e "Religião/Espetro políticoideológico" (2.3). Na terceira, que intitulámos "Cooperação/Demarcação" (D.3), recorrendo a variáveis como as "Relações institucionais" (3.1), as "Sociabilidades" (3.2), "Competição e o Budô" (3.3), Afirmação/resistência (3.4) e "Conflitos" (3.5). Por último, na quarta dimensão "Perfil dos karatecas" (D.4), aprofundamos o perfil sociológico dos praticantes através do "Sexo" (I.4.1.1) e Orientação sexual (I4.1.2) da V4.1 "Género", "Idade" (V4.2), "Escolaridade" (I4.3.1) "Condição perante o trabalho" (I4.3.2) "Profissão" (I4.3.3) e "Rendimento mensal" (I4.3.4) da V4.3 "Grupo social", "Residência" (V4.4), "Nacionalidade" (V4.5), "Estado civil" (V4.6) e "Experiência militar" (V4.7). Para cada uma das variáveis, foram definidas um conjunto de indicadores (exemplos: sacrifícios pessoais e profissionais associados à prática do karaté, violência no karaté, razões para o início da prática, conceções da prática, estilos de liderança, influência na alimentação, saúde e bem-estar, transmissão de valores, participação associativa, influência linguística, religião, espetro políticoideológico, entre outros) (Rosa, 2017).

Decorrentemente, recorreu-se a diversas técnicas de recolha de informação qualitativas e quantitativas, como a observação direta e observação-participante, entrevistas semi-diretivas e o inquérito por questionário, recorrendo a uma amostra não probabilística (bola de neve).

\section{Metodologia}

Nesta investigação recorremos a uma metodologia quantitativa e qualitativa. Ela foi conduzida em quatro grandes etapas: i) "estado da arte", obtido a partir da revisão bibliográfica; ii) na realização de um estudo exploratório para a descrição de informação relacionada com o karaté e a elaboração e teste do questionário, iii) problematização e consequente definição do objeto e hipóteses de investigação, e decorrentemente da elaboração, avaliação e aplicação de um questionário a uma amostra aleatória (pré-teste) de um número representativo de praticantes de karaté graduados (cintos castanhos e negros). A primeira versão do questionário foi ajustada após os resultados do préteste em três centros de prática (Lisboa, Almada e Évora); iv) consistiu no tratamento, análise e interpretação da informação recolhida através dos questionários e entrevistas, tendo em vista averiguar a veracidade das hipóteses. $\mathrm{Na}$ análise qualitativa, recorremos também à análise documental, à observação direta, à observação participante e às entrevistas, procurando aprofundar a temática em estudo. No caso da observação direta foi elaborada uma grelha com algumas situações a observar: o local de prática, a decoração do espaço, as interações entre praticantes de nível avançado e os menos avançados, as normas implícitas e explícitas, os treinos, a forma pedagógica de ensinar e os estágios de inverno e de verão. Esta informação foi importante para confrontar com a teoria e auxiliar na discussão das hipóteses em estudo. Conseguimos 31 entrevistas de informantes privilegiados (Rosa, 2017). A escolha recaiu sobre responsáveis pela FNK-P, representantes e dirigentes de associações e clubes de karaté e de outras artes marciais, treinadores/instrutores, assistentes/monitores, formadores, árbitros, praticantes, famílias, médicos, fisioterapeutas, farmacêuticos, juristas, professores do ensino secundário e superior, investigadores, etc. Perguntámos sobre o significado do karaté para os praticantes, as lesões, a influência na sua vida pessoal e profissional, as ligações do karaté português com o Japão, entre outras questões. As respostas obtidas serviram para reforçar as nossas hipóteses de trabalho e também para fundamentar a escolha da problemática em estudo.

\section{Participantes}

A população-alvo do estudo foi constituída pelos praticantes de karaté graduados (cintos castanhos e negros), em Portugal. Considerámos que os karatecas com nível avançado de prática (cintos castanhos e negros) são os pilares das comunidades e das estruturas organizativas (clubes, associações), justamente por demonstrarem uma continuidade ao longo dos anos. Neste sentido, não é a aprendizagem (ou a socialização) para esta cultura-comunidade que está aqui em causa. Consideramos que, geralmente, é só a partir do grau de cinto castanho que a própria comunidade de karatecas reconhece a pertença "em pleno estatuto" do praticante. É, em princípio, a partir desse grau que se pode ensinar karaté. A partir deste reconhecimento de competência e grau, a própria comunidade estabelecida de praticantes recruta e induz um membro devidamente credenciado. Visto não ter sido possível dispor de uma listagem com todos os praticantes graduados com cintos castanho e pretos no ativo, tivemos de recorrer à técnica de amostragem não-aleatória, por "bola de neve". Assim, partimos de uma pequena amostra de três centros de prática (Clube de Karaté Shotokai de Évora, em Évora, Associação Shotokai de Murakami-Kai, em Almada, e Associação Portuguesa de Karaté-Do, em Lisboa) e, em seguida, fomos adicionando outros elementos que tinham alguma relação com os que já estavam incluídos na amostra. Este tipo de amostragem não é probabilística ou representativa, mas constituída quando os participantes são difíceis de encontrar ou se a amostra se limita a um subgrupo da população. Nas épocas desportivas de 2010 e 2011, conseguimos o preenchimento de 244 questionários a nível nacional, de praticantes avançados, de ambos os sexos (221 homens e 33 mulheres), dos 13 aos 71 
anos, de 15 Distritos e 1 Região Autónoma (Açores), integrados em 58 clubes e 35 associações.
Relativamente aos estilos de karaté, a distribuição encontra-se no Quadro 1, na página seguinte.

Quadro 1. Estilos de karaté

\begin{tabular}{lcc}
\hline Estilo & N & \% \\
\hline Shotokai & 106 & 43.4 \\
Shotokan & 57 & 23.4 \\
Goju-Ryu & 44 & 18.0 \\
Wado-Ryu & 23 & 9.4 \\
Shito-Ryu & 14 & 5.7 \\
\hline Total & $\mathbf{2 4 4}$ & $\mathbf{1 0 0 , 0}$ \\
\hline
\end{tabular}

Fonte: Questionário “Estudo sobre o Karaté em Portugal”, 2010-2011

\section{Instrumentos}

Tendo em vista a natureza do objeto de estudo, considerou-se como mais adequado delinear uma estratégia de recolha de informação combinando métodos e técnicas das ciências sociais, de modo a obter dados que garantissem a discussão das hipóteses em análise de modo a avaliar a sua veracidade. Recorremos, assim, à observação direta (através da constituição de uma grelha com várias situações a observar: os locais de prática, a decoração, os treinos e a pedagogia associada, as interações entre praticantes, etc.), à observação participante (seguimos as aulas semanais de karaté durante vários anos, chegando a cinto negro), ao inquérito por questionário e a entrevistas semidiretivas. Esta informação, e o cruzamento dela, permitiu-nos aprofundar o objeto de estudo. Inspirados em Wacquant (2000), foi constituído um diário de campo, permitindo anotar informações importantes sobre o quotidiano dos centros de prática e dos contatos estabelecidos ao longo da investigação.

\section{Procedimentos}

Em termos de procedimentos, este trabalho teve o seu início com a análise e definição dos objetivos e das linhas orientadoras da estratégia de investigação. Foram revistos, posteriormente, seguindo as recomendações de alguns especialistas na matéria, dando uma maior consistência à investigação, em particular a identificação do problema em estudo, a definição do objeto de investigação e, decorrentemente, a construção metodológica de modo a operacionalizar as hipóteses, justificando e integrando a informação recolhida através das técnicas utilizadas. Nas reuniões e trocas de experiências foram revistas e analisadas as fases e as atividades a desenvolver na condução do estudo. A recolha de informação incidiu em várias épocas desportivas (2010 e 2011). Foi, igualmente, constituído um diário de campo com base nas nossas observações e contatos efetuados. De referir também que nesta investigação, que foi mais abrangente, procurámos informações sobre a história administrativa, biográfica e familiar de muitos praticantes, assim como sobre institucional, nomeadamente da Comissão Diretiva das Artes Marciais (CDAM) (1972-1987), que teve a seu cargo a superintendência e controle do ensino, aprendizagem das práticas das artes marciais e desportos de combate, cujos resultados foram apresentados em outros momentos (Rosa, 2007, 2017).

\begin{abstract}
Análise estatística
Em termos de análise, a base de dados construída a partir dos dados recolhidos pelos questionários junto dos praticantes foi trabalhada com o recurso ao programa estatístico informático SPSS (Statistical Package for Social Sciences), para Windows. Os dados foram submetidos a um conjunto de análises estatísticas descritivas e à utilização dos testes paramétricos e não paramétricos. Os resultados preliminares foram apresentados e discutidos com outros investigadores em vários eventos científicos. A base de dados construída a partir da informação disponível foi tratada com o recurso à análise estatística multivariada (ANOVA, regressão multivariada). A estratégia da análise multivariada dos dados foi delineada, tendo em vista estimar as relações existentes entre as variáveis ou indicadores em estudo.
\end{abstract}

\section{Resultados}

\section{Perfil dos praticantes}

No que respeita à repartição dos inquiridos por sexos, verifica-se que os homens são mais numerosos $(86.5 \%, \mathrm{n}=211)$ do que as mulheres $(13.5 \%, n=33)$. Ao recorrermos ao teste da binomial aplicada a variáveis dicotómicas, os resultados revelam que o número observado de homens (0.86) é significativamente superior ao número observado de mulheres (0.14), para um erro do tipo I de 0.05 ou 0.10 . Através da aplicação do teste paramétrico $t$ student $(t=3.089 ;$ d.f. $=244 ; \quad p<0.002)$ para duas médias, verifica-se que a média de idades dos 
homens situa-se nos 34.35 anos e nas mulheres nos 26.97 anos. A análise da distribuição por idades permite constatar que $59 \%(n=146)$ dos inquiridos tem idades compreendidas entre os 13 e os 35 anos; $39.3 \%(n=96)$ entre os 36 e os 65 anos e $0.8 \%(n=2)$ têm 66 e mais anos. Verifica-se que $38.2 \%(n=93)$ completaram uma formação de nível médio (bacharelato) ou superior (licenciatura, mestrado ou doutoramento $), 34.4 \%(\mathrm{n}=84)$ o ensino secundário ou profissional e $27.4 \%(\mathrm{n}=66)$ o ensino de $1 .^{\circ}, 2 .^{\circ} \mathrm{e}$ $3 .^{\circ}$ ciclos. O nível de ensino modal, que concluíram, é o ensino secundário. Relativamente à formação superior, é interessante notar que a área/disciplina que surge em primeiro lugar é a "Engenharia", com 26.1\% $(n=23)$, seguida das "Ciências do Desporto", com $15.9 \%(n=14)$. Na regularidade dos treinos de karaté dos inquiridos da nossa amostra, identificámos que: $47.5 \%(n=116)$ treinam três ou mais vezes por semana; $30.3 \%(n=74)$ treinam duas vezes por semana; $12.7 \%(n=31)$ afirmou treinar diariamente; $5.3 \%(n=13)$ referiu apenas uma vez por semana. Em suma, da análise das características dos karatecas em análise, podemos traçar, grosso modo, um perfil da população em estudo, que aponta para $\mathrm{o}$ fato de serem maioritariamente jovens masculinos, solteiros, com elevadas habilitações literárias, residentes nos centros urbanos, com uma regularidade de treino semanal, de vários estilos de karaté, detentores de elevadas graduações técnicas (cintos castanho e negro), e possuidores do curso de treinador-monitor de karaté (cf. Quadro 2, na página seguinte)

Quadro 2. Detenção de um curso de treinador de karaté

\begin{tabular}{|c|c|c|c|c|c|c|c|}
\hline Curso de Treinador & CDAM & FPK & FPKDA & FNK-P & $\begin{array}{c}\text { Outra } \\
\text { entidade }\end{array}$ & Total & $\%$ \\
\hline 1. ${ }^{o}$ Grau ou Treinador Monitor & 8 & 9 & 3 & 86 & & 106 & 63.1 \\
\hline 2. ${ }^{\circ}$ Grau ou Treinador de Nível I & 3 & 3 & & 37 & & 43 & 25.6 \\
\hline 3. ${ }^{\circ}$ Grau ou Treinador de Nível II & & & 2 & 6 & 2 & 10 & 6.0 \\
\hline Treinador de Nível IV & 2 & & & 2 & & 4 & 2.4 \\
\hline Treinador de Nível V & & & & & & 0 & 0.0 \\
\hline $\begin{array}{l}\text { Oficial de Mesa - Juiz Regional de } \\
\text { Comité }\end{array}$ & & & & 1 & & 1 & 0.6 \\
\hline Arbitragem de Competição & & & & & & 0 & 0.0 \\
\hline Outro Curso & & 1 & 1 & 1 & 1 & 4 & 2.4 \\
\hline Total & 13 & 13 & 6 & 133 & 3 & 168 & 100 \\
\hline
\end{tabular}

Fonte: Questionário "Estudo sobre o Karaté em Portugal”, 2010-2011

\section{Primeira hipótese}

Relativamente à nossa primeira hipótese de trabalho, recordamos que partimos do pressuposto que se encontraria um estilo de vida identitário entre os praticantes experientes do karaté, ainda que, decorrente de usos e disposições sociais particulares, se encontrasse alguma diferenciação segundo o estilo adotado na prática, independentemente do sexo, idade e escolaridade. Tendo por base as variáveis e indicadores mobilizados para medir as práticas, atitudes e valores identificadores de um estilo de vida identitário, os dados apontam para a confirmação da hipótese. Os dados permitiram constatar que a maioria dos karatecas sócios de um clube ou associação nunca participou nas assembleias-geral ( $45.3 \%$ e $48.1 \%$, respetivamente), estando, assim, afastados das decisões das direções. Quando se fala em investimento (envolvimento), é no karaté que os inquiridos mais apostam (65.2\%), no entanto, afirmam praticar outras modalidades desportivas incluindo outras artes marciais ou desportos de combate, ainda que em reduzido número (18.4\%). Em termos de sacrifícios pessoais, familiares e profissionais devido à dedicação à prática do karaté, a maioria dos praticantes afirma que não interfere com os seus compromissos familiares $(67.6 \%)$, nem com os profissionais $(67.8 \%)$, conseguindo, assim, conciliar a sua vida. $\mathrm{O}$ karaté, enquanto arte marcial nipónica, traz as marcas das suas origens e tem por objetivo a aprendizagem de técnicas de autodefesa. Todavia, a maioria dos praticantes nunca estiveram envolvidos num ou mais atos de violência fora do centro de prática, facto só referido por uma minoria (14.8\%). Quando isso acontece, são sobretudo os homens, $13.9 \%$ face a $0.8 \%$. Os dados apontam assim para o facto, de que a cultura do karaté reserva-o ao dojo, onde se jogam valores de ascese e não de violência capazes de serem transportados para a sociedade civil. Nos centros de prática cruzam-se homens e mulheres, jovens e adultos, e de forma menos presente pessoas de diferentes etnias, ainda assim, os valores dominantes não apresentam preconceitos sociais de género ou étnicos. $\mathrm{Na}$ realidade esta heterogeneidade da prática do karaté dota-o de uma singularidade propensa à criação de uma identidade própria ou específica. A este respeito verificámos 
que $44.3 \%$ dos inquiridos afirmam ter familiares ou pessoas próximas a praticar karaté. Sobre a alimentação, saúde e bem-estar, os inquiridos da nossa amostra afirmam, na sua esmagadora maioria, de que a prática do karaté não influencia ao nível das práticas alimentares (13.5\%). Também o seu envolvimento no karaté, não os leva a aprender a língua japonesa de forma formal, apenas $27.9 \%$ afirmam que sim. Na realidade, os dados denotam que as influências da cultura oriental não se encontram muito presentes nos seus quotidianos. Também, em termos crenças religiosas, os inquiridos são maioritariamente cristãos (67.6\% católicos e $1.6 \%$ de outras Igrejas), e sem religião $28.3 \%$. As crenças de índole oriental apresentam uma diminuta adesão (Budismo, 1.2\%). Ainda assim, apenas uma minoria afirma ter uma prática religiosa regular $(9.8 \%)$, proporcionalmente superior nas mulheres face aos homens (respetivamente, $20.6 \%$ e $8.2 \%$ ). No que concerne ao espectropolítico, verifica-se que os karatecas maioritariamente têm uma afiliação política situada no centro-esquerda (ambas com 33.2\%). Os que se posicionam nas extremidades (extrema-esquerda ou extrema-direita) são por isso minoritários. Ainda assim, os homens proporcionalmente afirmam mais ser de esquerda $(41.9 \%)$, e as mulheres do centro (55.6\%). A análise percentual do espectro-político segundo os estilos de karaté permitiu-se igualmente encontrar variações. Grosso modo, os de Shotokai posicionam-se proporcionalmente mais ao "Centro" (46.2\%), enquanto os do estilo Wado-Ryu à "Direita", e os do estilo Goju-Ryu e Shito-Ryu claramente à "Esquerda" $(46.2 \%$ e $71.4 \%$, respetivamente). Para concluirmos, podemos comprovar, em parte, a nossa primeira hipótese de investigação, isto é, de que se encontra um estilo de vida identitário entre os praticantes experientes de karaté, ainda que decorrente de usos e disposições sociais particulares se encontre alguma diferenciação, mas independentemente do estilo adotado na prática, em contradição com o pressuposto inicial.

\section{Segunda hipótese}

$\mathrm{Na}$ nossa segunda hipótese, que pressupõe que a maioria dos praticantes experientes de karaté concebe a sua prática como expressão do Budô, reproduzida de forma dominante pelos agentes de ensino da modalidade através de práticas de luta convencional, imagens, símbolos e veiculação de valores, independentemente do estilo de karaté, sexo, idade e escolaridade, constata-se que a maioria dos inquiridos da nossa amostra, pratica karaté de não competição $(74,2 \%)$, face a $23 \%$ que diz praticar competição institucionalizada, isto é, enquadrada pelos clubes, associações e federação (cf. Figura 1; Quadro 3, na página seguinte).

Figura 1: Âmbito da prática do karaté (\%)

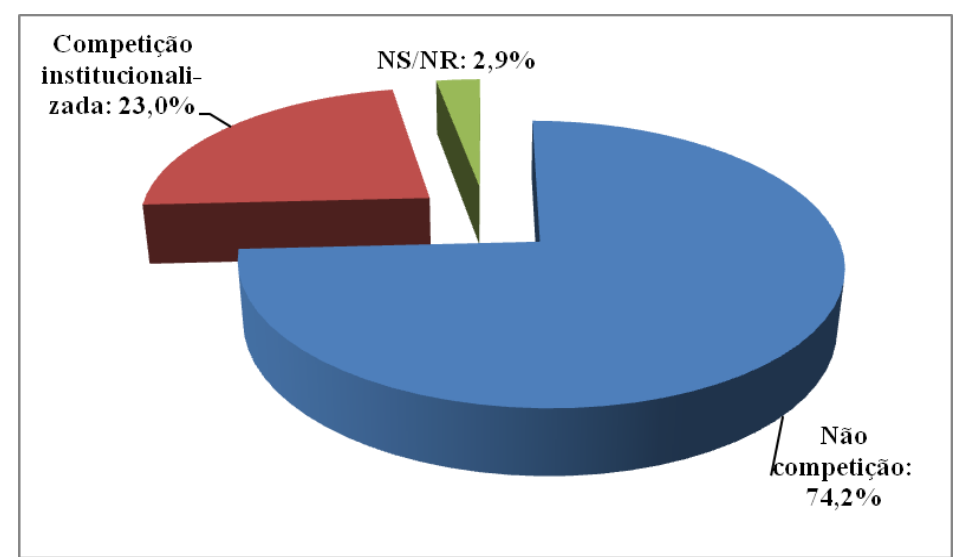

Fonte: Questionário “Estudo sobre o Karaté em Portugal”, 2010-2011

Quadro 3. Âmbito de prática segundo o estilo de karaté (\%)

\begin{tabular}{|c|c|c|c|c|c|c|}
\hline Modo de prática & $\begin{array}{l}\text { Shotokai } \\
(n=105)\end{array}$ & $\begin{array}{l}\text { Shotokan } \\
(n=54)\end{array}$ & $\begin{array}{c}\text { Goju-ryu } \\
(n=43)\end{array}$ & $\begin{array}{c}\text { Wado- } \\
\text { ryu } \\
(\mathrm{n}=\mathbf{2 1})\end{array}$ & $\begin{array}{c}\text { Shito-ryu } \\
(n=14)\end{array}$ & $\begin{array}{c}\text { Total } \\
(n=244)\end{array}$ \\
\hline Não competição & 90.5 & 63.0 & 72.1 & 52.4 & 71.4 & 74.2 \\
\hline $\begin{array}{l}\text { Competição } \\
\text { institucionalizada }\end{array}$ & 9.5 & 37.0 & 27.9 & 47.6 & 28.6 & 23.0 \\
\hline $\mathrm{NS} / \mathrm{NR}(\mathrm{n}=7)$ & & & & & & 2,9 \\
\hline Total & 100 & 100 & 100 & 100 & 100 & 100 \\
\hline
\end{tabular}

Fonte: Questionário “Estudo sobre o Karaté em Portugal”, 2010-2011 
Resultados que atestam a nossa hipótese, pois a maioria encontra-se fora do sistema de competição. Proporcionalmente, os homens praticam mais o karaté de não competição face às mulheres (respetivamente, $78 \%$ e $65.6 \%$ ), enquanto as mulheres a competição institucionalizada face aos homens (respetivamente, $34.4 \%$ e $22 \%$ ). Os praticantes que fizeram competição institucionalizada, mas que interromperam, evocam razões como a saúde, a escola, os pessoais, os familiares, a idade e os desportivos. Sobre a orientação ou conceção do karaté que os praticantes privilegiam (vertente pessoal), e a orientação da prática do karaté que é privilegiado no centro de prática ou dojo (vertente externa, direcionada pelo instrutor), os dados revelam-se praticamente semelhantes, havendo uma preferência pelo Budô $(34.8 \%)$ e a prática lúdica desportiva $(30.7 \%)$ (cf. Figura 2, na página seguinte).

Figura 2: Conceção ou orientação do karaté que privilegiam (\%)

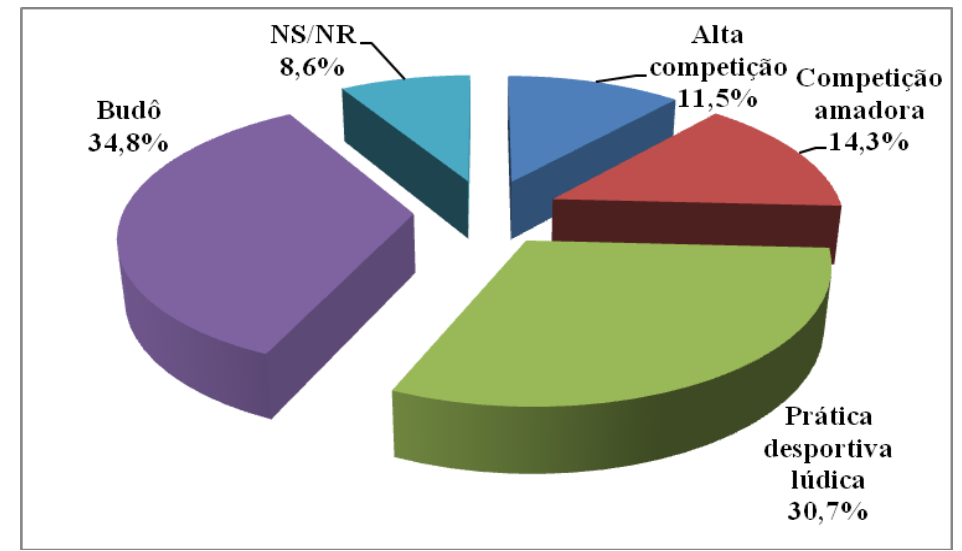

Fonte: Questionário “Estudo sobre o Karaté em Portugal”, 2010-2011

A prática do Budô é reforçada com a importância que os praticantes atribuem aos códigos das normas de conduta do dojo associado aos princípios éticos do Budô, e à manutenção dos ritos e símbolos oriundos do Japão, em particular de Okinawa. Por outro lado, é possível concluir que existem relações institucionais e afetivas com o Japão (e Okinawa). O karaté continua a ter uma ligação com a "terra berço" do karaté. Os praticantes (atletas, competidores e agentes de ensino) ainda se encontram "dependentes" dos ensinamentos dos mestres japoneses. Todavia, a maioria dos praticantes de karaté nunca foi ao Japão (93\%) para participar em estágios, treinos ou passagens de graduação, face uma minoria que disse que sim (7\%). A forma de obviar esta situação é solicitar a vinda de mestres japoneses a Portugal para promover estágios ou treinos específicos. Em torno do karaté, existem um conjunto de imagens e símbolos que têm uma relação direta com a prática. Para alguns agentes de ensino, i.e., mestre ou treinadores, "é o respeito pelo seu legado à iconografia ou idolatria japonesa ou oriental", que afirmam transmitir. Existe também uma preocupação em transmitir valores associados à prática, tais como o respeito para com o outro, éticos, pedagógicos, perseverança, espírito de amizade e cooperação, bem-estar e de Sensei, de mentor, orientador (na tradição oriental encontra relação com o guia espiritual que visa a ascese dos seus discípulos), testemunhos recolhidos junto dos nossos interlocutores privilegiados, como vimos, que atestam a hipótese em discussão. Relativamente ao estilo de autoridade ou liderança dos agentes de ensino nos seus centros de prática, os karatecas da nossa amostra consideram que ela é "algo democrático" (37.7\%). Como reforça Gaudin (2009), é organização estruturada das aprendizagens, fundada sobre uma progressão pedagógica, enquadrada por agentes de ensino investidos de uma autoridade "estatutária" (mais democrática ou mais autoritária) e formalizada. Por outro lado, ao começarem a ser um profissional remunerado pelos seus serviços, os alunos/atletas passam a ser "clientes", logo pouco compatível com uma liderança "bastante autoritária". Assim, nesta lógica, os agentes de ensino que se "apregoam de Samurais" (Diário de campo, 14 de junho de 2012) são "tudo menos Samurais" (Gaudin, 2009, p. 7). Julhe (2009) também acrescenta que a evolução do contexto conduz a uma diversificação de entradas na atividade, de conceber o ensino e as instituições desportivas. Os agentes de ensino são levados a produzirem estratégias que se querem ajustadas com a "evolução estrutural do campo", bem retratado por Bourdieu (1979). Em suma, com base nos resultados analisados, podemos comprovar a nossa hipótese de estudo, ou seja, de que a maioria dos praticantes experientes de karaté deste estudo concebe a sua prática como expressão do Budô, reproduzida de forma dominante pelos agentes de ensino da modalidade através de práticas de luta convencional, imagens, símbolos e veiculação de valores, independentemente do estilo de karaté, e do sexo, 
idade e escolaridade tal como pressupunha a hipótese em discussão, na medida em que nos testes de comparação com estas variáveis não se encontram diferenças com significância estatística.

\section{Terceira hipótese}

Na terceira hipótese de investigação, partimos, do pressuposto de que as relações entre os praticantes experientes de karaté da vertente de não-competição e de competição desportiva, têm-se vindo a caracterizar por tensões, dinâmicas de resistência e conflitos, geradores de cisões entre agentes de ensino, espaços de prática ou clubes e estrutura federativa, independentemente do estilo de karaté, sexo, idade e escolaridade. Os resultados apurados sobre a cooperação e demarcação no karaté permitem constatar que os interesses são essencialmente convergentes e de cooperação (39.3\%). Ainda assim, verifica-se uma percentagem elevada quando dizem que são interesses divergentes, mas sem conflitos abertos (23.4\%). Apenas uma minoria diz que as relações são conflituosas $(8.8 \%)$. Segundo os inquiridos, as relações entre praticantes são "bastante cooperativas e solidárias" (62.7\%) nos centros de prática, e isso verifica-se quer para os homens $(61.7 \%)$, quer para as mulheres $(72.7 \%)$. Existe alguma tensão entre os clubes, associações e a federação não impedindo uma cooperação institucional. As tensões, dinâmicas de resistência e conflitos passam pela perceção da modalidade (competição versus Budô), pelas dinâmicas internas associativas, vocações técnicas e controlo por parte dos agentes de ensino mestres ou treinadores, ao papel que a federação tem vindo a desempenhar, ainda que esta disponha de meios e poderes limitados. Os dados analisados, apesar de fornecerem evidências dos pressupostos da hipótese em discussão, incluindo a independência do estilo de karaté, o sexo, a idade e a escolaridade, levaram-nos a concluir que a leitura que se expressa da realidade se afigura redutora, e deste modo só em parte podemos afirmar que a hipótese se verifica. Como refere Bourdieu (1979), os interesses, os gostos, as preferências dependem da posição que cada um ocupa na hierarquia do espaço social. $\mathrm{Na}$ vida quotidiana são os indivíduos que se confrontam. Assim sendo, compreende-se a ideia de Bourdieu quando descreve o espaço social (1979) como um "campo de forças" e um "campo de lutas", na medida em que o espaço social é um espaço de poder que é distribuído de maneira assimétrica. Cada um tem um certo peso no "jogo", peso (capital que pode ser simbólico ou social) que utiliza para melhorar a sua posição. Ora, no caso da confrontação dos praticantes de karaté entre os aspetos do Budô e a competição é isso que se verifica. Somos então levados a concluir, que esta realidade reforça a nossa tese, pois fornece evidências à existência de uma identidade de campo do karaté, onde a cooperação não pode ser analisada sem que com ela existam eixos de tensão, de resto conclusão da tese de doutoramento em sociologia sobre a ética do desporto de Marivoet (2007). É, neste contexto, que concluímos que a nossa terceira hipótese apenas se verifica em parte, pois apenas colocou em foco uma parte da realidade.

\section{Discussão}

Se a segunda década do século XX marca a saída da arte de Okinawa para a ilha principal do Japão (Hondo), as décadas de vinte e trinta marcam a institucionalização mais personalizada dos nomes a dar à arte. Entre os nomes específicos que os fundadores vão dando às suas "escolas" e estilos $(r y u)$, destacam-se as quatro principais consagradas pela Federação Mundial de Karaté (FMK): Goju$R y u$, por Chojun Miyagi (1888-1953), Shito-Ryu, por Kenwa Mabuni (1888-1952), Shotokan, por Gichin Funakoshi (1868-1957) e Wado-Ryu, por Hirononi Ohtsuka (1892-1982). Entre os vários estilos/"escolas" "as tensões dominam" e cada estilo tende a fechar-se sobre si próprio, persuadido a deter a verdade, como um microcosmo hierarquizado de graduações. No topo do "microcosmos" está o mestre (instrutor/treinador). Resumindo, cada praticante julga estar na posse da verdadeira ciência e do verdadeiro segredo, caminhando, pois, na via do karaté que considera melhor.

A prática desportiva corresponde a um envolvimento gradual, reversível e, muitas vezes, não obrigatório. Livres de aderir e de deixar, as populações desportivas conhecem, em permanência, uma taxa de entradas (iniciantes) e de saídas (abandonos). Pelo fluxo de adesões, por um sistema de qualificação desportivo, promovidos de um nível baixo a um nível superior, e pela eliminação dos não-qualificados se opera uma triagem e uma verdadeira construção social de populações desportivas, com características bem particulares. Da nossa observação direta e participante notámos que a graduação técnica (a hierarquização) tem um peso considerável nas relações dentro dos grupos de praticantes e serve como indicador de uma pertença, bem como de uma experiência suficientemente longa para permitir o domínio dos códigos de comunicação do(s) grupo(s) (Rosa, 2017). Para além de comportamentos diferenciados, a existência de hierarquias traz consequências a vários níveis, inclusivamente ao nível da comunicação (Clément, 1981; Figueiredo, 2006; Julhe, 2009). De facto, é mais simples comunicar com aqueles que consideramos nossos iguais do que comunicar com os restantes indivíduos, quer sejam de estatutos superiores, quer inferiores. Entre os iguais há todo um conjunto de códigos linguísticos e comportamentais que torna mais simples a comunicação. Por outro lado, verifica-se que o espaço dos estilos de vida, por intermediário do 
habitus, evocado por Bourdieu (1979) e Wacquant (2000), é transponível para o karaté, enquanto princípio unificador e gerador de práticas. Como acrescenta Clément (1981, p. 289), "as práticas desportivas podem ser apreendidas como práticas sociais e culturais, e a este título constitutivas de um estilo de vida".

\section{Conclusão/Reflexões finais}

$\mathrm{Na}$ nossa investigação, quisemos saber se no processo de globalização das artes marciais o karaté terá preservado as suas características de arte marcial oriental. Considerámos que a tradição guerreira dos Samurais do Japão se encontraria presente no processo de globalização do karaté, traduzida na conceção de treino enquanto expressão do Budô (via marcial), veiculado por uma filosofia oriental constitutiva de um estilo de vida identitário, e envolvimentos organizacionais particulares, que se afirmam como forma de resistência ao modelo de competição desportiva ocidental, independentemente do estilo de karaté, do sexo, da idade e da escolaridade. A realidade dos dados obtidos revela que, apesar de alguma diferenciação, existe, um estilo de vida identitário entre os praticantes experientes de karaté ainda que, decorrente de usos e disposições sociais particulares, independentemente do estilo adotado na prática, contrariamente à nossa hipótese que o colocava como explicativo das diferenças encontradas, mas também do sexo, idade e escolaridade tal como considerado inicialmente, na medida em que as diferenças encontradas não apresentam significância estatística. A segunda hipótese definida, considerava que a maioria dos praticantes experientes de karaté conceberia a sua prática como expressão do Budô, reproduzida de forma dominante pelos agentes de ensino da modalidade através de práticas de luta convencional, imagens, símbolos e veiculação de valores, independentemente do estilo de karaté, sexo, idade e escolaridade. A realidade analisada fornece evidências que comprovam a nossa segunda hipótese. Nestas destaca-se o carácter multidimensional na orientação e valorização de diferentes aspetos do karaté. Ele oferece uma grande diversidade de âmbitos de prática (competição, lazer, Budô) e, por isso, diferentes usos sociais. Os dados demonstram que os praticantes na vertente de competição e de não competição concebem a sua prática como Budô, ainda que com uma valorização diferente, como seria de esperar superior nos segundos, dando grande importância à manutenção dos ritos e símbolos a ele associados, independentemente do estilo de karaté, sexo, idade e escolaridade. Ao refutar a ideia de competição (numa perspetiva de Budô), os praticantes de karaté querem-se demarcar do processo de desportivização hegemónico do Ocidente, daí a nossa questão de partida pretender saber, justamente, se os praticantes de karaté seriam portadores de uma arte marcial que os demarcava de ser desportivos, constituindo-os numa comunidade identitária com um estilo de vida próprio. A terceira hipótese de estudo traçada, pretendia averiguar se as relações entre os praticantes experientes de karaté da vertente de nãocompetição e de competição desportiva têm vindo a caracterizar-se por tensões, dinâmicas de resistência e conflitos, geradores de cisões entre agentes de ensino, espaços de prática ou clubes e estrutura federativa, independentemente do estilo de karaté, sexo, idade e escolaridade. Apesar da estabilização institucional, algumas tensões e conflitos persistem e inscrevem-se num processo de lutas de poder, visando reafirmar as suas prerrogativas. Ainda assim, os praticantes da nossa amostra referem que as relações entre as associações são convergentes e de cooperação. Como corrobora Bourdieu (1979), os indivíduos são portadores de determinadas estratégias que derivam de uma lógica de campo, nos quais evoluem. Ou seja, existe um espaço em que ocorrem as relações entre os indivíduos, grupos e estruturas sociais, espaço este sempre dinâmico, que obedece a leis próprias, animado pelas disputas ocorridas no seu interior, e cujo móbil é o interesse em ser bem-sucedido nas relações estabelecidas entre os seus componentes (seja ao nível dos agentes, seja ao nível das estruturas). Existe, assim, um "campo de concorrência onde se afrontam agentes sociais específicos ligados à posição que nele ocupam" (Bourdieu, 2003, p. 182). As tensões, conflitos, contestações, etc., no caso do karaté, são, sobretudo, pela vontade de se ter o protagonismo na modalidade, a conquista de terreno, ou seja, ter-se mais clubes e praticantes, à perceção da forma de prática, ao reconhecimento (ou a forma de entrega) das graduações e associações representativas de determinado estilo de karaté, a variedade e eficácia das técnicas utilizadas, no entanto, isso não impede uma boa cooperação institucional. Os dados apontam que as relações entre os praticantes experientes de karaté da vertente de não-competição e de competição desportiva têm vindo a caracterizarse por tensões, dinâmicas de resistência e conflitos, geradores de cisões entre agentes de ensino, espaços de prática ou clubes e estrutura federativa, independentemente do estilo de prática, sexo, idade e escolaridade, como afirmava a nossa terceira hipótese, embora a análise realizada nos permita concluir que a leitura que se expressa da realidade se afigura redutora, e deste modo só em parte podemos afirmar que a hipótese se verifica. Tratam-se, pois, de dinâmicas de afirmação de interesses e de poder dentro do campo do karaté, que coexistem com várias formas de cooperação, ambas contribuindo para o reforço da identidade do mesmo. Para concluirmos, podemos afirmar que, mergulhado nos contextos históricos, sociais e culturais específicos (Oriente e Ocidente), o karaté se transforma e se encontra em constante interação e mudança, tanto 
mais que no Oriente, em particular no Japão, país de que é originário, as tendências de globalização atuais também se fazem sentir, e com estas as mudanças sociais, os usos e costumes, e decorrentemente, o próprio desenvolvimento do karaté como referimos. Deste modo, o karaté pode ser entendido como uma manifestação desportiva que dá expressão ao cruzamento de culturas (Oriental e Ocidental), em perpétua evolução, onde é possível verificar as linhas força, de se apreender o que está em jogo e compreender o seu estado presente.

\section{Referências}

Bourdieu, P. (1979). La distinction. Critique sociale du jugement. Paris: Les Éditions de Minuit.

Braunstein, F. (1999). Penser les arts martiaux. Paris: PUF.

Clément, J.-P. (1981). La force, la souplesse et l'harmonie: Étude comparée de trois sports de combat: Lutte, judo, aïkido. In Christian Pociello (org.) (1981). Sport et société: Approche socioculturelle des pratique (pp. 285-301) Paris: Éditions Vigot.

Figueiredo, A. (2006). A institucionalização do karaté: Os modelos organizacionais do karaté em Portugal. (PhD). Lisboa: UTL-FMH.

García, C., Rosa, V., \& Gutièrrez, M. (2010). Introducción de las artes marciales asiáticas en Portugal. Revista Materiales para la Historia del Deporte, VIII, 9-17.

Gaudin, B. (2009). La codification des pratiques martiales: Une approche socio-historique. Actes de la recherche en sciences sociales, 179, 4-31.

Julhe, S. (2009). Les pratiques martiales japonaises en France. Actes de la recherche en sciences sociales, 179, 92-111.

Marivoet, S. (2007). Ética do desporto - Princípios, práticas e conflitos. Análise sociológica do caso português durante o Estado Democrático do Século $X X$. (PhD). Lisboa: ISCTE.

Rosa, V. (2007). Encuadramiento legal e institucional de las artes marciales y deportes de combate en Portugal. Revista de Artes Marciales Asiáticas, 2(4), 8-31.

Rosa, V. (2008). Las artes marciales y los deportes de combate en números: Una mirada exploratoria sobre los datos numéricos o estadísticos en Portugal. Revista de Artes Marciales Asiáticas, 3(2), 38-49.

Rosa, V. (2016). Perspetivas e entendimentos dos praticantes portugueses de karaté sobre o conceito de Budô. Revista de Artes Marciales Asiáticas, 10(2), 124-134.

Rosa, V. (2017). A prática desportiva do karaté em Portugal: Análise sociológica sobre as identidades, ideologias, comunidades e culturas dos karatecas (cintos castanho e negro) portugueses. (PhD), Lisboa: FEFD/ULHT.

Wacquant, L. (2000). Corps et âme. Carnets ethnographiques d'un apprenti boxeur. Marseille: Agone. 


\title{
Perceções discentes sobre a escola e a
}

\section{educação física: influências na prática de atividade física}

\author{
Francisca Góis ${ }^{1,4}$, Élvio Gouveia ${ }^{2}$, João Martins ${ }^{1,3}$, Valter Barbosa \\ Filho $^{4}$, Adilson Marques ${ }^{1,5}$ \\ ${ }^{1}$ Faculdade de Motricidade Humana, Universidade de Lisboa; \\ ${ }^{2}$ Departamento de Educação Física e Desporto, Universidade da Madeira; \\ ${ }^{3}$ Laboratório de Pedagogia, UIDEF, Instituto de Educação, Universidade de Lisboa; \\ ${ }^{4}$ Instituto Federal de Educação, Ciência e Tecnologia do Ceará; \\ ${ }^{5}$ Centro Interdisciplinar do Estudo da Performance Humana;
}

\section{Palavras-chave: Clima motivacional; Objetivo de realização; Satisfação escolar; Educação Física.}

Keywords:

Motivational climate;

Achievement goal; School satisfaction; Physical education.

\section{RESUMO}

Este estudo analisou as relações hipotetizadas pela Teoria dos Objetivos de Realização nas aulas de educação física e a satisfação escolar na predição das atitudes (o gosto pela atividade física e a auto eficácia) e nível de atividade física dos adolescentes de duas escolas secundárias. Participaram 624 adolescentes (326 rapazes), com idades entre $14 \mathrm{e}$ 17 anos de duas escolas em Fortaleza, Ceará, Brasil. Utilizou-se vários questionários como instrumento. Foi realizada a análise de regressão linear estratificada por escola, testando três modelos de forma hierárquica. A maioria dos alunos não atingiu as recomendações para atividade física $(<60 \mathrm{~min} / \mathrm{dia})$ e apresentaram moderada eficácia, não existindo diferença significativa entre as escolas. Houve diferença entre as escolas quanto ao gosto pela atividade física $(p=0.001)$, a satisfação escolar $(p=0.007)$, o objetivo mestria $(\mathrm{p}<.001)$, o objetivo aprovação social $(\mathrm{p}=0.002)$, o clima mestria $(\mathrm{p}<0.001)$ e o clima performance-aproximação (0.001). Como conclusão, o modelo que incluiu o clima motivacional, a satisfação escolar e os objetivos de realização, mostrou-se o mais adequado para predizer a atividade física dos alunos de ambas as escolas.

\section{ABSTRACT}

This study analyzed the relationships hypothesized by the Theory of Achievement Objectives in physical education classes and school satisfaction in the prediction of attitudes (the taste for physical activity and self-efficacy) and the level of physical activity of adolescents from two secondary schools. 624 adolescents (326 boys) participated, aged between 14 and 17 years old from two schools in Fortaleza, Ceará, Brazil. Several questionnaires were used as an instrument. Linear regression analysis stratified by school was performed, testing three models hierarchically. Most students did not meet the recommendations for physical activity $(<60 \mathrm{~min} /$ day $)$ and showed moderate effectiveness, with no significant difference between schools. There was a difference between schools regarding the taste for physical activity $(p=0.001)$, school satisfaction ( $p$ $=0.007)$, the mastery objective $(p<.001)$, the social approval objective $(p=0.002)$, the mastery climate $(p<0.001)$ and the performance-approximation climate $(0.001)$. In conclusion, the model that included the motivational climate, school satisfaction and achievement objectives, proved to be the most adequate to predict the physical activity of students from both schools. 


\section{Introdução}

As evidências apontam que quatro em cada cinco adolescentes no mundo são insuficientemente ativos (Guthold, Stevens, Riley, \& Bull, 2020). As transições características da adolescência, como: a mudança do ensino fundamental para o ensino médio, o aumento da carga de trabalho, a desmotivação, a falta de energia e as reduzidas oportunidades para serem fisicamente ativos, contribuem para esses níveis críticos de participação em atividades físicas (AF) (Martins, Marques, Sarmento, \& Carreiro da Costa, 2015). Além disso, fatores psicossociais podem influenciar as atitudes relacionadas a decisão de um indivíduo de iniciar ou continuar a participar de uma AF. Como exemplos, destacamos o gosto pela AF e o sentimento de autoeficácia, que é a confiança na capacidade de ser fisicamente ativo (Bai et al., 2018; Hardman et al., 2013; Martins et al., 2017).

A escola e a educação física (EF) podem contribuir para o comportamento relacionado a AF dos adolescentes (McLennan \& Thompson, 2015). A satisfação com o rendimento acadêmico e com as relações estabelecidas com os pares e adultos significativos da escola podem contribuir para uma esfera interpessoal mais positiva, favorável às condutas adaptativas relacionadas aos comportamentos saudáveis (Fernandes, Vasconcelos-Raposo, Bertelli, \& Almeida, 2011). Assim como, a participação nas aulas de EF parece estar relacionada a melhores índices de satisfação com a escola (Almeida \& Fernandes, 2019).

Com intuito de aumentar a participação dos alunos em AF, uma linha de pesquisa baseada na Teoria de Objetivos de Realização se propõe a compreender os processos e os climas motivacionais relacionados a EF. Os objetivos de realização referem-se a forma como o indivíduo percebe e avalia a sua competência e como esta perceção influencia no seu comportamento. Já o clima motivacional é influenciado pelos agentes sociais relevantes, como os professores, podendo ser mais ou menos favoráveis ao sucesso (Nichools, 1989).

Existem quatro tipos de objetivos e climas motivacionais relacionados a EF, sendo eles: mestria, quando a avaliação da competência é baseada no domínio; perfomance-aproximação, quando a avaliação da competência é baseada na comparação com outras pessoas ou padrões; performance-evitamento, quando adotam-se condutas de prevenção ou evitamento perante situações que podem receber críticas ou punições; e aprovação social, quando o comportamento do indivíduo é direcionado para demonstrar esforço ou compromisso social na realização das tarefas e não necessariamente na melhora das habilidades (Maehr \& Nicholls, 1980; Papaioannou, Tsigilis, Kosmidou, \& Milosis, 2007).
Existem evidências de que a orientação e o clima motivacional voltados para mestria influenciam positivamente a prática da $\mathrm{AF}$, enquanto as orientações para a performance relacionam-se a resultados negativos (Buch, Nerstad, \& Säfvenbom, 2017). Acredita-se que os professores de EF podem direcionar suas aulas para o clima mestria, melhorando os níveis de motivação e de satisfação dos alunos (Jaakkola, T., Yli-Piipari, S., Barkoukis, V., \& Liukkonen, 2017).

Assim, o objetivo desse estudo foi analisar as relações hipotetizadas pela Teoria dos Objetivos de Realização nas aulas de EF e satisfação escolar na predição das atitudes (o gosto pela $\mathrm{AF}$ e a auto eficácia) e nível de AF dos adolescentes de duas escolas secundárias. Os resultados poderão oferecer informações que colaborem na elaboração de políticas escolares e programas de EF que promovam a adoção do comportamento fisicamente ativo.

\section{Metodologia}

Trata-se de um estudo descritivo, com abordagem quantitativa, realizado em duas escolas públicas do município de Fortaleza, Ceará, Brasil, com alunos do ensino secundário. As escolas participantes eram centenárias, possuíam instalações esportivas para as aulas de EF e profissionais habilitados em EF.

\section{Participantes}

A amostra foi definida por conveniência, sendo excluídos os estudantes com mais de 17 anos de idade e aqueles que não possuíam Termo de Consentimento Livre e Esclarecido assinado pelo tutor. Participaram do estudo 624 adolescentes (rapazes 326, 298 moças), com idade entre 14 e 17 anos $(\mathrm{M}=15.86, \mathrm{DP}=0.940)$.

\section{Instrumentos}

Para caracterização dos participantes foi utilizado um questionário, onde os adolescentes responderam às questões sobre sexo, idade, escola e série. Para avaliação da prática de AF, utilizou-se o Questionário Internacional de AF para Adolescentes, versão curta, validado para o Brasil (Guedes, Lopes, $\&$ Guedes, 2005). Os adolescentes reportaram a frequência (dias/semana) e a duração (horas/minutos/dia) das atividades físicas moderadas a vigorosa (AFMV) praticadas na última semana. Os adolescentes foram orientados a incluírem o tempo de AF nas aulas de EF. Para a determinação do nível de AF considerou-se o somatório do produto do tempo despendido em cada tipo de AF pelas respetivas frequências de prática. Foram considerados suficientemente ativos aqueles que praticam $\geq 60$ minutos diários de AFMV, insuficientemente ativos os que praticam $<60$ 
minutos diários e inativos aqueles que referiram não haver praticado nenhuma AF na última semana (WHO, 2010).

O gosto pela AF foi verificado através da questão: "O que pensa sobre a AF?" respondida através de uma escala Likert de cinco pontos (não gosto muito $=1$ e gosto muito $=5$ ). A avaliação da autoeficácia para AF foi realizada através da versão validada para o contexto brasileiro do Patient-Centered Assessment and Counseling for Exercise (PACE) (Tassitano et al., 2015). Utilizou-se seis itens que verificavam o nível de confiança dos adolescentes em serem fisicamente ativos em determinadas situações. As respostas foram avaliadas através de uma escala Likert de cinco pontos (eu tenho certeza que não posso $=1$ e tenho certeza de que posso $=5$ ), com consistência interna $(\alpha=0.78)$. Na análise, o escore geral de autoeficácia foi computado pela soma de todos os itens da escala e posteriormente categorizada segundo os tercis: baixa, moderada e elevada autoeficácia. A satisfação escolar foi avaliada através do constructo KIDSCREEN-27, que apresentou níveis satisfatórios de reprodutibilidade, consistência interna e validade em adolescentes brasileiros (Farias, Loch, Lima, Sales, \& Ferreira, 2017). Foram utilizados os itens relativos a satisfação com ambiente escolar e aprendizagem, avaliados com uma escala do tipo Likert de quatro pontos (nunca, algumas vezes, frequentemente e sempre) que apresentou consistência interna ( $\alpha=$ 0.70). Essas variáveis foram tratadas como quantitativas.

Foram avaliados também o clima motivacional e a orientação de metas nas aulas de EF, a partir do questionário de objetivos de realização (AGQ) e questionário das perceções sobre a ênfase que os professores atribuem aos objetivos (PTEGQ) validados para língua portuguesa (Martins, 2015; Papaioannou et al., 2007). As respostas às questões do AGQ e PTEGQ foram dadas numa uma escala Likert de cinco pontos, onde os extremos eram: discordo muito $=1$ e concordo muito $=5$. Os itens do AGQ e os itens do PTEGQ estavam associados a uma das quatro subescalas: mestria, performanceaproximação, performance-evitamento e aprovação social. Para cada sujeito, foi obtida a média das respostas dos itens de cada subescala. Quanto mais elevada fosse a pontuação em determinada subescala mais elevada seria a sua orientação para os objetivos de realização e perceção do clima motivacional.

\section{Procedimentos}

Os estudantes pertenciam a duas escolas com diferentes abordagens pedagógicas nas aulas de EF. Essa distinção foi feita baseada na análise do programa da disciplina e na observação de 36 aulas de EF utilizando o System for Observing Instruction Time (SOFIT) (Mckenzie, Sallis, \& Nader, 1991). Foram observadas três aulas de uma mesma turma de cada um dos professores de EF (Escola 1=2 professores, Escola 2=11 professores). Antes da observação, o professor informava o conteúdo e o objetivo da aula. O SOFIT possibilitou a identificação do contexto de aula e o comportamento do professor. Os resultados detalhados sobre a caracterização das aulas foram apresentados em um estudo prévio (Góis et al., 2020).

A primeira escola, funcionava desde 1845 , possuía 750 alunos e passava por uma transição do ensino regular para o ensino integral. O novo programa de ensino se propunha a oferecer uma formação voltada para construção do projeto de vida do aluno. No momento da pesquisa não havia um programa de EF documentado, mas o Projeto Político Pedagógico da escola informava que todas as disciplinas deveriam seguir os Parâmetros Curriculares Nacionais que recomendavam o desenvolvimento de temas sobre as competências e habilidades relacionadas à cultura corporal, como a importância da prática da AF para saúde (BRASIL, 2000). A carga horária semanal da EF era de 50 minutos e o grupo docente da EF era composto por dois professores. As aulas aconteciam predominantemente no ginásio que apresentava necessidade de manutenção quanto a pintura, iluminação, traves, tabelas e postes de vólei. Os professores não tinham material esportivo suficiente e em boas condições para realizar as aulas. As atividades eram pouco diversificadas, predominantemente recreativas e com pouca mediação do professor (Góis et al., 2020). Para fins da descrição neste estudo, esta escola foi chamada de escola 1.

A segunda escola, funcionava desde 1952, possuía 1747 alunos e associava o ensino secundário a uma formação profissionalizante. A carga horária da EF era de 180 minutos por semana, dividida em dois ou três dias. A disciplina de EF era organizada em modalidades desportivas e AF. Os programas das disciplinas incluíam o desenvolvimento de habilidades técnicas, táticas e vivência de competições. Observou-se que a maioria das aulas eram práticas e seguiam o que estava descrito no programa (Góis et al., 2020). A escola possuía várias instalações esportivas que incluíam dois ginásios, duas piscinas e uma sala de musculação em boas condições. Havia um professor de EF para cada modalidade, no total de 11 profissionais. Havia também grande disponibilidade de material esportivo com boas condições. Neste estudo, esta escola foi denominada de escola 2.

A coleta foi realizada entre os meses de abril e outubro de 2018. Os adolescentes foram convidados a preencherem o instrumento em sala de aula, durante o horário da EF. Este estudo foi aprovado pelo Comitê de Ética em Pesquisa do Instituto Federal de Ciência, Educação e Tecnologia do Ceará (CAAE: 82461717.5.000-89). A participação dos adolescentes aconteceu mediante a apresentação do Termo de Consentimento Livre e Esclarecido 
assinado pelos responsáveis legais e do Termo de Assentimento do adolescente.

\section{Análise estatística}

Inicialmente, foi calculada a estatística descritiva (\%) para todas as variáveis em estudo. Devido ao tamanho da amostra $(n=624)$ e tendo em conta os princípios da Teoria do Limite Central, foram realizados testes paramétricos. Para comparar os alunos das escolas relativamente à prática de $\mathrm{AF}$, gosto pela $\mathrm{AF}$, autoeficácia para $\mathrm{AF}$, satisfação escolar, orientação dos objetivos e clima motivacional, utilizou-se o teste T-Student para amostras independentes. Foi realizada uma análise de regressão linear múltipla, com o método enter usando a prática de $\mathrm{AF}$, gosto pela $\mathrm{AF}$ e a autoeficácia como variáveis dependentes. Todas as análises foram realizadas com o SPSS 24, adotando um $\mathrm{p} \leq 0,05$ como nível de significância.

\section{Resultados}

A amostra foi constituída por 624 adolescentes de ambos os sexos (148 alunos da escola 1 e 476 alunos da escola 2), com idades entre 14 e 17 anos, cujas médias foram $16.22 \pm 0.92$ na escola 1 e $15.75 \pm$ 0.91 anos na escola 2. As informações sobre a descrição dos participantes por escola são apresentadas na tabela 1 .

Tabela 1. Descrição dos participantes por escola

\begin{tabular}{lcccc}
\hline & \multicolumn{2}{c}{ Escola 1 } & \multicolumn{2}{c}{ Escola 2 } \\
\hline Sexo & $\mathbf{n}$ & $\mathbf{\%}$ & $\mathbf{n}$ & $\mathbf{\%}$ \\
Masculino & & & & 52.9 \\
Feminino & 74 & 50.0 & 252 & 47.1 \\
Idade (anos) & 74 & 50.0 & 224 & \\
14 & & & & \\
15 & 6 & 4.1 & 42 & 8.8 \\
16 & 32 & 21.6 & 149 & 31.3 \\
17 & 33 & 22.3 & 172 & 36.1 \\
Gosto pela Atividade física & 77 & 52.0 & 113 & 23.7 \\
Não gosta & & & & \\
Indiferente & 24 & 16.3 & 30 & 6.3 \\
Gosta & 18 & 12.2 & 62 & 13.1 \\
Nível de Atividade física & 105 & 71.4 & 383 & 80.6 \\
Inativo & & & & \\
Insuficientemente ativo (<60 min/dia) & 29 & 20.4 & 28 & 5.9 \\
Suficientemente ativo ( $\geq 60$ min/dia) & 79 & 55.6 & 331 & 69.7 \\
Autoeficácia para Atividade física & 34 & 23.9 & 116 & 24.4 \\
Baixa & & & & \\
Moderada & 63 & 49.6 & 243 & 54.0 \\
Elevada & 26 & 20.5 & 118 & 26.2 \\
\hline Fonte: Os autor & 38 & 29.9 & 89 & 19.8 \\
\hline
\end{tabular}

A comparação entre as escolas revelou diferenças quanto a idade, gosto pela $\mathrm{AF}$, a orientação dos objetivos e clima motivacional (ver tabela 2).

As análises de regressão para AFMV são apresentadas na tabela 3 . Três modelos foram testados nas análises de regressão linear. No primeiro modelo introduziram-se os quatro domínios do clima motivacional. No segundo modelo incluiuse a satisfação escolar. E no terceiro modelo incluiuse os quatro domínios da orientação dos objetivos. O ajuste do modelo 1 não apresentou diferença significativa nas duas escolas. Já o ajuste do modelo 2 foi significativamente diferente do modelo 1 para as duas escolas ( $p=.009 ; p=.018$, respetivamente), bem como o modelo 3 foi diferente do modelo 2 ( $p$ $=.025 ; p=.014$, respetivamente).

$\mathrm{O}$ ajuste do modelo 3 foi o que melhor explicou a variância da AFMV nas duas escolas, sendo para a escola $1\left[\mathrm{~F}(9.119)=2.780 ; \mathrm{p}<0.05 ; \mathrm{R}^{2}=0.174\right]$, representando $17 \%$ da variância para $A F M V$ e para a escola 2, $\left[\mathrm{F}(9.465)=2.334 ; \mathrm{p}<0.05 ; \mathrm{R}^{2}=0.043\right]$, representando $4 \%$ da variância da AFMV. Observou-se que a AFMV da escola 1 apresentou associação positiva com a satisfação escolar e com o objetivo mestria. Enquanto, na escola 2 a AFMV esteve associada positivamente apenas ao objetivo mestria. 
Tabela 2. Valores médios das características gerais dos alunos por escola

\begin{tabular}{|c|c|c|c|}
\hline & Escola 1 & Escola 2 & $p$ \\
\hline & Média (DP) & Média (DP) & \\
\hline Idade & $16.22(.92)$ & $15.75(.91)$ & $<.001 * *$ \\
\hline AFMV_dia & $45.15(73.96)$ & $46.46(52.74)$ & .815 \\
\hline Gosto pela AF & $1.55(.75)$ & $1.74(.56)$ & $.001 *$ \\
\hline Autoeficácia & $3.12(1.08)$ & $2.99(.88)$ & .123 \\
\hline Satisfação escolar & $1.88(.52)$ & $2.00(.47)$ & .007 \\
\hline \multicolumn{4}{|l|}{ Orientação dos objetivos } \\
\hline Mestria & $3.57(.92)$ & $3.99(.68)$ & $<.001 * *$ \\
\hline Performance-aproximação & $2.83(.91)$ & $2.98(.90)$ & .093 \\
\hline Peformance-evitamento & $2.77(.90)$ & $2.88(.92)$ & .230 \\
\hline Aprovação Social & $3.11(.86)$ & $3.35(.77)$ & $.002 *$ \\
\hline \multicolumn{4}{|l|}{ Clima motivacional } \\
\hline Mestria & $2.85(1.11)$ & $3.84(.91)$ & $<.001 * *$ \\
\hline Performance-aproximação & $2.32(1.06)$ & $2.00(.93)$ & $.001 *$ \\
\hline Performance-evitamento & $2.07(.99)$ & $1.97(.75)$ & .195 \\
\hline Aprovação social & $2.45(1.03)$ & $2.60(.87)$ & .088 \\
\hline
\end{tabular}

Assim, AFMV dos alunos das escolas 1 e 2 podem ser previstas pelas equações 1 e 2 , respetivamente:

AFMV $=-258.998+12.48 \times$ clima mestria + 112.27 x clima performance aproximação + $3.05 \mathrm{x}$ clima performance evitamento -96.79 x clima aprovação social +140.39 x satisfação escolar +133.87 x objetivo mestria $+15.46 \mathrm{x}$

objetivo performance aproximação -80.09 x objetivo performance evitamento - $3.98 \mathrm{x}$ objetivo aprovação social

AFMV $=-83.296-12.89 \times$ clima mestria + $.63 \times$ clima performance aproximação -1.68 $\mathrm{x}$ clima performance evitamento $+25.94 \mathrm{x}$ clima aprovação social $+36.34 \mathrm{x}$ satisfação escolar $+66.52 \times$ objetivo mestria $+\quad 37.11 \quad \mathrm{x}$ objetivo performance aproximação $-22.03 \mathrm{x}$ objetivo performance evitamento $+1.93 \mathrm{x}$ objetivo aprovação social

As análises de regressão linear para variável gosto pela AF são apresentadas na tabela 4. O modelo 1 não se diferenciou do ajuste do modelo sem preditores nas duas escolas $(p=.301 ; p=.070$, respetivamente). Também, nas duas escolas, o ajuste do modelo 2 foi significativamente diferente do ajuste do modelo $1 \quad(p=.030 ; p<.001$, respetivamente), assim como o modelo 3 foi diferente do ajuste do modelo 2 ( $p=.010 ; p<.001$, respetivamente).

$\mathrm{O}$ ajuste do modelo 3 foi o que melhor explicou a variância para o gosto pela AF nas duas escolas, sendo para a escola $1[\mathrm{~F}(9.123)=2.738 ; \mathrm{p}<0.05$; $\left.\mathrm{R}^{2}=0.167\right]$ e para escola $2[\mathrm{~F}(9.465)=10.012$; $\left.\mathrm{p}<0.001 ; \mathrm{R}^{2}=0.162\right]$, explicando $16 \%$ da variância do gosto pela AF nas duas instituições.

Assim, o gosto pela AF dos alunos das escolas 1 e 2, pode ser previsto pelas equações 3 e 4 , respetivamente:

Gosto pela $\mathrm{AF}=.631-.04 \mathrm{x}$ clima mestria + $.00 \times$ clima performance aproximação $+.08 \times$ clima performance evitamento $+.07 \times$ clima aprovação social +.20 x satisfação escolar + $.12 \mathrm{x}$ objetivo mestria - .16 x objetivo performance aproximação - .16 x objetivo performance evitamento $+.25 \times$ objetivo aprovação social

Gosto pela $\mathrm{AF}=.503-.02 \times$ clima mestria $.02 \times$ clima performance aproximação - .04 x clima performance evitamento $+.04 \mathrm{x}$ clima aprovação social +.16 x satisfação escolar + $.23 \mathrm{x}$ objetivo mestria - .03 x objetivo performance aproximação - .00 x objetivo performance evitamento $+.05 \times$ objetivo aprovação social

As análises de regressão linear para a autoeficácia são apresentadas na tabela 5. Em ambas as instituições, o modelo 1 não apresentou diferença significativa do ajuste do modelo sem preditores ( $p$ $=.178 ; p=.108$, respetivamente). $\mathrm{O}$ ajuste do modelo 2 foi significativamente diferente do modelo 1 nas duas escolas $(p=.001 ; p<.001$, respetivamente), bem como o modelo 3 também se diferenciou do ajuste do modelo $2(p=.002 ; p<.001$, respetivamente). 
Tabela 4. Relação entre gosto pela atividade física, o clima motivacional e a orientação dos objetivos

\begin{tabular}{|c|c|c|c|c|c|c|c|c|}
\hline & \multicolumn{4}{|c|}{ Escola 1} & \multicolumn{4}{|c|}{ Escola 2} \\
\hline & B & $\mathbf{R}^{2}$ & IC 95\% & $P$ & B & $\mathbf{R}^{2}$ & IC 95\% & $p$ \\
\hline Modelo 1 & & .03 & & .301 & & .01 & & .070 \\
\hline$C M E$ & .07 & & $-.09 ; .23$ & .396 & .04 & & $-.01 ; .10$ & .164 \\
\hline$C P A$ & .03 & & $-.21 ; .28$ & .789 & -.02 & & $-.09 ; .04$ & .495 \\
\hline$C P E$ & -.07 & & $-.33 ; .19$ & .588 & -.05 & & $-.14 ; .02$ & .190 \\
\hline$C A S$ & .10 & & $-.14 ; .34$ & .427 & .05 & & $-.02 ; .12$ & .180 \\
\hline Modelo 2 & & .07 & & $.030 *$ & & .07 & & $<.001 * *$ \\
\hline$C M E$ & .03 & & $-.12 ; .20$ & .665 & .01 & & $-.05 ; .07$ & .716 \\
\hline$C P A$ & .00 & & $-.24 ; .25$ & .949 & -.02 & & $-.09 ; .04$ & .470 \\
\hline$C P E$ & -.02 & & $-.28 ; .23$ & .857 & -.04 & & $-.12 ; .03$ & .289 \\
\hline$C A S$ & .11 & & $-.12 ; .35$ & .351 & .04 & & $-.02 ; .11$ & .195 \\
\hline$S E$ & .28 & & $.02 ; .53$ & $.030 *$ & .30 & & $.19 ; .40$ & $<.001 * *$ \\
\hline Modelo 3 & & .16 & & $.010 *$ & & .16 & & $<.001 * *$ \\
\hline$C M E$ & -.04 & & $-.20 ; .12$ & .598 & -.02 & & $-.08 ; .04$ & .524 \\
\hline$C P A$ & .00 & & $-.24 ; .24$ & .987 & -.02 & & $-.09 ; .03$ & .408 \\
\hline$C P E$ & .08 & & $-.17 ; .34$ & .536 & -.04 & & $-.12 ; .03$ & .309 \\
\hline$C A S$ & .07 & & $-.15 ; .31$ & .515 & .04 & & $-.02 ; .11$ & .206 \\
\hline$S E$ & .20 & & $-.04 ; .45$ & .107 & .16 & & $.04 ; .27$ & $.005 *$ \\
\hline$O M E$ & .12 & & $-.08 ; .32$ & .237 & .23 & & $.15 ; .32$ & $<.001 * *$ \\
\hline$O P A$ & -.16 & & $-.36 ; .04$ & .114 & -.03 & & $-.09 ; .03$ & .318 \\
\hline$O P E$ & -.16 & & $-.33 ; .00$ & .055 & -.00 & & $-.06 ; .05$ & .769 \\
\hline$O A S$ & .25 & & $-.02 ; .52$ & .073 & .05 & & $-.03 ; .14$ & .210 \\
\hline
\end{tabular}

Notas: $\mathrm{B}=\mathrm{Beta}, \mathrm{IC}=$ intervalo de confiança, $\mathrm{CME}=$ mestria, $\mathrm{CPA}=$ performance-aproximação, $\mathrm{CPE}=$ performance-evitamento, $\mathrm{CAS}=$ aprovação social, $\mathrm{SE}=$ satisfação escolar, $\mathrm{OME}=$ objetivo mestria, $\mathrm{OPA}=$ objetivo performance-aproximação, $\mathrm{OPE}=$ objetivo performanceevitamento, $\mathrm{OAS}=$ objetivo aprovação social $* p<0.05, * * p<0.01$.

Fonte: Os autores.

Tabela 5. Relação entre o sentimento de autoeficácia, o clima motivacional e a orientação dos objetivos

\begin{tabular}{|c|c|c|c|c|c|c|c|c|}
\hline & \multicolumn{4}{|c|}{ Escola 1 } & \multicolumn{4}{|c|}{ Escola 2} \\
\hline & B & $\mathbf{R}^{2}$ & IC 95\% & $p$ & B & $\mathbf{R}^{2}$ & IC 95\% & $p$ \\
\hline Modelo 1 & & .04 & & .178 & & .01 & & .108 \\
\hline$C M E$ & .14 & & $-.08 ; .37$ & .220 & .05 & & $-.04 ; .15$ & .268 \\
\hline$C P A$ & .29 & & $-.06 ; .65$ & .102 & -.00 & & $-.11 ; .10$ & .912 \\
\hline$C P E$ & -.23 & & $-.60 ; .14$ & .223 & -.01 & & $-.14 ; .11$ & .817 \\
\hline$C A S$ & -.04 & & $-.39 ; .30$ & .794 & .10 & & $-.01 ; .21$ & .089 \\
\hline Modelo 2 & & .13 & & $.001 *$ & & .07 & & $<.001 * *$ \\
\hline$C M E$ & .07 & & $-.15 ; .29$ & .547 & .00 & & $-.09 ; .10$ & .921 \\
\hline$C P A$ & .24 & & $-.10 ; .58$ & .170 & -.00 & & $-.11 ; .09$ & .895 \\
\hline$C P E$ & -.12 & & $-.48 ; .23$ & .496 & .00 & & $-.12 ; .13$ & .965 \\
\hline$C A S$ & -.01 & & $-.35 ; .32$ & .944 & .09 & & $-.01 ; .20$ & .096 \\
\hline$S E$ & .61 & & $.26 ; .96$ & $.001 *$ & .46 & & $.29 ; .62$ & $<.001 * *$ \\
\hline Modelo 3 & & .24 & & $.002 *$ & & .22 & &.$<.001 * *$ \\
\hline$C M E$ & -.05 & & $-.27 ; .17$ & .649 & -.02 & & $-.11 ; .06$ & .630 \\
\hline$C P A$ & .24 & & $-.09 ; .57$ & .161 & -.03 & & $-.13 ; .06$ & .526 \\
\hline$C P E$ & .01 & & $-.34 ; .37$ & .930 & .01 & & $-.10 ; .13$ & .801 \\
\hline$C A S$ & -.06 & & $-.38 ; .26$ & .710 & .09 & & $-.01 ; .19$ & .086 \\
\hline$S E$ & .50 & & $.16 ; .84$ & $.004 *$ & .13 & & $-.03 ; .30$ & .123 \\
\hline$O M E$ & .46 & & $.18 ; .73$ & $.001 *$ & .46 & & $.33 ; .58$ & $<.001 * *$ \\
\hline$O P A$ & -.15 & & $-.43 ; .12$ & .265 & .08 & & $-.00 ; .18$ & .072 \\
\hline$O P E$ & -.07 & & $-.30 ; .15$ & .506 & -.13 & & $-.22 ;-.04$ & $.003 *$ \\
\hline$O A S$ & .03 & & $-.34 ; .40$ & .877 & .01 & & $-.11 ; .14$ & .855 \\
\hline
\end{tabular}

Notas: $\mathrm{B}=\mathrm{Beta}, \mathrm{IC}=$ intervalo de confiança, $\mathrm{CME}=$ mestria, $\mathrm{CPA}=$ performance-aproximação, $\mathrm{CPE}=$ performance-evitamento, $\mathrm{CAS}=$ aprovação social, $\mathrm{SE}=$ satisfação escolar, $\mathrm{OME}=$ objetivo mestria, $\mathrm{OPA}=$ objetivo performance-aproximação, $\mathrm{OPE}=$ objetivo performanceevitamento, $\mathrm{OAS}=$ objetivo aprovação social $* p<0.05, * * p<0.01$.

Fonte: Os autores.

O ajuste do modelo 3, explicou melhor a variância da autoeficácia nas duas escolas, sendo a escola 1
$[\mathrm{F}(9.123)=4.405 ; \mathrm{p}<0.001 ; \mathrm{R} 2=0.244]$ e para $\mathrm{a}$ escola $2\left[\mathrm{~F}(9.465)=14,578 ; \mathrm{p}<0.001 ; \mathrm{R}^{2}=0.220\right]$, 
explicando assim $24 \%$ e $22 \%$ da variância, respetivamente. No modelo 3 , a autoeficácia dos alunos da escola 1 apresentou associação positiva com a satisfação escolar e o objetivo mestria, enquanto na escola 2 houve associação positiva apenas com objetivo mestria. Houve ainda associação negativa entre a autoeficácia e o objetivo performance-evitamento na escola 2. Dessa maneira, a autoeficácia para AF dos alunos das escolas 1 e 2 pode ser prevista pelas equações 5 e 6 , respetivamente:

autoeficácia $=.79-.05 \times$ clima mestria $+.24 \mathrm{x}$ clima performance-aproximação $+.01 \mathrm{x}$ clima performance-evitamento - .06 x clima aprovação social $+.50 \times$ satisfação escolar + $.46 \mathrm{x}$ objetivo mestria - .15 x objetivo performance aproximação - .07 x objetivo performance evitamento $+.03 \times$ objetivo aprovação social

autoeficácia escola $2=.84-.22$ x clima mestria - $.03 \mathrm{x}$ clima performance aproximação $+.01 \mathrm{x}$ clima performance evitamento $+.09 \times$ clima aprovação social + $.13 \mathrm{x}$ satisfação escolar $+.46 \mathrm{x}$ objetivo mestria $+.08 \mathrm{x}$ objetivo performance aproximação - .13 x objetivo performance evitamento $+.01 \times$ objetivo aprovação social

\section{Discussão}

Este estudo analisou as relações hipotetizadas pela Teoria dos Objetivos de Realização nas aulas de EF e satisfação escolar na predição das atitudes (gosto pela AF e autoeficácia) e o nível de AF dos adolescentes de duas escolas secundárias da região Nordeste do Brasil. Os resultados demonstraram pontos comuns entre as escolas, apesar das diferenças estruturais e organizacionais para EF, como o não cumprimento das recomendações para AF pela maioria dos alunos, resultados que corroboram com estudos anteriores (Cureau et al., 2016). Esses resultados também sugerem que os alunos da escola 2 não contabilizaram o tempo de AFMV nas aulas de EF, uma vez que esta instituição apresentava uma carga horária de EF bem superior a da escola 1. No entanto, isso também pode indicar pouco envolvimento dos alunos com as atividades oferecidas nas aulas de EF da escola 2. As aulas de EF das escolas eram pouco diversificadas, sendo inclusive a principal característica do programa de EF da escola 2, onde o aluno praticava a mesma atividade durante todo o semestre letivo (Góis et al., 2020). O envolvimento dos alunos pode variar conforme o nível de motivação proporcionado pela atividade, principalmente considerando as diferenças de interesse por gênero (D. Guedes \& J. Guedes, 2001; Kremer, Reichert, \& Hallal, 2012).
A satisfação escolar e o objetivo mestria foram os principais preditores da AFMV e do gosto pela AF. As evidências têm indicado a existência de uma associação positiva entre a satisfação escolar, o objetivo mestria e os comportamentos saudáveis, sendo assim recomendados no contexto da AF (Balaguer, Duda, \& Castillo, 2017; Wadsworth et al., 2017). Sabe-se que o objetivo mestria pode proporcionar um efeito de satisfação duradoura na EF (Jakkola, Yili-Piipari, Barkourks, \& Liukkonen, 2015).

O gosto pela AF foi maior entre os alunos da escola 2, assim como a satisfação escolar e o objetivo mestria. A satisfação escolar reportada pelos alunos da escola 2 pode estar relacionada aos melhores recursos físicos e pedagógicos desta escola. Além disso, o fato da escola 2 oferecer uma formação profissionalizante, onde normalmente se oferecem experiências práticas, podem tornar as aulas mais prazerosas e motivantes. Esse mesmo resultado foi verificado por Coelho e Dell'Aglio (2019) que observaram maiores níveis de satisfação escolar em estudantes do ensino médio de escolas profissionalizantes em comparação aos estudantes de escolas regulares. As autoras não investigaram a causa dessa diferença. Esse mesmo estudo concluiu que a estrutura oferecida no ambiente escolar e a relação professor-aluno foram preditores da satisfação escolar. O objetivo mestria, outro preditor do gosto pela AF, também foi maior na escola 2 . Essa diferença pode ter sido influenciada pela melhor perceção dos alunos quanto a intencionalidade pedagógica do programa de EF da escola 2. Assim como, as condições precárias de trabalho podem ter afetado a perceção dos alunos na escola 1.

A autoeficácia para AF não apresentou diferença entre as instituições, sendo classificada como moderada. Desenvolver estratégias nas aulas de EF que melhore as perceções de autoeficácia em adolescentes pode reforçar as atitudes positivas em relação à AF (Farias, Reis, \& Hallal, 2014; Fernandes et al. 2011; Gao, Lochbaum, \& Podlog, 2011). Na escola 1, a satisfação escolar e o objetivo mestria foram preditores para autoeficácia e na escola 2, os principais preditores foram o objetivo mestria e o objetivo performance-evitamento que apresentou uma relação negativa. A associação negativa encontrada na escola 2 também foi reportada no estudo de İlker e Demirhan (2013), que analisaram a existência de diferenças entre os objetivos de realização em aulas de EF com diferentes climas motivacionais. Os autores concluíram que as atitudes nas aulas foram afetadas negativamente quando $o$ foco era não ser malsucedido, como ocorre na performanceevitamento. Esta conduta de evitamento pode estar relacionada ao programa com foco na formação desportiva desenvolvido pela escola 2, pois currículos centrados em esportes podem atender a 
uma minoria de alunos mais habilidosos, desencorajando e desmotivando os menos hábeis (Fairclough, Stratton, \& Baldwin, 2002).

Embora os dados apresentados sejam relevantes, este estudo apresenta limitações quanto a seleção dos adolescentes que pertenciam a duas escolas públicas secundárias da cidade de Fortaleza e que, portanto, verificou apenas duas abordagens pedagógicas. Por isso, não devem ser realizadas extrapolações para a população de adolescentes de outras escolas. Diante dessas limitações, os resultados do presente estudo devem ser interpretados com cautela. Sugere-se que em trabalhos futuros mais escolas sejam envolvidas e que sejam investigadas mais abordagens pedagógicas da EF.

\section{Conclusões/Reflexões finais}

Os resultados desse estudo demonstraram que as escolas apresentaram comportamentos e associações semelhantes quanto a prática de AFMV dos seus alunos. E mesmo adotando abordagens metodológicas distintas na EF, o modelo 3, que incluiu o clima motivacional, a satisfação escolar e a orientação dos objetivos, mostrou-se o mais adequado para predizer a AFMV, o gosto pela AF e à autoeficácia para $\mathrm{AF}$ dos alunos das duas escolas. De modo geral, a satisfação escolar e objetivo mestria se apresentaram como os principais preditores das atitudes e prática de AFMV dos adolescentes.

Espera-se que a partir dos dados provenientes deste estudo, seja possível uma reflexão sobre os programas escolares para o desenvolvimento de um comportamento ativo mais significativo e duradouro.

\section{Referências}

Almeida, L., \& Fernandes, H. M. (2019). Relationship between physical education, school satisfaction, psychological well-being and academic achievement in vocational students. Physical Education, Leisure and Health, 14, 17-19

Bai, Y., Allums-Featherston, K., Saint-Maurice, P. F., Welk, G. J., \& Candelaria, N. (2018). Evaluation of youth enjoyment toward physical activity and sedentary behavior. Pediatric Exercise Science, 30(2), 273-280.

Balaguer, I., Duda, J. L., \& Castillo, I. (2017). Motivational antecedents of well-being and health related behaviors in adolescents. Journal of Human Kinetics, 59(1), 121-130.

Brasil. (2000). Parâmetros curriculares nacionais (Ensino Médio). Retrieved from: http://portal.mec.gov.br/seb/arquivos/pdf/ciencian.p df.
Buch, R., Nerstad, C. G., \& Säfvenbom, R. (2017). The interactive roles of mastery climate and performance climate in predicting intrinsic motivation. Scandinavian Journal of Medicine \& Science in Sports, 27(2), 245-253.

Coelho, C. C., \& Dell'Aglio, D. D. (2019). Clima escolar e satisfação com a escola entre adolescentes de ensino médio. Revista Psicologia-Teoria e Prática, 21(1), 265-281.

Cureau, F. V., Silva, T. L., Bloch, K. V., Fujimori, E., Belfort, D. R., Carvalho, K. M. B., . . . Schaan, B. D. (2016). ERICA: Inatividade física no lazer em adolescentes brasileiros. Revista de Saúde Pública, $50,4 \mathrm{~s}$.

Fairclough, S., Stratton, G., \& Baldwin, G. (2002). The contribution of secondary school physical education to lifetime physical activity. European Physical Education Review, 8(1), 69-84.

Farias J., Jr., Loch, M. R., Neto, A. J., Sales, J. M., \& Ferreira, F. E. (2017). Reprodutibilidade, consistência interna e validade de construto do KIDSCREEN-27 em adolescentes brasileiros. Cadernos de Saúde Pública, 33, e00131116.

Farias, J. Jr., Reis, R., \& Hallal, P. C. (2014). Physical activity, psychosocial and perceived environmental factors in adolescents from Northeast Brazil. Cadernos de Saúde Pública, 30, 941-951.

Fernandes, H. M., Vasconcelos-Raposo, J., Bertelli, R., \& Almeida, L. (2011). Satisfação escolar e bemestar psicológico em adolescentes portugueses. Revista Lusófona de Educação, (18), 155-172.

Gao, Z., Lochbaum, M., \& Podlog, L. (2011). Selfefficacy as a mediator of children's achievement motivation and in-class physical activity. Perceptual and Motor Skills, 113(3), 969981.

Gois, F., Catunda, R., Gouveia, E. R., Martins, J., Hercules, E. D., \& Marques, A. (2020). Caracterização dos comportamentos de ensino, contexto de aula e atividade física em dois programas distintos de educação física. Retos, 38 , 379-384.

Guedes, D. P., Lopes, C. C., \& Guedes, J. E. (2005). Reprodutibilidade e validade do Questionário Internacional de Atividade Física em adolescentes. Revista Brasileira de Medicina $e$ Esporte, 11(2), 151-158.

Guthold, R., Stevens, G. A., Riley, L. M., \& Bull, F. C. (2020). Global trends in insufficient physical activity among adolescents: A pooled analysis of 298 population-based surveys with 1.6 million participants. The Lancet Child \& Adolescent Health, 4(1), 23-35. 
Hardman, C. M., Barros, S. S., Andrade, M. L., Nascimento, J. V., Nahas, M. V., \& Barros, M. V. (2013). Participação nas aulas de educação física e indicadores de atitudes relacionadas à atividade física em adolescentes. Revista Brasileira de Educação Física e Esporte, 27(4), 623-631.

İlker, G. E., \& Demirhan, G. (2013). The effects of different motivational climates on students' achievement goals, motivational strategies and attitudes toward physical education. Educational Psychology, 33(1), 59-74.

Jaakkola, T., Yli-Piipari, S., Barkoukis, V., \& Liukkonen, J. (2017). Relationships among perceived motivational climate, motivational regulations, enjoyment, and PA participation among finnish physical education students. International Journal of Sport and Exercise Psychology, 15(3), 273-290.

Kremer, M. M., Reichert, F. F., \& Hallal, P. C. (2012). Intensidade e duração dos esforços físicos em aulas de Educação Física. Revista de Saúde Pública, 46, 320-326.

Maehr, M., \& Nicholls, J. (1980). Culture and achievement motivation: A second look. In N. Warren (Ed.), Studies in across-cultural psychology (pp. 221-267). New York: Academic Press.

Martins, J. (2015). Educação física e estilos de vida: Porque são os adolescentes fisicamente (in) ativos? $(\mathrm{PhD})$. Faculdade de Motricidade Humana, Universidade de Lisboa, Lisboa, Portugal. Retrieved from: http://hdl.handle.net/10400.5/8346

Martins, J., Marques, A., Peralta, M., Palmeira, A., \& Da Costa, F. C. (2017). Correlates of physical activity in young people. Retos, (31), 292-299.

Martins, J., Marques, A., Sarmento, H., \& Carreiro da Costa, F. (2015). Adolescents' perspectives on the barriers and facilitators of physical activity: A systematic review of qualitative studies. Health Education Research, 30(5), 742-755.

McKenzie, T. L., Sallis, J. F., \& Nader, P. R. (1991). SOFIT: System for observing fitness instruction time. Journal of Teaching in Physical Education, 11(2), 195-205

McLennan, N., \& Thompson, J. (2015). Quality physical education (QPE): Guidelines for policy makers: UNESCO Publishing.

Nicholls, J. G. (1989). The competitive ethos and democratic education. Harvard: Harvard University Press.

Papaioannou, A., Tsigilis, N., Kosmidou, E., \& Milosis, D. (2007). Measuring perceived motivational climate in physical education. Journal of Teaching in Physical Education, 26(3), 236-259.
Tassitano, R. M., Farias Júnior, J. C., Rech, C. R., Tenório, M. C., Cabral, P. C., \& Silva, G. A. (2015). Validation of psychosocial scales for physical activity in university students. Revista de Saúde Pública, 49, 47.

Wadsworth, D. D., Rudisill, M. E., Hastie, P. A., Irwin, J. M., \& Rodriguez-Hernandez, M. G. (2017). Preschoolers' physical activity participation across a yearlong mastery-motivational climate intervention. Research Quarterly for Exercise and Sport, 88(3), 339-345.

World Health Organization (WHO) (2010). Global recommendations on physical activity for health: World Health Organization. 


\title{
Physical Education Cooperating
}

\section{Teachers' perspectives on professional}

\section{ethics}

\author{
Elsa Ribeiro-Silva ${ }^{1,2,3}$, Catarina Amorim ${ }^{1}$ \\ ${ }^{1}$ Faculdade de Ciências do Desporto e Educação Física, Universidade de Coimbra; \\ ${ }^{2}$ Centro de Investigação do Desporto e da Atividade Física; \\ ${ }^{3}$ Centro de Estudos Interdisciplinares do Século XX;
}

\begin{abstract}
Palavras-chave:
Professor cooperante; Formação inicial de professores;

Supervisão;

Ética profissional;

Educação física

\section{RESUMO}

A profissão docente, sendo uma profissão que acima de tudo requer interação humana, é inseparável da ética (Castilho, 2018). A formação inicial de professores é reconhecida pelo seu impacto no desenvolvimento profissional dos estagiários, sendo os professores cooperantes fundamentais nesta fase. A atitude ético-profissional é transversal a todos os conhecimentos relativo à formação docente, pelo que é importante estudar as perspetivas dos professores cooperantes sobre ética profissional. Este artigo apresenta estudos caso de professores cooperantes de educação física acerca da ética profissional dos estagiários. Foi seguida uma metodologia qualitativa, recolhendo dados através de uma entrevista semiestruturada com 5 questões. Foram entrevistados 5 professores cooperantes do Mestrado de Ensino de Educação Física da Universidade de Coimbra. Os dados foram estudados através de análise temática do conteúdo (Bardin, 2011) e revelaram que os professores cooperantes focam-se maioritariamente na conduta pessoal demonstrada pelos estagiários, revelando uma perspetiva reducionista de atitude ético-profissional.
\end{abstract}

\section{Keywords}

Postural balance,

Maturity, Physical education,

Performance.

\begin{abstract}
The teaching profession, being a profession that above all requires human interaction, is inseparable from ethics (Castilho, 2018). Initial teacher training is recognised by its impact in professional development of pre-service teachers, and cooperating teachers are fundamental in this stage. The ethical-professional attitude is transversal to all knowledge related to initial education. Therefore, it is important to study the perspective of cooperating teachers regarding professional ethics. This article presents case studies concerning Portuguese physical education cooperating teachers' perspective of pre-service teachers' professional ethics. We followed a qualitative methodology and data was collected from a semi-structured interview with 5 questions. It was interviewed 5 cooperating teachers of the master's degree in Teaching Physical Education in the University of Coimbra. Data was analysed through thematic content analysis (Bardin, 2011) and revealed that cooperating teachers focus mainly on the personal conduct shown by pre-service teachers. These results reveal a reductionist perception of the notion of professional ethics and the association of professional ethics to personal ethics.
\end{abstract}




\section{Introduction}

In each profession it is possible to describe a distinct work profile which we call professionality. The teaching profession, being one that above all requires human interaction and interrelation, is inseparable from ethics (Castilho, 2018).

To be awarded the qualified teacher status, preservice teachers must complete their teaching practicum, which is done under the supervision of a cooperating teacher. The cooperating teacher has a crucial and determinate position during the professionalisation and socialisation of pre-service teachers (Clarke \& Collins, 2007; Formosinho, 2009; Koster et al., 2005; Pérez-Castro, 2010) during a complex year of professional and self-development, contributing for the pre-service teachers' reflective capacity and adaptability to conflicting situations (Albuquerque, Graça \& Januário, 2005). This is due to the need of a constant follow up, which is a positive approach to the pre-service teacher's socialisation (Graber, 1995; Hushman, 2013). That has been reported by Pacheco and Flores (1999) for having implications in the pre-service teacher's academic and professional success, and their pedagogical practices (Moreira, 2004).

Research revealed how cooperating teachers have a positive influence in the pre-service teachers' attitudes about teaching and professional development (Machado et al. 2015; McCaughtry et al., 2005). This influence goes as far as informing, forming and transforming pre-service teachers' professional identity (Figueiredo, 2010). Understanding that ethics has a vital role integrating one with the professional life (Schwimmer \& Maxwell, 2017), it is crucial while socialising preservice teachers for its assessment of good and bad values.

The study developed by Caetano and Silva (2009) showed the difficulty and complexity of defining one single notion of professional ethics. Their results showed that teachers consider professional ethics as an expansion of personal ethics, acting as one. The definition of ethics reflects values that guide the teacher for the good, particularly the student's good. The ethical complexity of the teaching profession has still space to grow within professional ethics research, nonetheless it is possible to identify and increased concern in contemplating it in initial teacher education programs (Estrela \& Caetano, 2012; Gluchmanová, 2017; Maxwell et al., 2016). However, literature presents four problems while studying professional ethics: a disorientation in its definition; ideological controversy of professional ethics included in the university curriculum; reduced ability to convert curricular ethical subject into meaningful skills; and the weak ethical training of the professors in charge (Pérez-Castro, 2010).

In the Portuguese context, research has focused mainly on the relationship between the cooperating teachers and the pre-service teachers, while the relationship between the pre-service teachers and the university tutor has been somewhat ignored in the process. This fluctuation in research shows the immense influence cooperating teachers have during the school placement and, therefore, during the teaching practicum.

The research developed by Willemse, Lunenberg, and Korthagen (2005) reveals that there are studies that show different teachers' perspectives about tasks and roles where the ethical dimension manifests itself, however with a lack of coherence between the teachers' perspectives and the institutions. Therefore, the purpose of this study, of exploratory nature, is to understand cooperating teachers' perspectives of ethical-professional attitude. With the results it is possible to boost the formative quality of future physical education teachers, taking into account that ethical-professional attitude is transversal to all other dimensions of training (Caetano, 2017).

\section{Methodology}

To develop this study, we employed a qualitative methodology alongside the paradigm of social constructivism (Creswell \& Creswell, 2018) which is an approach to qualitative research where the investigators establish idiosyncratic meanings based on the subjects' reported experiences. Approaching our research using this paradigm revealed the cooperating teachers' understanding of professional ethics and its place in the supervision process.

\section{Participants}

Our participants were five cooperating teachers of the master's degree in teaching physical education, in the University of Coimbra. The following table (Table 1) describes the demographics of the participants in this study.

Most cooperating teachers were male and were on average 49.8 years old (SVD $=4.71$ years), teaching PE for 26.6 years (SVD $=6.07$ years) and in the cooperating teacher role for 11.2 years $(\mathrm{SVD}=8.79$ years).

\section{Instruments and Procedures}

To collect data, we have conducted semi-structured interviews (Flick, 2018) administered by the researchers. The interviews took place at each cooperating teachers' school and ran between 45 minutes to one hour. When meeting with the participants, we presented the objectives of the study and what was required of them. Subsequently, they were invited to read and sign an informed consent. This document contained the information related to the study such as the purpose and privacy protection policy. All interviews begun with closed questions in order to determine the participants' demographics and 
followed with an open-ended format where all participants were encouraged to answer freely and to whatever extent and detailed they wanted to.

This investigation is part of an extended research on the role of the cooperating teacher in developing preservice teachers' professional identity. For this analysis we only focused in the set of questions related to the ethical-professional attitude.

Using the interview method gave us detailed answers, resulting in more valuable data. All of the interviews were audio-taped and transcribed verbatim.

Table 1. Cooperating teachers demographics

\begin{tabular}{lcccc}
\hline Name* & Gender & Age & $\begin{array}{c}\text { Years as PE } \\
\text { teacher }\end{array}$ & $\begin{array}{c}\text { Years as } \\
\text { cooperating } \\
\text { teacher }\end{array}$ \\
\hline Alice & Female & 49 & 25 & 1 \\
Vitor & Male & 46 & 21 & 17 \\
Daniel & Male & 48 & 25 & 9 \\
Nelson & Male & 48 & 25 & 6 \\
Pedro & Male & 58 & 37 & 23 \\
\hline
\end{tabular}

*All names are pseudonyms

\section{Research methods}

For our strategy of inquiry, we used a series of case studies that contributed to an in-depth analysis while safeguarding the personal approach to the topic of study (Flick, 2018). This allowed us to examine the participants' experience as cooperating teachers while providing us with real testimonies of the way they see their own world.

Throughout our research we have used strategies to validate the veracity of our data by adopting peer debriefing. This method is described by Creswell and Creswell (2018) as a procedure that draws on other peoples' interpretation of the data. For that we have selected two specialist professors as peer debriefers. This was done by analysing data resulting from two different interviews.

A log was kept containing all the decisions made along the process of coding to prevent changes in the interpretation of the categories to guarantee reliability of the data. For that same reason, data was discussed between the researchers on regular meetings.

\section{Data analysis}

To achieve the objectives set in the beginning of our study in a coherent and structured way, we performed thematic content analysis to interpret data. This is a harmonious procedure to analyse data resulting from interviews (Bardin, 2011; Flick, 2018).

Using content analysis as our research method required the use of units which we have defined by all the information that fits the category through indicators that the reported facts are true. Therefore, sampling was done by relevance (Krippendorf, 2004). The interview transcripts were read repeatedly in order to identify codes coherent with the referential for ethical-professional attitude. We have re-analysed the transcripts until saturation occurred.

Some of the findings will be highlighted through interview extracts. The interviews were done in Portuguese. The quotations used in this article were translated to English, making it possible to lose context.

\section{Results and Discussion}

We chose to present the results question by question, in an attempt to answer them with some remarks given by the cooperating teachers.

What is your conception of an ethical-professional teaching attitude?

The cooperating teachers have an understanding of the ethical-professional attitude as being inseparable from the human condition, therefore, this attitude is indivisible from the teachers' ethical-professional commitment in the school community and in society. It involves the teachers' conduct towards the students and the surrounding educational community.

"The ethical-professional attitude depends essentially on intrinsic factors, which create an image of the good teachers' profile. It is a behaviour or profile that the teacher never abandons or never gives up, neither 
inside nor outside the school. Once a teacher, always a teacher." - Vitor

They emphasise the requirement of a commitment with professional development, responsibility and high quality of the teaching-learning process. This is in agreement with Castilho (2018), affirming that ethics and the teaching profession go hand in hand by virtue of considering the teaching profession as a profession of human interaction. For him "the teacher is a humanity professional” (Castilho, 2018, p. 232).

What is the importance you attach to the ethicalprofessional attitude during the initial teacher education?

The cooperating teachers interviewed placed high importance on the ethical-professional attitude during the initial teacher education. They consider this an extremely crucial teaching-learning dimension (if not the most important one). These results are in agreement with a cross-country study developed by Maxwell et al. (2016) where more than $90 \%$ of teachers acknowledged the importance of ethics during the initial teacher education curriculum. It is clear in our study that the cooperating teachers also consider the ethical-professional attitude inseparable from the teachers own professional identity formation.

"Probably is the most important. If the student already has or is willing to acquire, or eventually improve, this set of ideas and attitudes, will have his job as a future teacher facilitated. All those who dream or have dreamt of becoming teachers know, consciously or unconsciously, that it is a cornerstone to have a very ethical and professional attitude." Pedro

The ethical-professional attitude indicates the teachers' reason, decision making and action, also characterising the teachers' position towards the educational system (Gluchmanová, 2017). For this reason, it plays a vital role determining the quality of the pre-service teachers' outcome and, therefore, should have its own place during the initial teacher education starting from the first cycle of higher education teaching programs.

Which aspects of ethical-professional attitude do you think are the most relevant pre-service teacher should demonstrate?

Overall, answers given to this question were of three different nature. Some cooperating teachers state that it is important that their pre-service teachers show a set of personal characteristics related to respect for socially accepted values (like personal conduct, respect for human dignity and perseverance). Other cooperating teachers state that it is crucial that pre- service teachers demonstrate professional characteristics (like their conduct and their socially correct relationship with the school community, responsibility, entrepreneurship, critical and reflective capacity).

"How to present yourself, knowledge and transmission of the subjects to teach, commitment to the learning of your students, studying and deepening the subjects where you reveal weaknesses, always being available to students and the school, being critical and reflective, having an impeccable personal conduct inside and outside the school, be kind and understanding, arrive just before an appointment and to always be assiduous." - Pedro

There is also cooperating teachers claiming the importance to show professional attitudes (such as availability for students and school and the commitment to self-training and professional development).

How do you perceive your contribution to the preservice teachers' ethical-professional attitude formation?

The cooperating teachers consider that they contribute to pre-service teachers' ethicalprofessional formation by being an example, leading to the development of ethical attitudes essential to a good teacher, through reflection and orientation of proximity and in a positive learning climate. They consider themselves as a facilitator of the process of professionalism formation of the future teachers.

"With the daily occurrences, I encourage the preservice teachers to reflect on the behaviours and attitudes showed, if those were the most correct for the postposed objective and if they respected the differences of others and, obviously, how to act in the future." - Nelson

It is their belief that their duty is fulfilled by promoting awareness about the ethics of teaching and by setting an example. The cooperating teachers also focus on their carefully performed monitoring, encouraging pre-service teachers' critical thinking on their behaviours, through group debate. The cooperating teachers understand their important role during this particular aspect of initial teacher education, mainly by seeing themselves as examples of personal and professional conduct.

Refer three ethical-professional attitudes that you value the most in your pre-service teachers.

It is important for the cooperating teachers that their pre-service teachers demonstrate personal characteristics (like honesty, solidarity, responsibility and availability) and professional characteristics 
(such as punctuality, be respectful and value the profession). It is also crucial that pre-service teachers are autonomously and proactively committed to their own professional development in order to improve as a teacher. In the eyes of cooperating teachers, preservice teachers must respect the differences between students and manifest this in their teaching practices, be available for the students and school and, as well, for teamwork.

"Availability for students and school, working as a team, searching for professional development and consultation with colleagues in the department group" — Daniel

There is an evident dominance of a relational conception of ethics based on respect and responsibility which is in agreement with Estrela and Caetano's (2012) study.

\section{Conclusion}

Our research focused on cooperating teachers' understanding of their own professional ethics and the pre-service teachers they mentor though the teaching practicum of physical education.

For the cooperating teachers, ethical-professional attitude is a flawless conduct in the school community and society, commitment to self-training and the quality of the teaching-learning process. The cooperating teachers interviewed valued the preservice teachers' personal characteristics as their professional ethics. This is in agreement with Caetano and Silva's (2009) results of teachers associating professional ethics and personal ethics as being one. All cooperating teachers consider the ethicalprofessional attitude extremely important and fundamental during the initial teacher education and assume a position of examples to follow. For Estrela and Caetano (2012) this shows a relational conception of ethics built on respect. However, their notion of ethical-professional attitude is very limited in view of what many authors consider it to be, namely Caetano and Silva (2009) and later Caetano (2017).

These results allow us to agree with Estrela and Caetano (2012) and Gluchmanová (2017) about the importance of ethical training in the initial teacher education programs and lengthen that training to cooperating teachers, considering that they do not require specific training in pedagogical supervision to perform this function (Benites et al., 2012). Regardless of legal establishments and some effort of higher education institutions to attend to them, it is still evident the need for a greater commitment in the ethical-professional training.

\section{Conflict of interest}

The Authors declare that there is no conflict of interest.

\section{Funding}

The authors received no financial support for the research, authorship and/or publication of this article.

\section{Ethics}

All authors made significant contributions to develop this study. To protect the identity of the cooperating teachers, pseudonyms were given to them so they could not be identified. In the beginning of the study all cooperating teachers were asked to read and sign an informed consent.

\section{References}

Albuquerque, A., Graça, A., \& Januário, C. (2005). A supervisão pedagógica em educação física. A perspectiva do orientador de estágio. Lisboa: Livros Horizonte.

Bardin, L. (2011). Análise de conteúdo. São Paulo: Edições 70.

Benites, L., Neto, S., Borges, C., \& Cyrino, M. (2012). Qual o papel do professo-colaborador no contexto do estágio curricular supervisionado na Educação Física? Revista Brasileira Ciência $e$ Movimento, 20(4), 13-25.

Caetano, A. P. (2017). Ética e complexidade na formação de professores. Revista Diálogo Educacional, 17(52), 797-821. doi: 10.7213/1981416X.17.053.AO05

Caetano, A. P., \& Silva, M. L. (2009). Ética profissional e formação de professores. Revista de Ciências da Educação, 8, 49-60.

Castilho, S. (2018). Para uma ética prática da profissão docente. in M. C. Neves, \& D. Justino (2018). Ética aplicada: Educação (pp. 217-230). Lisboa: Edições 70.

Clarke, A., \& Collins, S. (2007). Complexity science and student teacher supervision. Teaching and Teacher Education, 23(2), 160-172. doi: 10.1016/j.tate.2006.10.006

Creswell, J. W., \& Creswell, J. D. (2018). Research design: Qualitative, quantitative, and mixed methods approaches ( $5^{\text {th }}$ Ed.). Los Angeles: Sage Publications.

Estrela, M. T., \& Caetano, A. P. (2012). Reflexões sobre a formação ética inicial de professores. Interacções, 21, 219-230.

Figueiredo, Z. (2010). Experiências profissionais, identidades e formação docente em educação física. Revista Portuguesa de Educação, 23(2), 153-171. 
Flick, U. (2018). An introduction to qualitative research $\left(6^{\text {th }}\right.$ Ed.). London: Sage Publications.

Formosinho, J. (2009). Formação de professores: Aprendizagem profissional e acção docente. Porto: Porto Editora.

Gluchmanová, M. (2017). Theoretical and practical aspects of a professional ethics of teaching. Human Affairs, 27(1), 75-81. doi: 10.1515/humaff-2017$\underline{0007}$

Graber, K. C. (1995). The influence of teacher education programs on the beliefs of student teachers: general pedagogical knowledge, pedagogical content knowledge, and teacher education course work. Journal of Teaching in Physical Education, 14(2), 157-178. doi: 10.1123/jtpe.14.2.157

Hushman, G. (2013). Investigating the impact of teacher socialization on a physical education teacher candidate during the student teaching process. Teacher Education Quarterly, 40(4) 81-92.

Koster, B., Brekelmans, M., Korthagen, F., \& Wubbels, T. (2005). Quality requirements for teacher educators. Teaching and Teacher Education, 21(2), 157-176. doi: 10.1016/j.tate.2004.12.004

Krippendorff, K. (2004). Content analysis: An introduction to its methodology ( $2^{\text {nd }} \mathrm{ed}$; pp. 105-119). California: Sage Publications.

Machado, M., Matos, Z., Monteiro, I., \& Batista, P. (2015). Estilos de supervisão e reflexão no estágio em educação física. Journal of Sport Pedagogy and Research, 1(3), 30-39.

Maxwell, B., Tremblay-Laprise, A. A., Filion, M., Boon, H., Daly, C., van den Hoven, M., Heilbronn, R., Lenselink, M., \& Walters, S. (2016). A fivecountry survey on ethics education in preservice teaching programs. Journal of Teacher Education, 67(2), 135-151. doi.: 10.1177/0022487115624490

McCaughtry, N., Kulinna, P. H., Cothran, D., Martin, J., \& Faust, R. (2005). Teachers mentoring teachers: A view over time. Journal of Teaching in Physical Education, 24(4), 326-343. doi: $\underline{10.1123 / \text { jtpe. } 24.4 .326}$

Moreira, A. (2004). O papel da supervisão numa pedagogia para a autonomia. in F. Vieria, et al. (org.) (2004). Pedagogia para a autonomia: Resistir e agir estrategicamente. Actas do encontro do grupo de trabalho - Pedagogia para a autonomia 2 (pp. 133147). Braga: CIEd,

Pacheco, J. A., \& Flores, M. A. (1999). Formação e avaliação de professores. Porto: Porto Editora.

Pérez-Castro, J. (2010). Elementos para la reflexión en torno a la ética profesional de los estudiantes de posgrado. Revista Electrónica de Investigación Educativa, 12(Número Especial 2). Retrieved from: https://redie.uabc.mx/redie/article/view/253
Schwimmer, M., \& Maxwell, B. (2017). Codes of ethics and teachers' professional autonomy. Ethics and Education, 12(2), 141-152. doi: $10.1080 / 17449642.2017 .1287495$

Willemse, M., Lunenberg, M., \& Korthagen, F. (2005). Values in education: A challenge for teachers educators. Teaching and Teacher Education, 21, 205217 


\title{
Coach-Athletes Communication: Data from the
}

\section{Communication Behaviors Evaluation System}

\author{
A. Rui Gomes ${ }^{1}$, Albino Almeida ${ }^{2}$, Rui Resende ${ }^{3}$, Catarina Morais ${ }^{4}$ \\ ${ }^{1}$ University of Minho, School of Psychology. Portugal. \\ 2 Adaptation, Performance, and Human Development Research Group. Portugal. \\ ${ }^{3}$ University Institute of Maia. Portugal. Life Quality Research Centre (CIEQV Centro de Investigação em \\ Qualidade de Vida). \\ ${ }^{4}$ Research Centre for Human Development, Faculty of Education and Psychology, Universidade Católica \\ Portuguesa. Portugal.
}

\begin{tabular}{|c|c|}
\hline $\begin{array}{l}\text { Palavras-chave } \\
\text { Comunicação de } \\
\text { treinadores, } \\
\text { Desempenho, } \\
\text { Treinadores, } \\
\text { Liderança. }\end{array}$ & $\begin{array}{l}\text { RESUMO } \\
\text { Este estudo analisa a comunicação entre treinadores e atletas, utilizando o Sistema de } \\
\text { Avaliação de Comportamentos de Comunicação (SACC). Este sistema proporciona uma } \\
\text { perspetiva ampla das interações entre treinadores e atletas, considerando a perspetiva de } \\
\text { ambos e de observadores. Os comportamentos foram avaliados através do Questionário de } \\
\text { Comportamentos Comunicacionais (QCC), versão para treinador, atletas e observador. O } \\
\text { estudo incluiu } 64 \text { atletas de futsal masculino, com idades entre } 13 \text { e } 43 \text { anos }(M=18.98 \text {, } \\
D P=7.05 \text { ) e os seus treinadores, do sexo masculino, com idades entre } 29 \text { e } 43 \text { anos ( } M= \\
35.75, D P=5.26 \text { ). Os resultados revelaram seis aspetos: (1) o CBQ assumiu uma estrutura } \\
\text { de dois fatores (comportamentos positivos e negativos), mas um item foi suprimido; (2) os } \\
\text { treinadores assumiram comportamentos positivos com mais frequência do que } \\
\text { comportamentos negativos; (3) os comportamentos espontâneos positivos foram } \\
\text { ligeiramente mais frequentes do que os comportamentos reativos positivos; (4) os } \\
\text { treinadores avaliaram-se como apresentando mais comportamentos reativos negativos do } \\
\text { que comportamentos espontâneos negativos; (5) feedback positivo e incentivo após } \\
\text { insucesso foram os comportamentos positivos mais frequentes; (6) feedback negativo foi o } \\
\text { comportamento negativo mais frequente. O SACC assumiu-se como uma ferramenta útil } \\
\text { para avaliar a comunicação entre treinadores e atletas. }\end{array}$ \\
\hline
\end{tabular}

Keywords

Coaches' communication, Performance, Sports coaches, Sports leadership.

\section{ABSTRACT}

This study analyzes coach-athletes' communication using the Communication Behaviors Evaluation System (CBES). This system provides a broad and complete perspective regarding the interactions between coaches and athletes by including data from coaches, athletes and from an observer. The CBES was used to monitor the communication between coaches and athletes from four different teams, during one game (observation). Athletes and coaches evaluated their communication behaviors using the Communication Behaviors Questionnaire (CBQ). The study included sixty-four futsal male athletes aged between 13 and 43 years-old $(M=18.98, S D=7.05)$ and their coaches, all male and aged between 29 and 43 years-old $(M=35.75, S D=5.26)$. Results revealed six important aspects: (1) the CBQ assumed a two-factor structure of positive and negative behaviors but one item has deleted; (2) coaches assumed positive behaviors more frequently than negative behaviors; (3) positive spontaneous behaviors were slightly more frequent than positive reactive behaviors; (4) coaches perceived themselves as displaying more negative reactive behaviors than negative spontaneous behaviors; (5) positive feedback and encouragement after failure were the most frequent positive behaviors; and (6) negative feedback was the most frequent negative behavior. In sum, CBES assumed to be a useful tool to evaluate coaches-athletes' communication. 


\section{Introduction}

Coaches' ability to communicate in an effective way is critical because almost all tasks involved in leading athletes require high communication skills from coaches. In fact, they need to effectively communicate to be able to transmit their goals and philosophy of coaching to athletes, both in training sessions and during competitions. Equally important, coaches' ability to communicate promotes on athletes the perception that the coach is trustworthy and respectful (Jowett \& Felton, 2013). Because of that, researchers still dedicate a significant amount of effort to explain the communication process between coaches and athletes.

In a review of coaching science research from 1970 to 2001, Gilbert and Trudel (2004) concluded that the study of coaching behavior was the main area under investigation, including systematic observation methods of coaching behaviors. McKenzie and van der Mars (2015) argue that systematic observation of coaching behaviors offers enormous potential by delivering contextually rich information about coachathletes' interactions. A more recent systematic review of observation methods in coaching research between 1997 and 2016, identified 26 studies using several instruments, reporting that the most common were the Arizona State University Observation Instrument (ASUOI) and the Coach Analysis Intervention System (CAIS) (Cope, Partington, \& Harvey, 2017).

In the Arizona State University Observation Instrument, the categories of pre-instruction, concurrent instruction, and post instruction represented $55 \%$ of all the recorded behavioral intervals (Potrac, Jones, \& Cushion, 2007). On the other hand, the Coach Analysis and Intervention System (CAIS) developed by Cushion and colleagues (2012) is a multidimensional and hierarchical analysis system that identifies specific behaviors occurring in complex coaching environments. This system allows to evaluate 23 primary behaviors related to physical behavior, feedback/reinforcement, instruction, verbal/non-verbal, questioning, and management.

Another coding system extensively used in literature of youth sports coaching is the Coach Behavior Assessment System (CBAS) developed by Smith, Smoll, and Hunt (1977) which evaluates the behaviors of athletic coaches in naturalistic settings. The system consists of 12 behavioral categories derived from content analyses of coaching behaviors during practices and games. The behaviors are subdivided into reactive and spontaneous categories: reinforcement and nonreinforcement are behaviors that occur in response to positive behaviors or effort of athletes; mistake contingent technical instruction, mistake-contingent encouragement, punishment, punitive technical instruction, and ignoring mistakes occur in response to athletes' mistakes and errors; and keeping control occurs as response to their misbehaviors. Spontaneous behavioral categories included general technical instruction, general encouragement, organization, and general communication (Cumming, Smith, \& Smoll, 2006). More recently, Turnnidge and Côté (2019) developed a systematic observation instrument called Coach Leadership Assessment System (CLAS), which aims at examining coaches' leadership behaviors in sports. This system consists of 18 behavioral categories across five higher-order dimensions: transformational (11 codes), transactional ( 2 codes), neutral ( 1 code), laissez-faire ( 1 code), and toxic ( 2 codes) coaching, as well as one non-codable category.

All in all, these coding systems reinforce the need to continue evaluating coach and athletes' interactions for two main reasons. First, these systems provide useful information about coaches' "communication profiles" that can be related to measures of wellbeing and performance of athletes, answering to the question "Are there optimal and suboptimal profiles of coaches' communication?" Second, they also offer useful information about how to educate coaches to assume the role of coaching, answering to the question "What communication behaviors should be included in coaching educational programs?"

In this study, we aim to extend current knowledge on coaches and athletes communication by evaluating the communication behaviors of four coaches and respective athletes. For that, we propose, for the first time, the Communication Behaviors Evaluation System (CBES) that evaluates 16 communication behaviors, divided into two axes: (a) impact axis: includes positive behaviors and negative behaviors, and (b) initiative axis: includes spontaneous and reactive behaviors (see Figure 1). The impact axis encompasses behaviors that can facilitate or debilitate the communication between two or more people, while the initiative axis encompasses behaviors that are first delivered by one person and behaviors that are delivered by one person in response to others' behaviors.

The definition of the 16 proposed behaviors is displayed on Figure 2. Our system tries to improve current knowledge on communication behaviors in five aspects: (i) the proposed behaviors are very substantial, expanding the focus on technical behaviors assumed by leaders, particularly in sport context; (ii) the proposed behaviors are very wide, including transformational behaviors (as, for, example, positive vision) and transactional behaviors (as for, example, positive feedback) that have been established in literature as important dimensions to explain leaders behaviors (Gomes, 2014); (iii) the proposed behaviors evaluate potential negative behaviors assumed by leaders in a very descriptive way, by including six behaviors; (iv) the proposed behaviors allow to better comprehend the magnitude of interactions that facilitate or debilitate the 
communication process; (v) the proposed behaviors allow to better comprehend the magnitude of interactions that are initiated or responded by the leader; and (vi) the proposed behaviors are evaluated from the perspective of the leaders, the followers, and from the observer point of view.

\begin{tabular}{|c|c|c|c|}
\hline \multirow{4}{*}{ 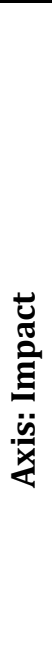 } & & \multicolumn{2}{|c|}{ Axis: Initiative } \\
\hline & & Spontaneous & Reactive \\
\hline & 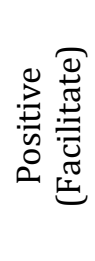 & $\begin{array}{l}\text { 1. Positive vision } \\
\text { 2. Encouragement } \\
\text { 3. Positive instruction } \\
\text { 4. Comprehension }\end{array}$ & $\begin{array}{l}\text { 5. Positive feedback } \\
\text { 6. Keeping control } \\
\text { 7. Comprehension after failure } \\
\text { 8. Disagreement } \\
\text { 9. Corrective positive instruction } \\
\text { 10. Encouragement after failure }\end{array}$ \\
\hline & 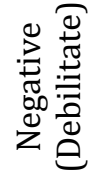 & $\begin{array}{l}\text { 11. Negative vision } \\
\text { 12. Negative instruction } \\
\text { 13. Indifference }\end{array}$ & $\begin{array}{l}\text { 14. Corrective negative instruction } \\
\text { 15. Ignore successes } \\
\text { 16. Negative feedback }\end{array}$ \\
\hline
\end{tabular}

Figure 1. Axes of the Communication Behaviors Evaluation System (CBES).

The CBES was used in this study for the first time to evaluate the behaviors assumed by four coaches of athletes in different age groups, from young to adult athletes. We evaluate four teams in order to augment the magnitude of data collection and to analyze potential changes on communication behaviors according to the ages of athletes. Specifically, our study has three goals: (a) Testing the structure of the coding system of behaviors evaluated in the CBES; (b) Analyzing the magnitude of each behavior included in the CBES, by using three distinct sources of information (coach, athletes, and observation); and (c) Analyze the fluctuations on perceived performance of coaches and athletes, and relate the date with communication behaviors included in the CBES.

\footnotetext{
Communication behaviors of the CBES

1. Positive vision: communication centered on optimism regarding what can be achieve.

2. Encouragement: communication centered on incentivizing success and improvement.

3. Positive instruction: communication centered on focusing on what needs to be improved.

4. Comprehension: communication centered on focusing on understanding ideas, expectations, and desires of others).

5. Positive feedback: communication centered on reinforcing and recognizing others' efforts.

6. Keeping control: communication centered on reestablishing order and calmness.

7. Comprehension after failure: communication centered on understanding ideas, expectations, and desires of others following failure or uncomfortable situation.

8. Disagreement: communication centered on assertive and respectful statement of disagreement.

9. Corrective positive instruction: communication centered on corrective but positive instruction after a failed action.

10. Encouragement after failure: communication centered on support and incentive following a failed action.

11. Negative vision: communication centered around pessimism regarding what can be achieved.

12. Negative instruction: communication centered on what needs to be avoided or not done.

13. Indifference: communication centered on ignorance or limiting the expression of ideas, expectations, or desires.

14. Corrective negative instruction: communication centered on corrective and negative instruction that follows a failed action.

15. Ignore successes: communication centered on failing to recognize or devaluating others' efforts

16. Negative feedback: communication centered on showing disapproval and/or irritation.
}

Figure 2. Definition of the CBES' Communication behaviors. 


\section{Methods}

\section{Participants}

This study included sixty-four futsal male athletes of one club in Madeira Island, Portugal. Athletes were aged between 13 and 43 years-old $(M=18.98, S D=$ 7.05 ) and belonged to four different teams (all in the Regional Honor Division), according to their age group (cf. Table 1). Their number of practice years ranged between 1 and 15 years $(M=4.58, S D=3.78)$, and their titles between 0 and $1(M=0.11, S D=0.32)$. Athletes respective coaches also agreed to participate in the study. Only $23 \%$ of athletes were playing futsal with their respective coach for more than 1 year $(M=$ $1.30, S D=0.58)$, and only seven athletes of Team 3 achieved a title with the current coach. Coaches' profiles are displayed in Table 2. All coaches were male, aged between 29 and 43 years-old $(M=35.75$, $S D=5.26)$.

Table 1. Athletes Demographic Characteristics

\begin{tabular}{|c|c|c|c|c|}
\hline & $\begin{array}{c}\text { Team } 1 \\
\text { U15 }\end{array}$ & $\begin{array}{c}\text { Team } 2 \\
\text { U17 }\end{array}$ & $\begin{array}{c}\text { Team } 3 \\
\text { U19 }\end{array}$ & $\begin{array}{l}\text { Team } 4 \\
\text { Adults }\end{array}$ \\
\hline Number of athletes & 18 & 16 & 16 & 14 \\
\hline Age range & $13-15$ & $15-17$ & $17-20$ & $20-43$ \\
\hline $\operatorname{Age}(M ; S D)$ & $13.67(0.69)$ & $15.75(0.86)$ & $18.19(0.91)$ & $30.43(6.70)$ \\
\hline Practice years $(M ; S D)$ & $2.72(1.45)$ & $2.75(1.44)$ & $4.19(2.56)$ & $9.50(4.60)$ \\
\hline$N$ of years with current coach $(M ; S D)$ & $1(0.00)$ & $1(0.00)$ & $1.69(0.87)$ & $1.57(0.51)$ \\
\hline Current championship ranking & $2^{\text {nd }}$ place & $1^{\text {st }}$ place & $2^{\text {nd }}$ place & $2^{\text {nd }}$ place \\
\hline
\end{tabular}

Table 2. Coaches Demographic Characteristics

\begin{tabular}{lcccc}
\hline & Team 1 & Team 2 & Team 3 & Team 4 \\
U15 & U17 & 33 & 38 & 43 \\
\hline Age & 29 & 1 & 10 & 2 \\
Number of years as futsal coach & 1 & 1 & 5 & 2 \\
Number of years coaching the current team & 1 & & 2 \\
\hline
\end{tabular}

\section{Procedure}

Once permission was obtained from the club, the second author - who was responsible for data collection - met with each team and their respective coaches to explain the aim of the study and to collect their individual consent. Legal guardians of underage athletes were also contacted to provide consent. The study included a multidimensional approach. On one hand, subjective data were collected through selfreported questionnaires completed by both athletes and coaches. Athletes completed a short questionnaire assessing their coach typical communication behaviors throughout the season, as well as their perceptions regarding their individual and collective performance during the season; whilst coaches fulfilled a short questionnaire indicating their perceptions regarding their typical communication behaviors throughout the season and their perceptions on the team's collective performance during this period. On the other hand, a more objective measure was used to evaluate coaches' communicational behavior - specifically, their communication behavior during a match was registered using an observation sheet.

The futsal seasons in Portugal occur from OctoberJune and data were collected in February. Coach and athletes filled out the instruments independently, thinking about the communication behaviors assumed by coaches until that moment. Then, coaches received a training workshop on leadership and communication behaviors between the completion of the self-reported questionnaires (which occurred before) and their game observation (which occurred after this training). Finally, the observation occurred during only one game after coaches' workshop. The original plan for this study was a longitudinal design with several evaluations of coaches' communication behaviors. Thus, the idea was that coaches received continuous feedback and training on leadership and communication throughout the season to increase their positive communication behaviors and decrease the frequency of negative behaviors. However, due to COVID-19 pandemic, this was not possible and, because the season ended 
earlier, data was collected only once (cross-sectional study).

\section{Instruments}

Communication Behaviors Questionnaire (CBQ; Gomes, 2019). The CBQ evaluates coaches' communication behaviors into different behaviors based on two axes: (a) initiative, which refers to whether the communication was initiated by the individual (spontaneous) or as a response/result of a communication behavior assumed by another person (reactive); (b) impact of communication that can be either positive or negative. The intersection of initiative and impact results on 16 communication behaviors, organized on four dimensions. Dimension one refers to spontaneous positive communication behaviors and includes (1) positive vision: communication centered on optimism regarding what can be achieved; (2) encouragement: communication centered on incentivizing success and improvement; (3) positive instruction: communication centered on focusing on what needs to be improved, and; (4) comprehension: communication centered on focusing on understanding ideas, expectations, and desires of others. Dimension two refers to reactive positive communication and includes: (5) positive feedback: communication centered on reinforcing and recognizing others' efforts; (6) keeping control: communication centered on reestablishing order and calmness; (7) comprehension after failure: communication centered on understanding ideas, expectations, and desires of others following failure or uncomfortable situation, (8) disagreement: communication centered on an assertive and respectful statement of disagreement, (9) corrective positive instruction: communication centered on corrective but positive instruction after a failed action, and (10) encouragement after failure: communication centered on support and incentive following a failed action. Dimension three refers to spontaneous negative communication and includes: (11) negative vision: communication centered around pessimism regarding what can be achieved; (12) negative instruction: communication centered on what needs to be avoided or not done, and; (13) indifference: communication centered on ignorance or limiting the expression of ideas, expectations, or desires. Finally, Dimension four refers to reactive negative communication, and includes (14) corrective negative instruction: communication centered on corrective and negative instruction that follows a failed action; (15) ignore successes: communication centered on failing to recognize or devaluating others' efforts, and; (16) negative feedback: communication centered on showing disapproval and/or irritation. This instrument can be applied in two different ways. The first one is as a self-report questionnaire, in which participants rate their agreement $(1=$ completely disagree, $5=$ completely agree) with sixteen different statements, one for each communication behavior. The coaches completed this version self-assessing their behavior throughout the season, and athletes answered assessing their coaches' behavior. The second version of the application refers to the assessment of these behaviors through observation. Therefore, an experienced observer completed the observation spreadsheet. Exploratory Factor Analysis (with principal component factor analysis) with Varimax rotation revealed two dimensions related to the positive and negative impacts of communication $(K M O=.764 ;$ Bartlett's Test $=564.224, d f=105, p<$ .001 ; Explained variance $=56 \%$ ). However, this solution was achieved after deleting item 11 of negative vision due to double saturation in both factors. This item was removed from the analysis of athletes and coaches' results (for congruence sake) but not from observation results because the methodology of data collection was different in this last case. Alpha values were acceptable for positive $(\alpha=.90)$ and negative $(\alpha=.83)$ dimensions of communication behaviors.

Sport Performance Perception Questionnaire (SPPQ; Gomes, 2016). The SPPQ was used to evaluate perceptions regarding sport performance. Athletes rated their agreement $(1=$ completely disagree, $5=$ completely agree) with 10 different statements regarding their perceptions of their individual (5 items, e.g., "I had the performance I wanted", $\alpha=.86$ ) and collective performance (5 items, e.g., "The team had the performance we wanted", $\alpha=.80$ ) throughout the season. Coaches answered only to the collective performance dimension. Exploratory Factor Analysis (with principal component factor analysis) with Varimax rotation, revealed two dimensions related to perceptions of individual and collective performance $(K M O=.822 ;$ Bartlett's Test $=286.285, d f=45, p<$ .001 ; Explained variance $=61 \%$ ). Alpha values were acceptable for individual $(\alpha=.86)$ and collective $(\alpha=$ $.80)$ dimensions of SPPQ.

\section{Results}

\section{Data Analysis Strategy}

When comparing athletes' perceptions among the different coaches' communication behaviors and their sport performances, paired-sample t-tests and repeated-measures ANOVAs were conducted (as the normality assumption was not violated: $-0.34>s k<$ $1.89,-0.21>k<3.25$; cf. Kline, 2011). When comparing athletes' perceptions across teams, Kruskal-Wallis test was conducted due to the low $n$ of athletes in each team. Only results with a $p$-value below .05 after Bonferroni corrections are reported as significant. However, no statistical tests were conducted when comparing coaches and athletes' perceptions, coaches' perceptions across teams, or observations across teams, as no sufficient $n$ was 
collected (4 coaches, 1 observation). Thus, conclusions were cautiously drawn from the averages.

\section{Coaches' Overall Communication Behaviors}

According to athletes' perceptions, coaches presented positive behaviors more frequently than negative behaviors $\left[M_{\text {positive }}=4.40, S D=0.78 ; M_{\text {negative }}=1.53\right.$, $S D=0.94, t(63)=20.48, p<.001, g=4.35]$. This is consistent with both coaches' perceptions $\left(M_{\text {positive }}=\right.$ $\left.4.25, S D=0.68 ; M_{\text {negative }}=1.85, S D=0.68\right)$, and with the observation $\left(M_{\text {positive }}=15.01 \%, M_{\text {negative }}=\right.$ $3.54 \%$ ). When examining the four dimensions of the communication behavior, both athletes and coaches presented the same pattern by perceiving the positive spontaneous behaviors as slightly more frequent than the positive reactive behaviors; however, the repeated-measures ANOVA showed that this difference was not statistically significant for athletes [athletes: $M_{\text {spontaneous }}=4.44, S D=0.77, M_{\text {reactive }}=$ 4.37, $S D=0.80 ; F(1,63)=326.17, p<.001, \eta \mathrm{p} 2=$ $.838 ;$ p $_{\text {post-hoc }}=1.00 ;$ coaches: $M_{\text {spontaneous }}=4.38, S D$ $\left.=0.62, M_{\text {reactive }}=4.17, S D=0.72\right]$. These perceptions are in accordance with the observation $\left(M_{\text {spontaneous }}=\right.$ $9.12 \%, M_{\text {reactive }}=7.06 \%$ ). Regarding the negative behaviors, athletes perceived a similar prevalence of negative spontaneous and reactive communication behaviors $\left(M_{\text {spontaneous }}=1.56, S D=0.96 ;\right.$ Mreactive $=$ $\left.1.51, S D=0.92, p_{\text {post }-h o c}=1.00\right)$. On the other hand, coaches' perceptions perceive themselves as displaying more negative reactive $(M=2.08, S D=$ $0.95)$ than negative spontaneous behaviors $(M=1.50$, $S D=0.50)$, which is supported by the observation $\left(M_{\text {reactive }}=4.31 \% ; M_{\text {spontaneous }}=2.76 \%\right)$.

When looking specifically to the means of positive behaviors, athletes and coaches have similar perceptions: both perceived reactive behaviors as more frequent, specifically positive feedback and encouragement after failure as some of the more frequent behaviors (athletes added the corrective positive instructions, while coaches perceived more encouragement (cf. Table 3). Both athletes and coaches also perceived keeping control as the least frequent positive behavior. The results of the observation (cf. Table 4) point out that, indeed, positive feedback is one of coaches' more frequent communication behaviors. However, the other top two behaviors referred to encouragement (which is in accordance with coaches' perceptions) and positive instruction, whilst the least frequent positive behaviors referred to comprehension, disagreement and comprehension after failure. Athletes' perceptions regarding coaches' negative communication behavior are very similar, slightly highlighting negative feedback as more frequent. Coaches agreed with this perception and considered negative feedback a somewhat frequent communication behavior (cf. Table 3). Coaches perceptions are supported by the observation, as over
$7 \%$ of coaches' communication behavior refer to negative feedback (cf. Table 3).

\section{Coaches' Communication Behavior: Differences Among Teams}

The observation results showed that, regarding positive spontaneous behaviors, encouragement was the most frequent communication behavior displayed by coaches across the four teams. This result is consistent with athletes' and coaches' perceptions for Team 1 and Team 2, as both athletes and coaches perceived encouragement as the most frequent behavior. In Team 3, athletes perceived positive instruction and coaches positive vision as the more frequent behavior displayed by the coach, contradicting the observation results. In Team 4, a different pattern arises: both athletes and the coach perceived comprehension as the more frequent behavior; however, the coach of this team equally highlights the display of encouragement (cf. Table 4). It is important to note that, across teams, only one difference arises as statistically significant: Athletes from Team 1 athletes perceived encouragement as more frequent than athletes from Team $4, H(3)=$ $11.93, p=.008, p_{\text {post-hoc }}=.033$ (all other $H<7.62, p>$ $.055)$.

Regarding positive reactive behaviors, the observation results showed that positive feedback is the most common communication behavior displayed by the coaches of Team 1,2 and 3; while for the Team 4 coach, keeping control and corrective positive instruction appeared more often. Team 1 athletes have a consistent perception with the observation; however, their coach perceived comprehension and encouragement after failure as more common behaviors, which is not in accordance with the observation and his athletes' perceptions. On Team 2, coaches perceived positive feedback (alongside with encouragement after failure and corrective positive instruction) as the most frequent behavior they display, which is aligned with the observation, while his athletes perceived comprehension after failure and corrective positive instruction as more frequent communication behaviors of their coach. A discrepancy between athletes' and coach's perception also happens with Team 3: while the coach referred positive feedback as the most frequent behavior (perception supported by the observation), athletes referred corrective positive instruction and encouragement after failure. In Team 4 , both athletes and coach perceived disagreement and encouragement after failure as the more frequent behaviors, contradicting the observation results. When comparing athletes' perceptions across teams, a difference between Team 1 and Team 4 arises again, as the former perceives positive feedback as more frequent than the latter $\left[H(3)=8.56, p=.036, p_{\text {post-hoc }}\right.$ $=.024$, all other $H<6.58, p>.087]$. 


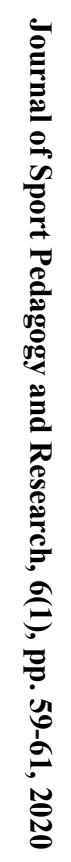

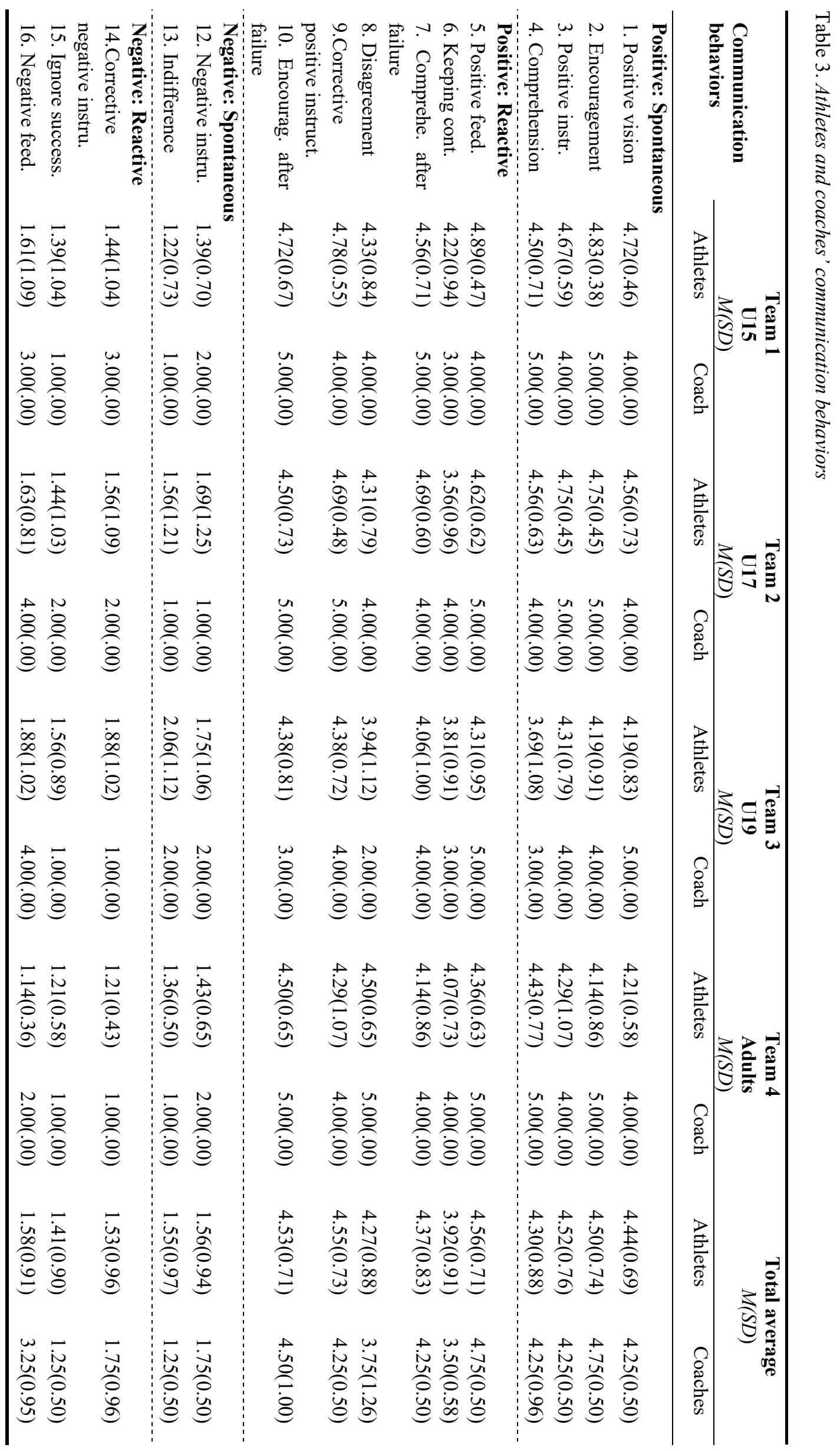

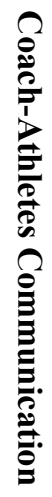


Table 4. Coaches behaviors: Observation results

\begin{tabular}{|c|c|c|c|c|c|}
\hline communication & $\begin{array}{c}\text { Team } 1 \\
\text { U15 } \\
(n ; \%)\end{array}$ & $\begin{array}{c}\text { Team } 1 \\
\text { U17 } \\
(n ; \%)\end{array}$ & $\begin{array}{c}\text { Team } 3 \\
\text { U19 } \\
(n ; \%)\end{array}$ & $\begin{array}{c}\text { Team } 4 \\
\text { Adults } \\
(n ; \%)\end{array}$ & $\begin{array}{c}\text { Average } \\
(n ; \%)\end{array}$ \\
\hline \multicolumn{6}{|l|}{ Spontaneous (positive) } \\
\hline 1. Positive vision & $7.59 \%$ & $10.85 \%$ & $6.45 \%$ & $7.61 \%$ & $8.12 \%$ \\
\hline 2. Encouragement & $11.72 \%$ & $11.63 \%$ & $10.48 \%$ & $13.04 \%$ & $11.72 \%$ \\
\hline 3. Positive instruction & $11.03 \%$ & $10.08 \%$ & $11.29 \%$ & $9.78 \%$ & $10.55 \%$ \\
\hline 4. Comprehension & $6.21 \%$ & $6.98 \%$ & $5.65 \%$ & $5.43 \%$ & $6.07 \%$ \\
\hline \multicolumn{6}{|l|}{ Reactive (positive) } \\
\hline 5. Positive feedback & $12.41 \%$ & $10.85 \%$ & $12.90 \%$ & $7.61 \%$ & $10.94 \%$ \\
\hline 6. Keeping control & $4.14 \%$ & $5.43 \%$ & $5.65 \%$ & $9.78 \%$ & $6.25 \%$ \\
\hline 7. Comprehension after failure & $4.83 \%$ & $3.88 \%$ & $3.23 \%$ & $4.35 \%$ & $4.07 \%$ \\
\hline 8. Disagreement & $4.14 \%$ & $6.98 \%$ & $7.26 \%$ & $5.43 \%$ & $5.95 \%$ \\
\hline 9. Corrective positive instruction & $4.83 \%$ & $6.20 \%$ & $8.06 \%$ & $9.78 \%$ & $7.22 \%$ \\
\hline 10. Encouragement after failure & $8.97 \%$ & $7.75 \%$ & $7.26 \%$ & $7.61 \%$ & $7.90 \%$ \\
\hline \multicolumn{6}{|l|}{ Spontaneous (negative) } \\
\hline 11. Negative vision & $2.07 \%$ & $2.33 \%$ & $4.03 \%$ & $1.09 \%$ & $2.38 \%$ \\
\hline 12. Negative instruction & $6.90 \%$ & $3.88 \%$ & $1.61 \%$ & $2.17 \%$ & $3.64 \%$ \\
\hline 13. Indifference & $2.07 \%$ & $2.33 \%$ & $2.42 \%$ & $2.17 \%$ & $2.25 \%$ \\
\hline \multicolumn{6}{|l|}{ Reactive (negative) } \\
\hline 14. Corrective negative instruction & $3.45 \%$ & $1.55 \%$ & $4.84 \%$ & $3.26 \%$ & $3.27 \%$ \\
\hline 15. Ignore successes & $1.38 \%$ & $1.55 \%$ & $3.23 \%$ & $3.26 \%$ & $2.35 \%$ \\
\hline 16. Negative feedback & $8.28 \%$ & $7.75 \%$ & $5.65 \%$ & $7.61 \%$ & $7.32 \%$ \\
\hline
\end{tabular}

The observation showed that negative instruction was the most frequent spontaneous negative communication behavior in coaches of Team 1,2 and 4. This behavior is particularly salient in Coach of Team 1, while negative vision appeared more often in the Team 3 coach. Even though the overall perceived frequency of these type of behaviors is low for both coaches and athletes (all $M<2.01$ ), negative instruction was perceived by athletes and coaches of all teams as appearing slightly more often, except for Team 3, in which athletes perceived indifference as being displayed by the coach more often than negative instruction. Interestingly, when looking at differences across teams, Team 3 athletes perceived indifference as significantly more often displayed than athletes from Team $1[H(3)=9.26, p=.026$, $p_{\text {post-hoc }}=.035$; negative instruction: $H(3)=1.10, p=$ .777]. Finally, regarding negative reactive communication behaviors, the observation results showed that negative feedback was the most frequent behavior coaches displayed across the four teams. With the exception of the coach of Team 4, who does not perceive himself to behave this way, all coaches believed that they provide negative feedback to athletes more often than what athletes perceive it. Particularly, coaches of Team 2 and 3 considered that they displayed negative feedback quite often, which contradicts their athletes' perceptions. There are no 
statistically significant differences in athletes' perceptions of coaches negative reactive communication behaviors across teams (all $H<5.76$, $p>.124)$.

\section{Teams' and Coaches' Performance Perceptions}

When looking to athletes' perceptions regarding their individual and collective performance, it can be concluded that they perceived collective performance as higher than individual performance $\left[M_{\text {collective }}=\right.$ $3.95, S D=0.91 ; M_{\text {individual }}=3.67, S D=1.03, t(63)=$
3.23, $p=.002, g=0.38$ ], and this pattern was consistent across the four teams (cf. Table 5). Differences between teams regarding individual $[F$ $(3,60)=0.94, p=.430]$ and collective performance are not significant $[F(3,60)=0.85, p=.471]$. Interestingly, athletes' perceptions of their collective performance are inferior $(M=3.95, S D=0.91)$ to the respective team coach $(M=4.15, S D=0.91)$, with exception of the coach of Team 4 , in which athletes and coach present the same score.

Table 5. Athletes and coaches sport performance perceptions

\begin{tabular}{|c|c|c|c|c|c|}
\hline \multirow{4}{*}{$\begin{array}{l}\text { SPPQ } \\
\text { Sport Performance } \\
\text { Perceptions }\end{array}$} & Team 1 & Team 2 & Team 3 & $\begin{array}{l}\text { Team } 4 \\
\end{array}$ & Total \\
\hline & U15 & U17 & U19 & Adults & average \\
\hline & $M(S D)$ & $M(S D)$ & $M(S D)$ & $M(S D)$ & $M(S D)$ \\
\hline & Athletes & Athletes & Athletes & Athletes & Athletes \\
\hline $\begin{array}{l}\text { Individual } \\
\text { Performance }\end{array}$ & $3.90(0.97)$ & $3.52(1.16)$ & $3.73(1.05)$ & $3.49(0.86)$ & $3.67(1.03)$ \\
\hline $\begin{array}{l}\text { Collective } \\
\text { Performance }\end{array}$ & $4.14(0.82)$ & $3.91(0.85)$ & $3.88(0.97)$ & $3.81(0.96)$ & $3.95(0.91)$ \\
\hline \multirow{2}{*}{$\begin{array}{l}\text { Collective } \\
\text { Performance }\end{array}$} & Coach & Coach & Coach & Coach & Coaches \\
\hline & 4.20 & 4.40 & 4.20 & 3.80 & $4.15(0.65)$ \\
\hline
\end{tabular}

\section{Discussion}

This study tested a new system of communication behaviors codification for the first time. This system was applied in the context of a collective sports with athletes of different ages and our data suggests four main conclusions.

First, the CBES offered promising indications of validity dividing the coaching behaviors by the impact produced in the communication process (positive or negative). However, item 11 of negative vision needs to be reformulated to better capture the intrinsic meaning of this communication behavior. Nevertheless, the system seems to capture the phenomenon (56\% of explained variance) and may represent a valid system of analysis for researchers and practitioners interested in studying the impact produced by the communication ability of coaches on psychological wellbeing and performance of athletes. This may reflect an advance in the coaching literature because most of the actual communication coding systems still misses information about their psychometric properties.

Second, positive behaviors assumed by coaches were more prevalent than negative behaviors, which is in accordance with athletes' and coaches' perceptions, as well as with observation results. This reinforces a favorable pattern of communication between coaches and athletes for all teams included in our study. Quite interesting is the fact that athletes perceived spontaneous and reactive behaviors to have similar prevalence, meaning that coaches either use behaviors in a spontaneous form (by their choice) or in a reactive form (responding to previous actions of athletes). However, coaches seem to have a more negative opinion about their own behaviors, by perceiving themselves as displaying more negative reactive than negative spontaneous behaviors which is supported by the observation. In sum, coaches seem to be more prone to negative behaviors when athletes do not act according to their expectations in competition.

Third, the analysis of each behavior pointed out positive feedback and encouragement after failure as the more frequent behaviors assumed by coaches and keeping control as the least frequent positive behavior. Data from the observation confirms that, indeed, positive feedback was one of coaches' more frequent communication behaviors. However, it should be noted that positive vision, encouragement, 
positive instruction, comprehension, and comprehension after failure are also highly reported communication behaviors from the perspective of athletes and coaches. There is substantial evidence on literature that coaches concentrate their behaviors on instruction and positive feedback (e.g., Calpe, Guzmán, \& Grijalbo, 2013; Potrac et al., 2007; Tharp \& Gallimore, 1976; Soriano, Ramis, Cruz, \& Sousa, 2014). Our results extend these findings by providing insights about other important behaviors assumed by coaches, as is the case of positive vision and comprehension. For negative behaviors, both athletes and coaches agreed that negative feedback was the most frequent behavior, but coaches thought that they assumed this behavior more often than athletes did. Coaches perceptions were supported by the observation, as over 7\% of coaches' communication behavior referred to negative feedback. This result reinforces that there are open opportunities to improve coaches' behaviors, as suggested by the literature on coaching education (Gould, Nalepa, \& Mignano, 2020; Mouratidis, Lens, \& Vansteenkiste, 2010; Sagar \& Jowett, 2012).

Fourth, differences among teams indicate that athletes from Team 1 (U15) perceived encouragement and positive feedback as more frequent than athletes from Team 4 (adults); indifference was also less reported from athletes of Team 1 than athletes of Team 3 (U19). Although without statistical differences, athletes and coach from Team 1 reported higher perceptions of individual and collective performance than athletes and coaches from Teams 3 and 4 .

All in all, our data suggests that coaches assumed a positive pattern of communication when interacting with athletes, which seems to slightly decrease as athletes get older. One possible reason for this result may be related to pressure to win in older athletes, which may decrease coaches' tolerance to error. In fact, some research suggests that pressure to win increases along the sport process of athletes' development (Francka \& Stambulovaa, 2019; Jenkins, 2018; Mallett \& Côté, 2006).

Although our data offers promising results for the communication system divided into positive and negative behaviors versus spontaneous and reactive behaviors, two aspects limit the interpretation of conclusions. First, one negative behavior (negative vision) was not included in the final analysis due to the results from factorial analysis. This means that authors should refine the item in future studies to stabilize the factor structure of the communication system. Second, data from the observation should be collected in future studies by using video technology to allow subsequent data categorization by an experts' panel.

Future research can expand our results by introducing other variables into the analysis, as is the case of the score of the game and the fluctuations of coaching behaviors because there is evidence that coaches change their behaviors according to the score during games (Calpe et al., 2013). Moreover, it would be interesting to analyze differences according to the sex of both coaches and athletes, as there is evidence that suggests communication patters change between man and women (Gearity, 2018; Norman, 2017). Moreover, perceived competence may be also an important factor. Haselwood and colleagues (2005) investigated the relationship between female athletes and head coaches, and the results suggested that effective head coach communication was not based on gender but on perceived communicative competence of the individual. Finally, it may be important to test changes in communication according to the type of sport, namely the ones more interactive and collective and the ones without direct contact between athletes and coaches.

\section{Conclusions}

CBES considered coaches' communication behaviors according to two different axes: impact of communication (positive vs. negative) and initiative (spontaneous vs. reactive), including 16 different behaviors. This evaluation system expands some of the systems current more used by considering transformational and transactional behaviors, as well as a wider range of negative behaviors, allowing for a wider comprehension of interactions that facilitate or debilitate the communication processes. Equally important, this system was applied in a $360^{\circ}$ perspective, as data was collected from coaches, athletes and an observer, allowing a better understanding of the phenomenon. The results overall support the idea that this is a useful tool for coaches to improve their communication skills.

\section{Funding}

This study was conducted at the Psychology Research Centre (PSI/01662), School of Psychology, University of Minho, and supported by the Portuguese Foundation for Science and Technology and the Portuguese Ministry of Science, Technology and Higher Education (UID/PSI/01662/2019), through the national funds (PIDDAC).

\section{References}

Calpe, V., Guzmán, J., \& Grijalbo, C. (2013). Relationship between score and coaches' verbal behaviour. Journal of Human Sport and Exercise, 8(3), 728-737. doi:10.4100/jhse.2013.8.Proc3.19

Cope, E., Partington, M., \& Harvey, S. (2017). A review of the use of a systematic observation method in coaching research between 1997 and 2016. Journal of Sports Sciences, 35(20), 2042-2050. doi:10.1080/02640414.2016.1252463 
Cumming, S. P., Smith, R. E., \& Smoll, F. L. (2006). Athlete-perceived coaching behaviors: Relating two measurement traditions. Journal of Sport \& Exercise Psychology, 28, 205-213.

Cushion, C., Harvey, S., Muir, B., \& Nelson, L. (2012). Developing the Coach Analysis and Intervention System (CAIS): Establishing validity and reliability of a computerised systematic observation instrument. Journal of Sports Sciences, 30(2), 201-216. doi:10.1080/02640414.2011.635310

Francka, A., \& Stambulovaa, N. B. (2019). The junior to senior transition: A narrative analysis of the pathways of two Swedish athletes. Qualitative Research in Sport, Exercise and Health, 11(3), 284298. doi:10.1080/2159676X.2018.1479979

Gearity, B. T. (2018). Working with coaches and their teams in youth and collegiate sport in the USA: An interview with Dr. Andy Gillham. International Journal of Sports Science \& Coaching, 13(3), 323325. doi:10.1177/1747954118771136

Gilbert, W., \& Trudel, P. (2004). Analysis of coaching science research published from 1970-2001. Research Quarterly for Exercise \& Sport, 75, 388399.

Gomes, A. R. (2014). Leadership and positive human functioning: A triphasic proposal. In A. R. Gomes, R. Resende, \& A. Albuquerque (Eds.), Positive human functioning from a multidimensional perspective: Promoting high performance (Vol. 3, pp. 157-169). New York: Nova Science. [Available at] http://hdl.handle.net/1822/28118.

Gomes, A. R. (2016). Sport Performance Perception Questionnaire (SPPQ). Unpublished technical report: Braga School of Psychology, University of Minho.

Gomes, A. R. (2019). Communication Behaviors Questionnaire $(C B Q)$. Unpublished technical report: Braga: School of Psychology, University of Minho.

Gould, D., Nalepa, J., \& Mignano, M. (2020). Coaching generation $\mathrm{Z}$ athletes. Journal of Applied Sport Psychology, 32(1), 104-120. doi:10.1080/10413200.2019.1581856

Haselwood, D., Joyner, A., Burke, K., Geyerman, C., Czech, D., Munkasy, B., \& Zwald, A. (2005). Female athletes' perceptions of head coaches' communication competence. Journal of Sport Behavior, 28(3), 216230 .

Jenkins, S. (2018). Working with coaches and their teams in youth and collegiate sport in the USA: An interview with Dr Andy Gillham. International Journal of Sports Science \& Coaching, 13(3), 305314. doi:10.1177/1747954118771132

Jowett, S., \& Felton, L. (2013). The role of psychological factors in recreational sport participation. $\quad$ Retrieved from
https://www.semanticscholar.org/paper/The-Roleof-Psychological-Factors-in-RecreationalFelton/b28140f4b5cf9746bc1ebd3df161df0e0ced78 $\underline{0 \mathrm{f}}$

Kline, R. B. (2011). Principles and practice of structural equation modeling analysis (3rd ed.). New York: The Guilford Press.

Mallett, C., \& Côté, J. (2006). Beyond winning and losing: Guidelines for evaluating high performance coaches. The Sport Psychologist, 20, 213-221. doi:10.1123/tsp.20.2.213

McKenzie, T. L., \& van der Mars, H. (2015). Top 10 research questions related to assessing physical activity and its contexts using systematic observation. Research Quarterly for Exercise and Sport, 86(1), 13-29. doi:10.1080/02701367.2015.991264

Mouratidis, A., Lens, W., \& Vansteenkiste, M. (2010). How you provide corrective feedback makes a difference: The motivating role of communicating in an autonomy-supporting way. Journal of Sport \& Exercise Psychology, 32, 619-637.

Norman, L. (2017). 'It's sport, why does it matter?' Professional coaches' perceptions of equity training. Sports Coaching Review 7(2), 190-211. doi:10.1080/21640629.2017.1367181

Potrac, P., Jones, R., \& Cushion, C. (2007). Understanding power and the coach's role in professional english soccer: A preliminary investigation of coach behaviour. Soccer \& Society, 8(1), 33-49. doi:10.1080/14660970600989509

Sagar, S. S., \& Jowett, S. (2012). Communicative acts in coach-athlete interactions: When losing competitions and when making mistakes in training. Western Journal of Communication, 76(2), 148-174. doi:10.1080/10570314.2011.651256

Smith, R. E., Smoll, F. L., \& Hunt, E. (1977). A system for the behavioral assessment of athletic coaches. Research Quarterly. American Alliance for Health, Physical Education and Recreation, 48(2), 401-407. doi:10.1080/10671315.1977.10615438

Soriano, G., Ramis, Y., Cruz, J., \& Sousa, C. (2014). Un programa de intervención individualizado con entrenadores de fútbol. Cuadernos de Psicología del Deporte, 14(3), 99-106.

Tharp, R. G., \& Gallimore, R. (1976). Basketball's John Wooden: What a coach can teach a teacher. Psychology Today, 9(8), 74-78.

Turnnidge, J., \& Côté, J. (2019). Observing coaches' leadership behaviours: The development of the Coach Leadership Assessment System (CLAS). Measurement in Physical Education and Exercise Science, 23(3), 214-226. doi:10.1080/1091367X.2019.1602835 


\section{Viabilidade do planeamento por etapas: visão dos estudantes-estagiários}

\section{João Andrade', André Cruz¹, Daniel Patrício', Raquel Correia', Adilson Marques ${ }^{1}$}

${ }^{1}$ Faculdade de Motricidade Humana, Universidade de Lisboa;

\section{Palavras-chave Educação física, Planeamento, Planeamento por etapas.}

\section{Keywords} Physical education, Planning, Step-by-step planning.

\section{RESUMO:}

O planeamento faz parte do processo de ensino-aprendizagem, tendo influência na sua eficácia. A concretização desta tarefa é, muitas vezes, difícil pelas variantes que o contexto da prática de ensino apresenta. $\mathrm{O}$ modelo de planeamento de educação física recomendado em Portugal e definido pelos Programas Nacionais de Educação Física (PNEF) é o planeamento por etapas. Este modelo de planeamento perspetiva estruturar as aprendizagens ao longo do ano, numa lógica de continuidade e acompanhamento do aluno. Não existe evidência que suporte que este tipo de planeamento seja mais eficaz que qualquer outro. Como ferramenta imprescindível para o professor, é importante averiguar se este tipo de planeamento é viável, indo ao encontro dos objetivos a que se propõe. Logo, o objetivo deste documento foi averiguar a perceção dos estudantes-estagiários acerca da viabilidade do planeamento por etapas no ensino da educação física. Realizouse um grupo focal, como método de recolha de dados, constituído por quatro estudantesestagiários. Os estudantes-estagiários concluíram que este modelo de planeamento é viável, admitindo que esta viabilidade está dependente de determinados fatores.

\section{ABSTRACT:}

Planning is a part of teaching-learning processes influencing its effectiveness. The accomplishment of this task is often difficult by the innumerable variants that the practical context of teaching presents. For this reason, it undergoes through several changes during its application. The model of physical education planning recommended in Portugal and defined by the PNEF (guiding document), is the step-by-step planning. This planning model structures the learning throughout the year, in logic of progression and monitoring the student's development. There is no evidence to support this type of planning to be more effective compared to any other. As an indispensable tool for the teacher, it is important to find out if this type of planning is feasible, meeting the objectives that it proposes. Therefore, the purpose of this document was to investigate the perception of pre-service teachers about the viability of the step-by-step planning in the teaching process of physical education. As a method of data collection, a focus group was formed constituted by four pre-service teachers. The pre-service teachers concluded that this planning model is viable, admitting that its feasibility is dependent on certain factors. 


\section{Introdução}

O planeamento define-se pelo conjunto de decisões tomadas na fase pré-interativa de ensino. $\mathrm{O}$ planeamento confere uma intenção pedagógica organizada em função dos objetivos a atingir e das estratégias a adotar, seja a curto, médio ou longo prazo, evitando que a intervenção se torne uma casualidade. Este ganha relevância no contributo que oferece à estruturação da relação entre o ensino e a aprendizagem, ou seja, entre a teoria e a prática, o que promove a eficácia pedagógica (Bento, 1998). Permite lidar com a imprevisibilidade, tendendo a reduzi-la e prevendo os vários cenários e erros que podem, hipoteticamente, acontecer. Além disso, está associado à prevenção de comportamentos desviantes e a uma melhor gestão do tempo (Januário, 1996). Assim sendo, a progressão da prática de ensino é reflexo do planeamento, pelo que o professor deverá considerar os diversos fatores que se encontram em permanente interação entre 0 professor, o aluno e o contexto, em prol das aprendizagens (Januário, 2017).

No contexto escolar o planeamento é fundamental, pois antevê e estabelece o processo de forma a atingir os objetivos e finalidades propostas. Os objetivos surgem para assegurar a efetivação do plano, conferindo um suporte ao professor, evitando que este se desvie do planeado (Assis, Oliveira, \& Santos, 2013).

Professores que possuem melhor qualidade nas decisões de planeamento formulam objetivos mais claros e específicos, representam melhor o cenário de ensino, tomam maior número de decisões e possuem um maior número de rotinas de planeamento e de instrução (Januário, 2017). Deste modo, contribuem para a qualidade do processo de ensino-aprendizagem. A qualidade do planeamento é tão eficaz consoante o nível de correspondência com a sua implementação efetiva (Derri, Papamitrou, Vernadakis, Koufou, \& Zetou, 2014). No entanto, o mesmo é considerado como uma tarefa complexa, sendo que a sua aplicação, por norma, está associada a muitas dificuldades e dúvidas (Sáenz-López, 2011), que são acrescidas nos estudantes-estagiários (Teixeira e Onofre, 2009). Esta associação é explicada pelo facto do planeamento ser influenciado por diversos fatores que têm de ser tidos em conta aquando da tomada de decisões. Estas dificuldades poderão ser agravadas pela inexperiência dos professores (Viciana \& MayorgaVega, 2013).

Enquanto documento orientador oficial para a ação dos professores de educação física em Portugal, os Programas Nacionais de Educação Física (PNEF) sugerem que a organização geral de um ano letivo deverá ser realizada através de um planeamento por etapas (Ministério da Educação, 2001). Este modelo assume-se como um modo de operacionalização do plano anual de turma, facilitando a orientação e regulação do processo ensino-aprendizagem. Assim, o mesmo pressupõe a existência de diferentes etapas no planeamento que são definidas como períodos que regulam e conduzem o processo educativo. Estas etapas devem possuir características diferentes ao longo do ano letivo consoante a evolução das aprendizagens dos alunos e as intenções do professor. Ao longo do ano letivo, são sugeridas três etapas. A primeira etapa diz respeito à avaliação inicial que visa compreender onde cada aluno se situa relativamente ao programa previsto e efetuar um prognóstico da sua evolução ao longo do ano. A segunda etapa reporta-se à aprendizagem e desenvolvimento dos conteúdos em si. Por fim, a terceira etapa pretende rever e consolidar as matérias abordadas, garantindo oportunidades de recuperação aos alunos para que alcancem patamares mais elevados (Ministério da Educação, 2001). A organização das mesmas deve considerar o calendário escolar (como as interrupções letivas), as características das instalações disponíveis (plano de rotação) e ainda as condições climatéricas ao longo do ano, procurando aproveitar, de uma forma eficaz, todos os recursos da escola (Ministério da Educação, 2001).

Embora seja o modelo de planeamento recomendado nos PNEF, não existe evidência da sua eficácia. Assim, para compreender melhor a sua viabilidade, o objetivo do presente trabalho foi analisar a perceção dos estudantes-estagiários sobre a operacionalização do modelo de planeamento por etapas.

\section{Metodologia}

\section{Participantes}

O grupo focal foi constituído por quatro estudantesestagiários, alunos do último ano do mestrado em educação física. Os estagiários realizaram estágio em escolas localizadas no distrito de Lisboa. A identificação dos estagiários ao longo do documento foi efetuada da seguinte forma: E1, E2, E3 e E4. Os participantes foram informados acerca dos objetivos do estudo, participando de forma voluntária.

\section{Instrumento}

De modo a realizar a entrevista semiestruturada foi utilizado um guião construído pelos autores. As questões do guião perseguiam o objetivo do trabalho, sendo:

1. Nos locais onde estão a realizar o estágio pedagógico, põem em prática o planeamento por etapas?

2. Tendo em conta a vossa experiência, quais as vantagens e desvantagens do planeamento por etapas?

3. Todos os espaços escolares são polivalentes? 
4. Como é aplicado o plano de etapas se os espaços não forem polivalentes?

5. A rotação dos espaços intervém na lecionação das matérias prioritárias? (Ex.: Pretendese dar uma unidade de ensino de Ginástica, mas estão no espaço exterior: a rotação dos espaços condiciona ou não?)

6. Conseguiram, em todos os momentos, concretizar o vosso planeamento por etapas? Se não, o que alteraram?

7. Quais as principais dificuldades que sentiram com o planeamento por etapas? Que repercussões tiveram essas dificuldades nas aprendizagens dos alunos?

8. Na vossa opinião, o planeamento por etapas é viável?

Em alguns momentos da entrevista foram colocadas questões adicionais com o objetivo de clarificar alguns aspetos. Houve sempre a preocupação de redirecionar a entrevista sempre que existisse algum desvio à temática central.

\section{Procedimentos}

A entrevista sob a forma de grupo focal foi dirigida por um entrevistador principal, auxiliado por outros dois investigadores, que colocou as questões conforme se apresentam no guião. Todavia, existia a liberdade para os outros elementos do grupo colocarem questões, se assim achassem pertinente. A maioria das questões foi colocada de forma aberta para que cada elemento do grupo focal pudesse responder livremente. Em alguns momentos da entrevista foram solicitados especificamente alguns elementos do grupo com o objetivo de dinamizar a entrevista e incentivar a discussão. A escolha deste método de recolha de dados visou, além de recolher dados de uma forma mais detalhada, fomentar a interação entre os elementos da amostra numa lógica de discussão e reflexão sobre o tema comum e os seus diferentes contextos de intervenção. Não conta apenas com o contributo individual de cada um, mas sim com uma construção coletiva (Morgan, 1996). A entrevista teve lugar numa sala de aula com os participantes dispostos numa mesa. A entrevista teve a duração aproximadamente de 45 minutos sendo, posteriormente, transcrita na sua integra.

\section{Análise de dados}

Foi efetuada uma análise de conteúdo das respostas obtidas, o que permitiu criar quatro categorias principais que orientaram o escrutínio desta temática e dos fatores que a influenciam. As categorias são: implementação do planeamento por etapas, polivalência de espaços, vantagens do modelo de planificação por etapas e desvantagens do modelo de planificação por etapas. As mesmas foram fundamentais para o desenvolvimento desta investigação, pois permitiram a utilização de informação valiosa que seria perdida numa investigação com uma análise quantitativa (Moretti et al., 2011).

\section{Resultados e Discussão}

\section{Implementação do planeamento por etapas}

Todos os estagiários afirmaram que usaram o modelo de planeamento por etapas. Todavia, nenhum afirmou que o fez por iniciativa, mas como sendo o único modelo possível no âmbito do estágio. Sendo que o estágio deve estar enquadrado nos PNEF, é lógico que deveriam seguir as indicações dos PNEF. Por outro lado, como os PNEF são documentos orientadores, muito provavelmente deveria ter sido dada autonomia aos estagiários para escolherem o modelo de planeamento. Ao serem privados dessa autonomia, pela orientação que receberam para o estágio, ficaram privados da capacidade de decisão fundamentada como profissionais reflexivos que deveriam ter autonomia pela tomada de decisões na prática docente. Além disso, a sua consciência sociocultural e ética fica empobrecida (Oliveira \& Serrazina, 2002).

\section{Polivalência dos espaços}

O modelo de planeamento por etapas assenta num conjunto de pressupostos, sendo um dos quais a polivalência dos espaços (Ministério da Educação, 2001). A polivalência dos espaços traduz-se nas possibilidades que os mesmos conseguem oferecer para a lecionação das diferentes matérias. Cada espaço de aula privilegia a abordagem a determinadas matérias. Porém, é importante não limitar os espaços às matérias a que melhor se apropriam (Brás \& Monteiro, 1998). Tendo em conta a realidade vivida em Portugal, constata-se que nem todas as escolas conseguem assegurar este princípio. Os estudantes-estagiários entrevistados afirmam viver esta realidade, referindo que nem todos os espaços, em que lecionam, são polivalentes.

"Não, não tenho tabelas no exterior. E tenho um polidesportivo enorme que não tem tabelas, por isso só posso fazer basquete naquele espaço.” (E4)

"Por exemplo, um dos ginásios, que é o
ginásio que tem espelhos para a ginástica,
tem lá os aparelhos todos, mas tudo o que
seja jogos desportivos coletivos, tudo o que
envolva bolas não é possível por causa dos
espelhos." (E3) O planeamento, como já referido anteriormente, é uma tarefa de complexa execução e que engloba uma grande diversidade de fatores. Essa complexidade repercute-se, diretamente, na 
dificuldade em planear que é acrescida em professores em formação (Teixeira e Onofre, 2009). Foram identificadas diversas dificuldades que os professores enfrentam nos primeiros anos de lecionação como o estatuto, gestão dos recursos materiais e instalações assim como a organização e controlo da aula (Sáenz-López, 2011). Os estudantes-estagiários afirmaram que o mapa de rotação dos espaços, definido pela escola, é determinante para o planeamento sendo a sua base de sustentação.

\section{“Tu geres-te pelo mapa de rotações.” (E1) \\ “(...) tu não fazes a unidade de ensino e depois olhas para o mapa de rotação. É totalmente ao contrário. Tu olhas para o mapa de rotações e depois é que fazes a tua unidade de ensino." (E2)}

$\mathrm{O}$ PNEF critica as escolas que se organizam em função do mapa de rotações. Esta crítica é justificada com o facto deste modo de organização se subjugar às instalações não conseguindo corresponder às dificuldades e necessidades de aprendizagem dos alunos (Ministério da Educação, 2001). Porém, todos os estagiários dizem estar dependentes do mapa de rotação dos espaços para planear, expondo a realidade vivida.

\section{Vantagens do modelo de planificação por etapas}

Na ótica dos estagiários, a principal vantagem deste tipo de planeamento é a aprendizagem progressiva e não delimitada no tempo. Justificam com o facto de o professor poder abordar determinada matéria ao longo do ano, em diferentes momentos, proporcionando um maior acompanhamento e desenvolvimento das aprendizagens nas diversas matérias.

"É assim, eu também estou a fazer o planeamento por etapas. Acho que neste planeamento por etapas os alunos conseguem aprender mais e essa aprendizagem fica melhor consolidada ao contrário do planeamento sem ser por etapas. Acho que se prende essencialmente nessa vantagem para os alunos." (E3)

“(...) eu estou a fazer por etapas e concordo que a aprendizagem é melhor porque não é...dada naquele momento e depois acaba e nunca mais volta a dar, é melhor porque o aluno vai a pouco e pouco aprendendo."

"Ou seja, eu volto a estar uma semana em cada espaço que é para fazer avaliação final de todas as matérias em todos os espaços." (E4)
No entanto, não existe evidência que sustente que as aprendizagens, provenientes de um processo orientado por um planeamento por etapas, sejam mais significativas ou consolidadas que qualquer outro tipo de planeamento.

\section{Desvantagens do modelo de planificação por etapas}

Quando se referem às desvantagens verificam-se algumas inconsistências no seu discurso. Os estudantes-estagiários apontam a descontinuidade e o impedimento da lecionação de algumas matérias como principais desvantagens do planeamento por etapas. Reconhecem tais desvantagens como limitações à aprendizagem que estão, diretamente, ligadas ao princípio da polivalência de espaços e ao modo como é construído o mapa de rotação de espaços.

“(..) no planeamento por etapas, por exemplo, nós temos aulas de ginásio de três em três semanas. Eu tenho uma aula à quarta e à quinta dou ginástica, ginástica de solo, ginástica de aparelhos... Depois, só passadas três semanas é que volto a essa matéria."

"Ainda por cima a minha primeira aula é a dos 50 minutos, é quase voltar a relembrar as coisas básicas." (E1)

"Porque por mais que a prioridade dos meus alunos seja futebol ou andebol, por exemplo futebol e andebol. Mas se eu vou estar, só vou passar por isso no final do período, nesses espaços ou os únicos espaços onde eu posso fazer isso."

"Posso trabalhar, lá está, de forma mais isolada, mas nunca tenho a situação real. Por isso condiciona e muito, na minha opinião, condiciona muito isso, as prioridades das matérias que nós temos." (E4)

A aprendizagem é condicionada quando não são proporcionadas as condições de prática adequadas ao desenvolvimento de determinadas matérias, em certos momentos. A repetição é considerada como um fator determinante para o processo de aprendizagem e encontra-se relacionada com os processos de armazenamento e transmissão da informação motora ao nível do sistema nervoso. Se não existir essa estimulação estes processos não ocorrerão, prejudicando o processo de aprendizagem (Squire \& Kandel, 1999). Em contextos de aprendizagem de tarefas desportivas, a repetição tem de ser enquadrada num processo intencional que só terá efeito através de um planeamento adequado (Passos, 2013).

Os estudantes-estagiários referiram ser possível contornar estas limitações, impostas à 
aprendizagem, através da adaptação das condições de prática ou pela realização de outro tipo de atividades não previstas.

"Consegues, mas consegues sempre adaptar. Porque mesmo que não faças uma situação real de jogo, por exemplo não tens tabelas para jogar, mas eu posso fazer no polidesportivo, posso utilizar a mesma bola de basquete para o aquecimento, para o drible, para defesa individual, para essas questões todas, podes não trabalhar de forma formal, mas podes trabalhar de forma isolada e consegues..." (E3)

"Faço mais condição física, outras modalidades..." (E1)

A divisão de uma matéria nas suas componentes, como sugere um dos estudantes-estagiários, pode ser benéfico para colmatar algumas lacunas. Todavia, não nos podemos esquecer que a avaliação das aprendizagens proposta pelos PNEF tem por base, frequentemente, as situações jogadas. Estas situações poderão ser formais ou derivadas da estrutura formal não desvirtuando o seu objetivo principal (Ministério da Educação, 2001). Logo, incorre-se o risco de as aprendizagens nucleares não serem desenvolvidas e consolidadas. Além disso, o princípio da diferenciação defendido pelos PNEF poderá estar em causa (Ministério da Educação, 2001). Este princípio não será respeitado sempre que $\mathrm{o}$ professor não conseguir adaptar o currículo às necessidades do aluno (Roldão, 2003), como é preconizado, devido a este constrangimento.

Posto isto, os estudantes-estagiários pronunciaramse acerca da viabilidade do planeamento por etapas. A opinião neste assunto, como em outros já referidos, foi unânime considerando que este modo de planeamento é viável. No entanto, estão conscientes de que a viabilidade está dependente de determinados fatores como a polivalência dos espaços, a capacidade de adaptação do professor e o número de matérias a abordar.

\section{Limitações}

É necessário reconhecer as limitações deste estudo como o facto de ter sido realizado apenas com quatro estudantes-estagiários, com pouca experiência de lecionação. Portanto, as ilações retiradas não são representativas da realidade vivida em Portugal ou da zona em que foi realizado.

\section{Conclusão}

Os estudantes-estagiários entrevistados concluíram que o planeamento por etapas, recomendado pelos PNEF, deve ser o tipo de planeamento privilegiado para a atividade educativa. Fundamentam as suas opiniões com a perceção de aprendizagem dos alunos derivada de um melhor acompanhamento dos mesmos. Todavia, não existe literatura que suporte o desenvolvimento e consolidação das aprendizagens deste modelo de planeamento. O pressuposto da polivalência dos espaços é violado pelas características das escolas onde lecionam. A opinião dos estudantes-estagiários também é unânime quando afirmam que a construção do mapa de rotações, aliada à não polivalência dos espaços, é determinante no planeamento. Mesmo assim, as suas opiniões mantêm-se, afirmando poder contornar esse facto pela adaptação de alguns aspetos. É certo que, devido a estes constrangimentos, os alunos ficam, frequentemente, privados das melhores condições de prática que a escola pode providenciar pela logística da rotação de espaços imposta, condicionando as suas aprendizagens. O planeamento por etapas perde a sua intencionalidade devido aos constrangimentos identificados, pelo que se considera que não é viável.

\section{Referências}

Assis, R. M., Oliveira, M., \& Santos, N. (2013). Planejamento de ensino: Algumas sistematizações. Revista Eletrônica de Educação do Curso de Pedagogia, 1(4). doi: 10.5216/rir.v1i4.214

Bento, J. O. (1998). Planeamento e avaliação em educação física ( $2^{\mathrm{a}}$ ed.). Lisboa: Livros Horizonte.

Brás, J., \& Monteiro, J. E. (1998). A importância do grupo para o desenvolvimento da educação física. Horizonte, 15(86), 1-12.

Derri, V., Papamitrou, E., Vernadakis, N., Koufou, N., \& Zetou, E. (2014). Early professional development of physical education teachers: effects on lesson planning. Procedia - Social and Behavioral Sciences, 152, 778-783.

Januário, C. (1996). Do pensamento do professor à sala de aula. Coimbra: Livraria Almedina.

Januário, C. (2017). O planejamento de jovens professores de educação física. Educação física escolar: Referências para o ensino de qualidade, 109-118.

Ministério da Educação. (2001). Programa de educação física (reajustamento) $-3^{\circ}$ ciclo do ensino básico. Ministério da educação. Lisboa.

Moretti, F., Vliet, L. Van, Bensing, J., Deledda, G., Mazzi, M., Rimondini, M., ... Fletcher, I. (2011). A standardized approach to qualitative content analysis of focus group discussions from different countries. Patient Education and Counseling, 82(3), 420-428.

Morgan, D. L. (1996). Focus groups. Annual Review of Sociology, 22, 129-152. 
Oliveira, I., \& Serrazina, L. (2002). A reflexão e o professor como investigador. Reflectir e Investigar Sobre a Prática Profissional, 29, 29-42.

Passos, P. (2013). Comportamento motor, controlo e aprendizagem. Lisboa: Edições FMH.

Roldão, M. (2003). Diferenciação curricular revisitada. Conceito, discurso e práxis. Porto: Porto Editora.

Sáenz-López, P. (2011). Describing problems experienced by spanish novice physical education teachers. The Open Sports Sciences Journal, 4(1), 19.

Squire, L., \& Kandel, E. (1999). Memory: From mind to molecules. New York: Scientific American Library, 12(1), 135-137.
Teixeira, M., \& Onofre, M. (2009). Dificuldades dos professores estagiários de educação física no ensino. Sua evolução ao longo do processo de estágio pedagógico. In X Symposium Internacional Sobre el Practicum $Y$ las Práticas en Empresas en la Formación Universitária (pp. 1159-1170). AIDU Asociación Iberoamericana de Didáctica Universitaria. Poio, Pontevedra, Espanha.

Viciana, J., \& Mayorga-Vega, D. (2013). Effect of internships on pre-service teachers' conceptions of planning in physical education. European Scientific Journal, 9(19), 253-261. 